\title{
Closed-Loop Control Test of an Active Pitch Link in the Non-Rotating Frame
}

by

Melissa Richardson

A thesis submitted to the Faculty of Graduate and Postdoctoral Affairs in partial fulfillment of the requirements for the degree of

Master of Applied Science

in

Aerospace Engineering

Carleton University

Ottawa, Ontario

(C) 2011

Melissa Richardson 
Library and Archives

Canada

Published Heritage

Branch

395 Wellington Street

Ottawa ON K1A ON4

Canada
Bibliotheque et

Archives Canada

Direction du

Patrimoine de l'édition

395, rue Wellington

Ottawa ON K1A ON4

Canada
Your file Votre reférence

ISBN: 978-0-494-83207-3

Our file Notre référence

ISBN: 978-0-494-83207-3

\section{NOTICE:}

The author has granted a nonexclusive license allowing Library and Archives Canada to reproduce, publish, archive, preserve, conserve, communicate to the public by telecommunication or on the Internet, loan, distribute and sell theses worldwide, for commercial or noncommercial purposes, in microform, paper, electronic and/or any other formats.

The author retains copyright ownership and moral rights in this thesis. Neither the thesis nor substantial extracts from it may be printed or otherwise reproduced without the author's permission.
AVIS:

L'auteur a accordé une licence non exclusive permettant à la Bibliothèque et Archives Canada de reproduire, publier, archiver, sauvegarder, conserver, transmettre au public par télécommunication ou par l'Internet, prêter, distribuer et vendre des thèses partout dans le monde, à des fins commerciales ou autres, sur support microforme, papier, électronique et/ou autres formats.

L'auteur conserve la propriété du droit d'auteur et des droits moraux qui protège cette thèse. $\mathrm{Ni}$ la thèse ni des extraits substantiels de celle-ci ne doivent être imprimés ou autrement reproduits sans son autorisation.
In compliance with the Canadian Privacy Act some supporting forms may have been removed from this thesis.

While these forms may be included in the document page count, their removal does not represent any loss of content from the thesis.
Conformément à la loi canadienne sur la protection de la vie privée, quelques formulaires secondaires ont été enlevés de cette thèse.

Bien que ces formulaires aient inclus dans la pagination, il n'y aura aucun contenu manquant.

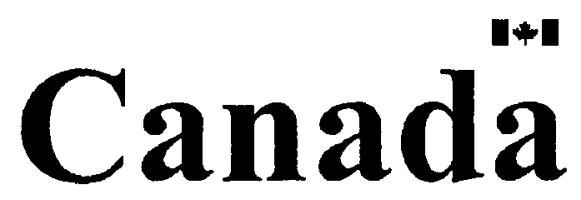




\begin{abstract}
Due to the vibration and noise generated during helicopter forward flight and descent the use of helicopters are limited. Passive vibration reduction techniques are currently used and can be tuned to improve vibration or noise for only a specific flight regime (i.e. forward flight at a specific speed). In efforts to improve helicopter flight conditions over an entire flight regime, active vibration suppression devices are currently being developed and tested worldwide.
\end{abstract}

The SHARCS (Smart Hybrid Active Rotor Control Systems) project focuses on proving the Hybrid Control concept that uses two or more active control techniques to simultaneously reduce vibration and noise over an entire flight envelope. The research presented in this thesis focuses on experimentally proving the vibration reduction abilities of an Active Pitch Link (APL). The APL reduces vibrations transmitted from the rotor blade, due to aerodynamic loading, into the fuselage and is designed to replace a conventional pitch link.

Non-rotating experiments have proven that the APL meets all major design requirements, including a fail-safe mode in case of power or actuator failure. For the first time a closed-loop control algorithm used to control the activation of the APL prototype was experimentally implemented. Computational estimates were confirmed and the APL can reduce vibrations transmitted though the pitch link up to $60 \%$. This reduction is limited to a specific frequency ensuring that installation of the APL will not interfere with the controls of the helicopter.

Functionality of the APL is confirmed by non-rotating tests and it is now ready for rotational testing before being coupled with a separate active control device. 


\section{Acknowledgements}

I would like to thank my supervisors Dr. Daniel Feszty and Dr. Fred Nitzsche for their guidance, continual knowledge and financial support throughout this research. I would also like to thank the National Research Council (NRC) Canada, particularly Norman Ball, and Smart Rotor Systems Inc. for their support and insight during experimental testing.

In addition, I would like to thank my family for their support and understanding, especially my husband Lindsay Roy for his continual encouragement. 


\section{Table of Contents}

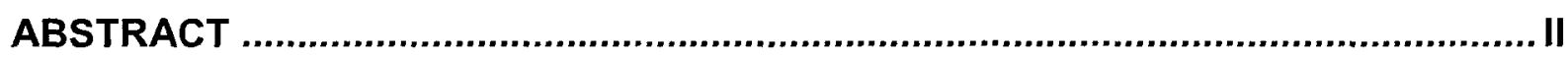

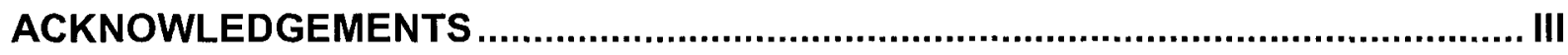

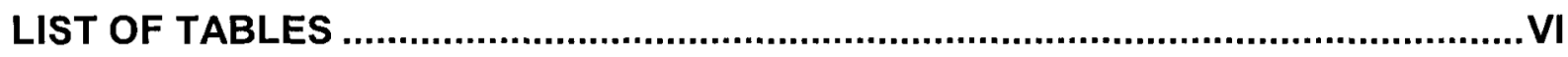

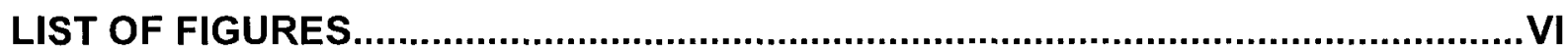

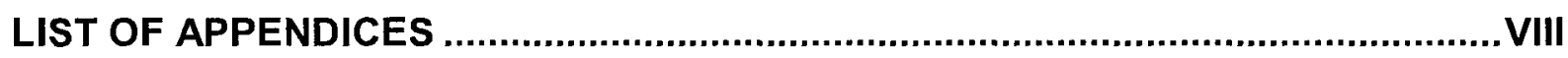

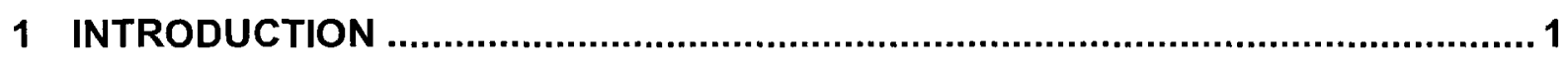

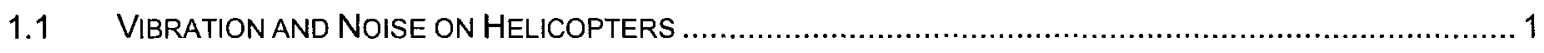

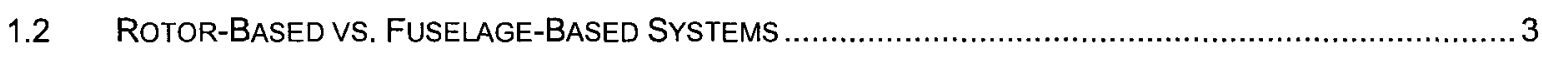

1.3 FLOW CONTROL VS. STRUCTURAL CONTROL CONCEPTS ........................................................ 4

1.4 REVIEW OF RotOR-BASEd ACTIVE VIBRATION SUPPRESSION RESEARCH ....................................5

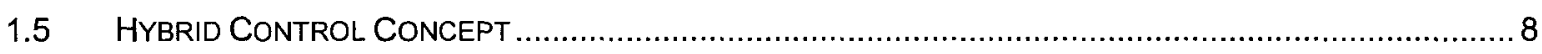

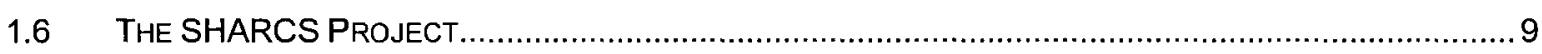

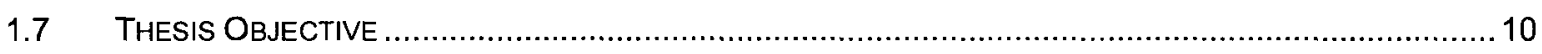

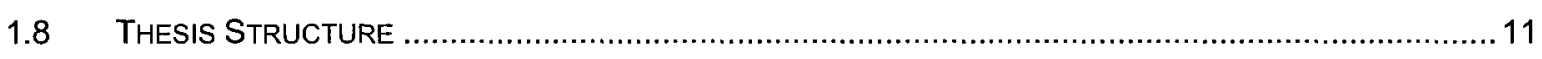

2 ACTIVE PITCH LINK (APL) PROTOTYPE DESIGN ........................................... 12

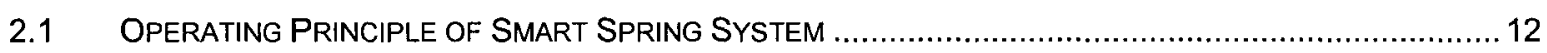

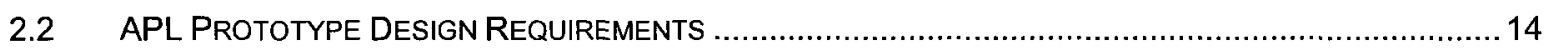

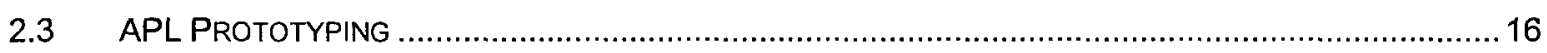

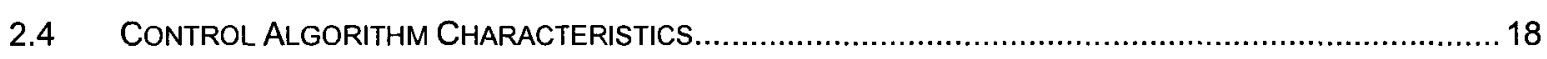

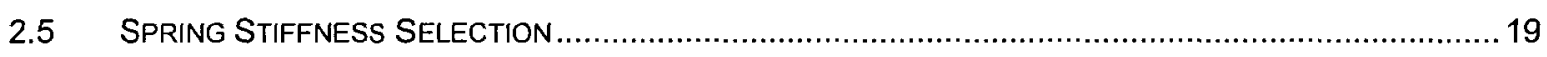

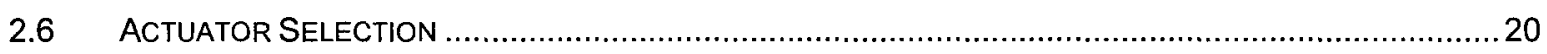

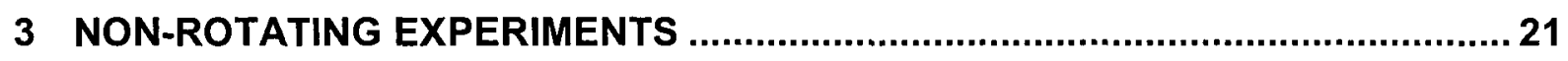

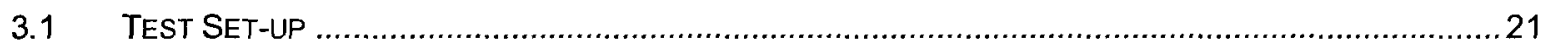

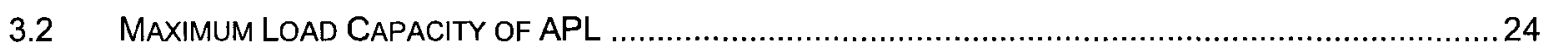

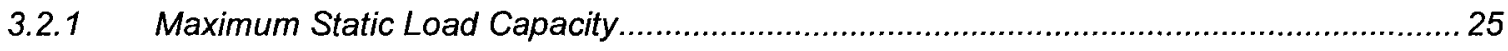

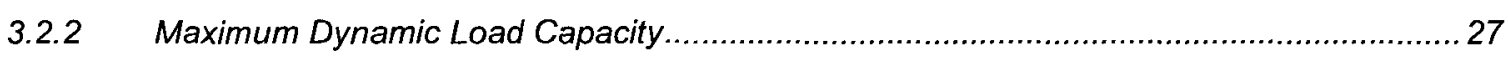

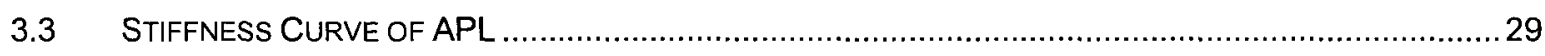

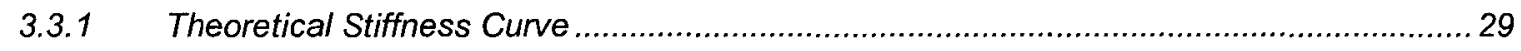

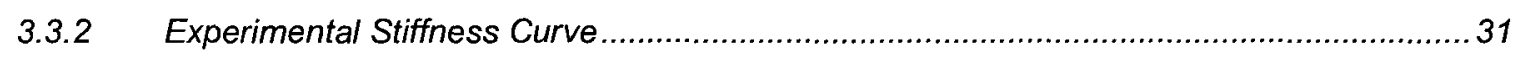

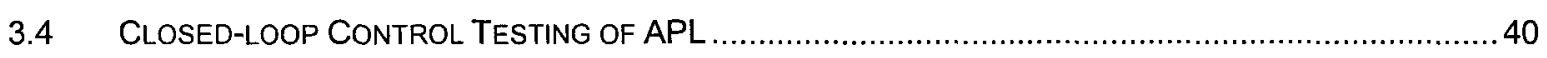




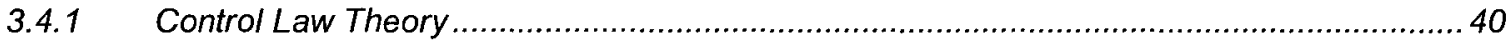

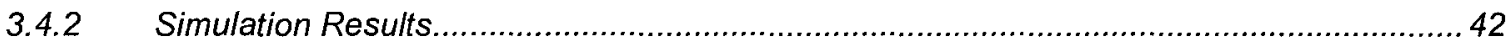

3.4.3 Experimental Implementation of Control Law ......................................................... 43

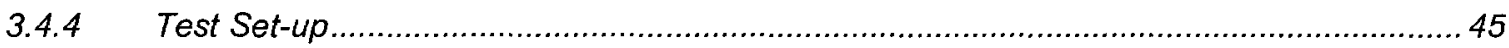

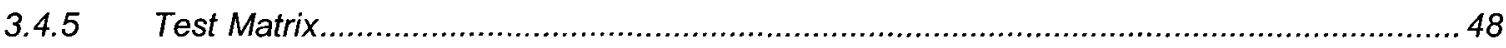

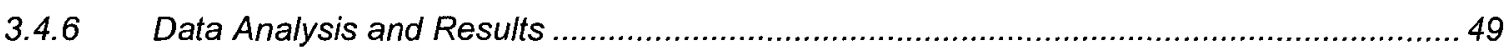

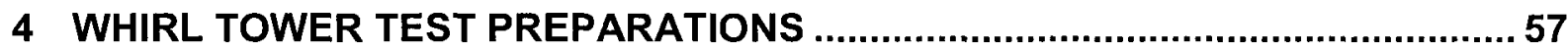

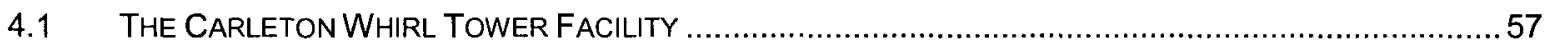

4.2 BASELINE VIBRATORY LOADS OF PITCH LINK IN WHIRL TOWER ..................................................60

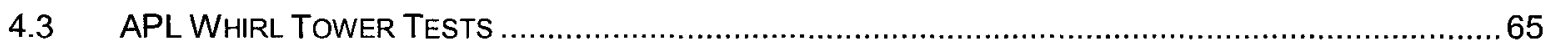

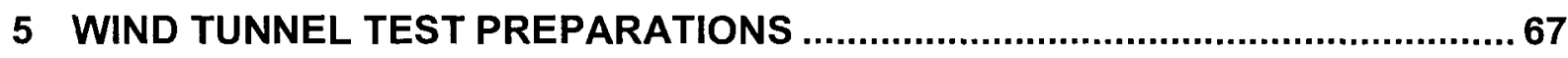

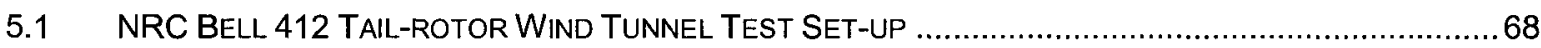

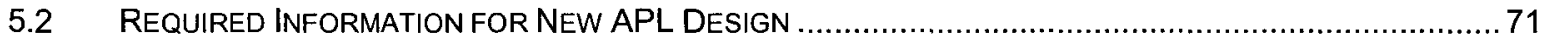

5.2.1 Modal Analysis and Numerically Extrapolated Fan Plot ................................................. 72

5.2.2 Experimentally Determined Pitch Link Loads during Rotation ...................................... 73

6 CONCLUSIONS AND FUTURE WORK ....................................................... 75

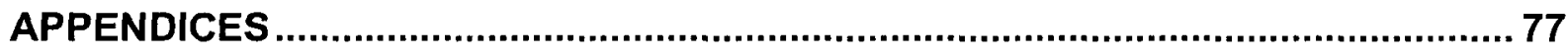

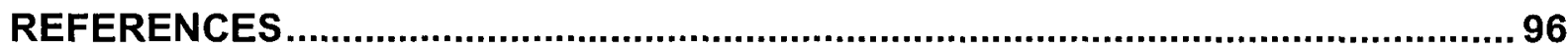




\section{List of Tables}

Table 1: Overview of worldwide research of rotor-based active control systems [12]...6

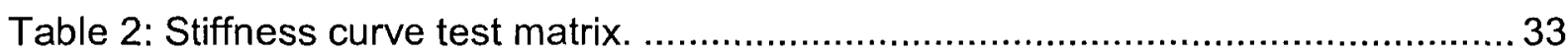

Table 3: Control law parameters determination - test matrix of 20 data points............ 48

Table 4: Vibration reduction achieved for each parameter combination for closed-loop control algorithm................................................. 53

Table 5: Properties of NRC $3 \mathrm{~m} \times 6 \mathrm{~m}$ open-circuit propulsion wind tunnel.................68

Table 6: Modal analysis of Bell 412 tail-rotor.................................................. 72

\section{List of Figures}

Figure 1: Bell 427 main rotor hub [1] ............................................................ 1

Figure 2: The SHARCS Hybrid Control concept............................................... 10

Figure 3: Sketch of Smart Spring concept..................................................... 12

Figure 4: APL prototypes: (a) $1^{\text {st }}$ generation - 2003 (b) $2^{\text {nd }}$ generation -2006

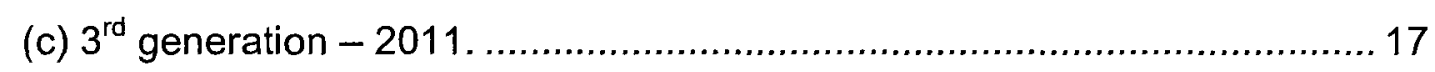

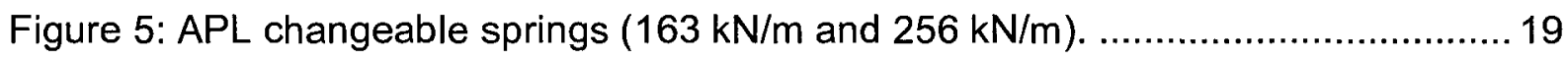

Figure 6: 3D CAD drawing of non-rotating test apparatus.................................. 22

Figure 7: Test apparatus for non-rotating dynamic tests of APL. .......................... 23

Figure 8: APL bottom bracket with strain gauges for output load measurement. ......... 23

Figure 9: Hall sensor mounted external to spring on APL. ...................................... 24

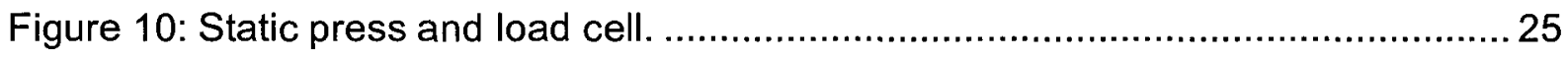

Figure 11: Theoretical change in APL stiffness [36] ....................................... 30

Figure 12: Stiffness curve test procedure for $1^{\text {st }}$ initial condition

- stationary (data point 2)......................................................... 35

Figure 13: Stiffness curve test procedure for $2^{\text {nd }}$ initial condition

- movement (data point 2) .................................................... 36

Figure 14: Spring displacement time history $-1^{\text {st }}$ initial condition,

$150 \mathrm{~V}$ input voltage. 


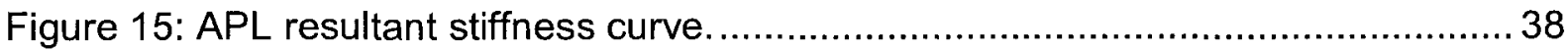

Figure 16: Base-excited Smart Spring system [39] ................................................ 41

Figure 17: Arduino Duemilanove microcontroller. ...................................................... 44

Figure 18: Schematic of test set-up for closed-loop control experiment....................... 47

Figure 19: Time history data for closed-loop control experiment,

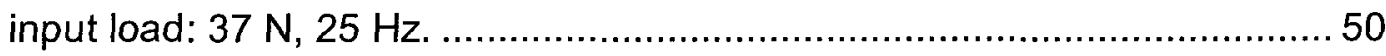

Figure 20: Time history of APL output load for closed-loop control experiment. ........... 51

Figure 21: FFT analysis of APL output load, input load: $37 \mathrm{~N}, 25 \mathrm{~Hz} \ldots \ldots \ldots \ldots \ldots \ldots \ldots \ldots . . . . . . . . . . . .52$

Figure 22: Vibration reduction due to APL closed-loop control law. .............................54

Figure 23: Vibration reduction due to "soft spring" mode only ................................... 55

Figure 24: The Carleton Whirl Tower facility's test chamber and control room. ............ 58

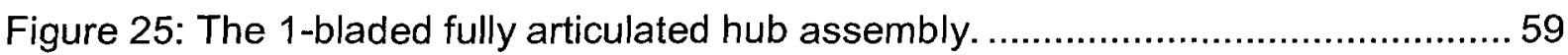

Figure 26: SHARCS aeroelastically scaled carbon-fibre blade before

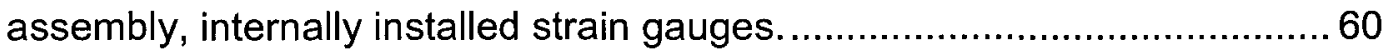

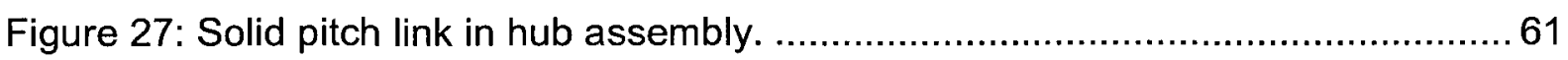

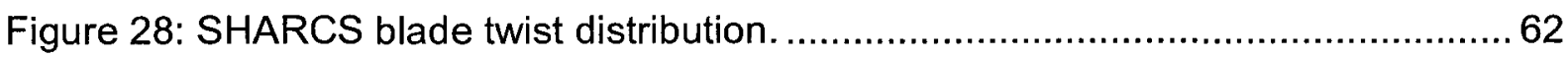

Figure 29: Baseline vibratory load through the pitch link for 0 degree root pitch angle at various rotational frequencies....................................63

Figure 30: Mean (a) static and (b) dynamic baseline vibratory loads

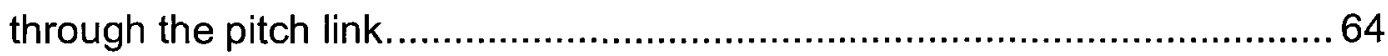

Figure 31: FFT analysis of baseline vibratory pitch link loads. ...................................6

Figure 32: The APL installed for functionality and closed-loop control tests in the rotating frame. 66

Figure 33: NRC $3 \mathrm{~m} \times 6 \mathrm{~m}$ open-circuit propulsion external fan and test section with the Bell 214 tail-rotor set-up.................................................68

Figure 34: Comparison of (a) NRC test set-up to (b) in service rotor. ......................... 70

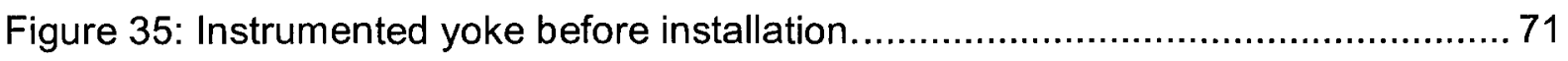

Figure 36: Numerically extrapolated fan plot for Bell 412 tail-rotor............................... 73

Figure 37: Mean (a) dynamic and (b) static pitch link loads in forward flight. ................ 74 


\section{List of Appendices}

Appendix A: Determining magnitude of average peaks (averagepeak.m) .................. 77

Appendix B: Stiffness curve (StiffnessCurve.m) .................................................. 77

Appendix C: Closed-loop control algorithm for Arduino microcontroller

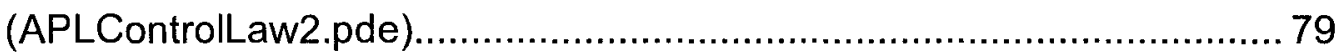

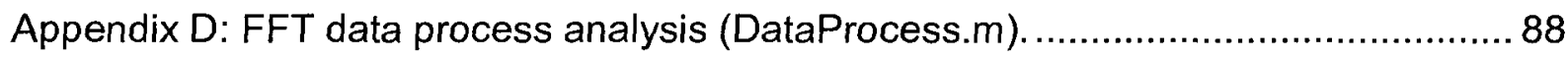

Appendix E: Numerical extrapolation - fan plot (FanPlot.m)........................................ 89

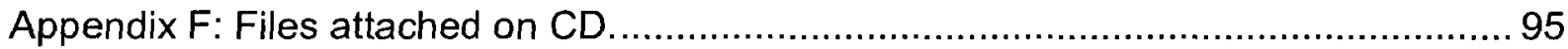




\section{Introduction}

\subsection{Vibration and Noise on Helicopters}

Helicopter flight generates excessive noise and vibration that is harmful to passenger health, the surrounding environment and the aircraft itself. The source of this noise and vibration is largely due to the aerodynamic loading experienced by the helicopter rotor blades and is most prominent in forward flight and descent. Most of the vibrations created by the blades are transferred to the fuselage via the main rotor shaft and the control system, i.e. the pitch link. Figure 1 displays a main rotor hub of a Bell 427 helicopter. This is an example of a typical helicopter control system using a pitch link and swash plate, where the pitch angle of each blade is controlled though the pitch link which is connected to a swash plate. This swash plate transfers the required control command from the fuselage to the rotating frame and the vibration experienced by the rotor blade is transferred to the fuselage through the pitch link of each blade.

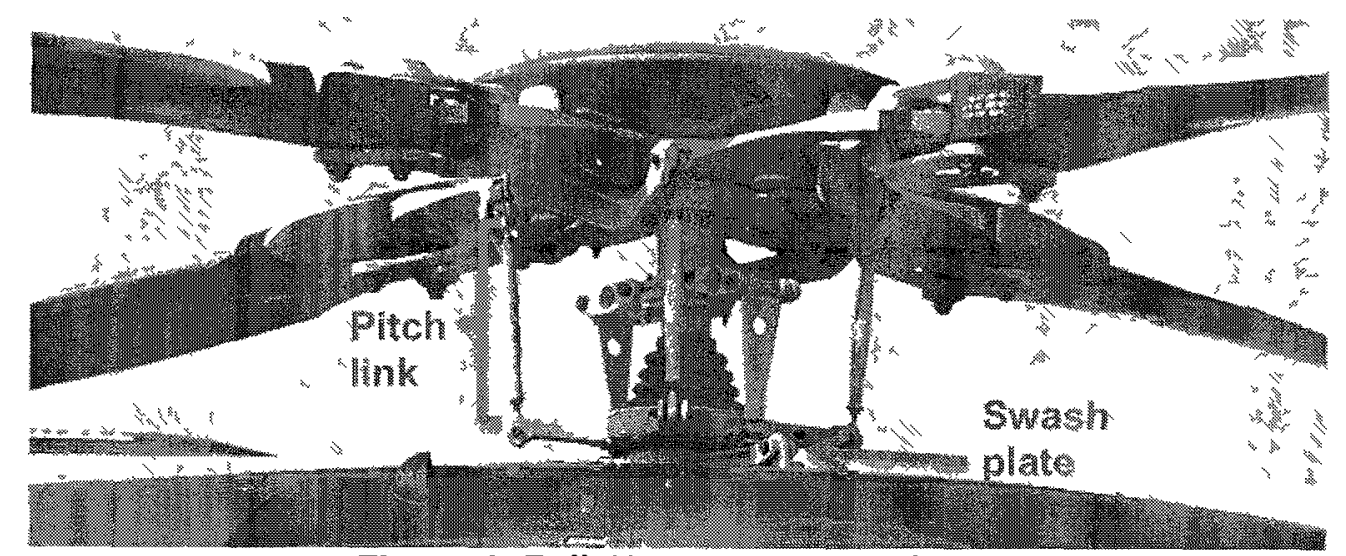

Figure 1: Bell 427 main rotor hub [1]. 
The amplitude of vibrations transferred to the helicopter fuselage during flight is usually about $0.4 \mathrm{~g}$ 's [2]. In comparison, the "jet-smooth ride" of fixed wing aircraft have less than $0.05 \mathrm{~g}$ 's of transferred vibrational forces. The frequency of helicopter vibration is between the range of $1 / \mathrm{rev}$ to $\mathrm{N} / \mathrm{rev}$, where $N$ is the number of blades on the helicopter. Typically, this frequency range is between $2-8 \mathrm{~Hz}$, depending on the size and design of the helicopter. It should be noted that the resonance frequency of the human's upper body is approximately $5 \mathrm{~Hz}$. Therefore, it is important to either reduce the magnitude of helicopter vibration or shift the frequency range in order to protect the health of passengers and crew [3].

In addition to the health risks associated with helicopter vibration, mechanical limitations are imposed on the helicopter as well. For example, the maximum forward flight speed is limited by the vibration in the control system (i.e. the pitch link) rather than the maximum engine capabilities [4].

Reducing and controlling vibrations during the flight of a helicopter is currently a major area of research in the helicopter industry. The reduction of vibrations has major benefits to the health of the pilot, the comfort of the passengers, may improve helicopter performance, and will reduce the current high cost of maintenance with less wear on the mechanical components. Noise reduction means that helicopters can be used in more urban public areas and for military operations, while lessening the overall environment noise pollution.

Traditionally, passive vibrations reduction techniques such as stiffeners, dampers or isolators are used to control helicopter vibration. The main advantage 
of these devices is their simplicity. However, there are several limitations to these types of passive techniques, such as significant weight contributions to the aircraft. Also, they function only through a narrow frequency band range and can be tailored for only a specific flight regime (i.e. forward flight at a specific speed) [5]. Due to these limitations, most research in this field currently focuses on active vibration reduction. These systems are lighter than the passive devices and can function throughout a larger frequency band, allowing the aircraft to be efficient in all flight conditions.

\subsection{Rotor-Based vs. Fuselage-Based Systems}

Active vibration systems can be installed either in the fuselage or on the rotor hub. Since helicopter vibrations are fundamentally generated by the rotor, fuselage-based systems can only reduce vibrations before being transmitted to the passengers, crew or sensitive equipment in the helicopter. On the other hand, rotor-based systems have the potential to reduce vibration at the main source, i.e. on the rotating blades. Their main advantage is therefore that vibration is reduced before it is transmitted to the fuselage or other mechanical components of the helicopter. This not only increases passenger comfort but also reduces wear on the mechanical components of the helicopter therefore decreasing the cost of repairs and maintenance. This makes the rotor-based active vibration suppression system much more attractive and promising than fuselage-based systems. The research presented in this thesis focuses on a rotor-based vibration suppression technology. 


\subsection{Flow Control vs. Structural Control Concepts}

Rotor-based vibration and noise reduction systems can be categorized into two separate types: flow control and structural control systems.

Flow control systems directly alter the aerodynamics of a blade by actively altering the blade geometry. Examples of flow control systems are the Actively Controlled Flap (ACF), the Active Twist Rotor (ATR) and the Actively Controlled Tip (ACT). As will be discussed later, these systems are being researched worldwide, and each alters the aerodynamics of the blade in order to reduce noise or vibration.

In contrast to flow control systems, structural control systems directly alter the stiffness of the blade, which indirectly alters the aerodynamics by modifying the effective stiffness of the blade. The structural control concept was first conceived by Nitzsche in 1993 [6] [7] and was independently confirmed by Gandhi in 1999 [8] [9]. Both researchers used theoretical and numerical analysis to show that actively changing the root stiffness of the blade can significantly reduce the vibrations transferred from the rotor to the fuselage. The next step was to design and develop a device that can enable root stiffness control.

In 1999, Nitzsche proposed and patented the Smart Spring concept, which is a generic stiffness control mechanism [10] (described fully in Section 2.1). A device designed with this concept can change the stiffness of a system over a certain range based on the input voltage to the actuator. Development of a Smart Spring device used specifically to modify the root stiffness of a helicopter rotor blade resulted in the design and manufacturing of the Active Pitch Link (APL). 


\subsection{Review of Rotor-Based Active Vibration Suppression Research}

Currently there are four main types of rotor-based active vibration suppression technologies being developed and tested worldwide. These technologies include: the Actively Controlled Flap (ACF), the Active Twist Rotor (ATR), the Actively Controlled Tip (ACT) and the Active Pitch Link (APL).

Table 1 summarizes ongoing research and outlines the level of development for each technology. Note that the level of development is represented by the chain of "feasibility study - system design - whirl test - wind tunnel test - flight test". The closer a research group is to flight testing, the more mature their technology is. Note that only technologies that allow Individual Blade Control (IBC), which means that each blade's actuation can be set independently, are listed in this table. Therefore, Higher Harmonic Control research has been omitted from this review. The exception is Sikorsky and Lord's Hub Mounted Vibration Suppression System (HMVS) [11], which does not appear to allow Individual Blade Control (IBC), but is the first rotor-based active control system mass-produced and currently in operation [12]. 
Table 1: Overview of worldwide research of rotor-based active control systems [12].

\begin{tabular}{|c|c|c|c|c|c|}
\hline Institution & Type & Country & $\begin{array}{l}\text { Active } \\
\text { Control } \\
\text { System }\end{array}$ & $\begin{array}{l}\text { Level of } \\
\text { Advancement }\end{array}$ & Ref. \\
\hline $\begin{array}{l}\text { Eurocopter + ZFL + } \\
\text { DLR + NASA + } \\
\text { U.S.Army }\end{array}$ & $\begin{array}{l}\text { Industry } \\
\text { Res. Inst. } \\
\text { Military } \\
\end{array}$ & $\begin{array}{l}\text { Germany } \\
\text { U.S.A. }\end{array}$ & $\begin{array}{l}\mathrm{APL}^{*} \text { (electro- } \\
\text { hydraulic) } \\
\mathrm{ACF}^{\star}\end{array}$ & $\begin{array}{l}\text { Flight Test } \\
\text { Flight Test }\end{array}$ & {$[13],[14]$} \\
\hline Boeing & Industry & U.S.A. & ACF & $\begin{array}{l}\text { Whirl Test } \\
\text { Wind Tunnel Test }\end{array}$ & [15], [16] \\
\hline $\begin{array}{l}\text { Sikorsky + ZFL + } \\
\text { NASA + } \\
\text { U.S. Army }\end{array}$ & $\begin{array}{l}\text { Industry } \\
\text { Res. Inst. } \\
\text { Military } \\
\end{array}$ & U.S.A. & $\begin{array}{l}\text { APL* (electro- } \\
\text { hydraulic) } \\
\text { ACF* }^{*}\end{array}$ & $\begin{array}{l}\text { Wind-Tunnel Test } \\
\text { Wind Tunnel Test }\end{array}$ & {$[17],[18]$} \\
\hline $\begin{array}{l}\text { Sikorsky + Lord + } \\
\text { U.S. Army }\end{array}$ & $\begin{array}{l}\text { Industry } \\
\text { Military } \\
\end{array}$ & U.S.A. & HMVS & Flight Test & {$[11]$} \\
\hline $\begin{array}{l}\text { DLR + } \\
\text { ONERA }\end{array}$ & Res. Inst. & $\begin{array}{l}\text { Germany } \\
\text { France }\end{array}$ & ATR & Whirl Test & {$[19]$} \\
\hline $\begin{array}{l}\text { NASA + } \\
\text { US Army + } \\
\text { M.I.T. }\end{array}$ & $\begin{array}{l}\text { Res. Inst. } \\
\text { Military } \\
\text { Academia } \\
\end{array}$ & U.S.A. & ATR & Wind Tunnel Test & {$[20]$} \\
\hline $\begin{array}{l}\text { ONERA + DLR+ } \\
\text { Eurocopter }\end{array}$ & $\begin{array}{l}\text { Res. Inst. } \\
\text { Industry }\end{array}$ & $\begin{array}{l}\text { France } \\
\text { Germany }\end{array}$ & $\mathrm{ACF}$ & Wind Tunnel Test & {$[21]$} \\
\hline $\begin{array}{l}\text { Kawasaki Heavy } \\
\text { Ind. }\end{array}$ & Industry & Japan & $\mathrm{ACF}$ & Whirl Test & {$[22]$} \\
\hline $\begin{array}{l}\text { JAXA + } \\
\text { Mitsubishi }\end{array}$ & $\begin{array}{l}\text { Res. Inst. } \\
\text { Industry }\end{array}$ & Japan & $A C F$ & Wind Tunnel Test & [23] \\
\hline $\begin{array}{l}\text { KARI + } \\
\text { Konkuk University }\end{array}$ & $\begin{array}{l}\text { Res. Inst. } \\
\text { Academia }\end{array}$ & Korea & ATR & Feasibility + Design & [24] \\
\hline $\begin{array}{l}\text { AgustaWestland + } \\
\text { PennState }\end{array}$ & $\begin{array}{l}\text { Industry } \\
\text { Academia }\end{array}$ & $\begin{array}{l}\text { Italy/U.K. } \\
\text { U.S.A. }\end{array}$ & $\begin{array}{l}\text { ACF (Gurney } \\
\text { Flap) } \\
\text { Variable Chord } \\
\text { Blade } \\
\end{array}$ & $\begin{array}{l}\text { Feasibility + Design } \\
\text { Feasibility + Design }\end{array}$ & [25] \\
\hline $\begin{array}{l}\text { University of } \\
\text { Michigan }\end{array}$ & Academia & U.S.A. & $\begin{array}{l}\text { ATR } \\
\text { ACF }\end{array}$ & $\begin{array}{l}\text { Whirl Test } \\
\text { Whirl Test }\end{array}$ & {$[26],[27]$} \\
\hline $\begin{array}{l}\text { University of } \\
\text { Maryland }\end{array}$ & Academia & U.S.A. & $\begin{array}{l}\text { ACF } \\
\text { Passive Pitch } \\
\text { Link }\end{array}$ & $\begin{array}{l}\text { Wind Tunnel Test } \\
\text { Whirl Test }\end{array}$ & {$[28],[29]$} \\
\hline Georgia Tech & Academia & U.S.A. & $\begin{array}{l}\text { Active Lead- } \\
\text { Lag Damper }\end{array}$ & Feasibility + Design & [30] \\
\hline Carleton University & Academia & Canada & $\begin{array}{l}\text { APL }^{* *}(\text { piezo- } \\
\text { electric) } \\
\text { ACF** } \\
\text { ACT }\end{array}$ & $\begin{array}{l}\text { Whirl Test } \\
\text { Whirl Test } \\
\text { Feasibility + Design }\end{array}$ & $\begin{array}{l}\text { [31], [32], } \\
\text { [33] }\end{array}$ \\
\hline \multicolumn{4}{|c|}{$\begin{array}{ll}\text { Abbreviations: } & \text { APL - Active Pitch Link } \\
& \text { ACF - Actively Controlled Flap } \\
& \text { ATR - Active Twist Rotor (patented by } \\
& \text { Carleton University) } \\
& \text { ACT - Actively Controlled Tip } \\
& \text { HMVS - Hub Mounted Vibration Suppre }\end{array}$} & \multicolumn{2}{|c|}{$\begin{array}{l}\text { * uses APL and ACF separately only } \\
\text { * uses APL and ACF in a combined way }\end{array}$} \\
\hline
\end{tabular}


The ACF, ATR and ACT concepts are all blade-based systems, which mean they modify the rotor blade geometry itself. On the other hand, the APL is a hubbased system, which leaves the blade geometry unmodified and changes its stiffness only. This is an important advantage for the APL since no modifications are required to be made to an already refined blade design, therefore allowing it to be retrofit to any helicopter.

The Actively Controlled Flap (ACF) is the most widely researched technology and has gone through flight testing. This device can optimally reduce noise or vibration, but only at the expense of the other i.e. when it is optimized to reduce noise, vibration levels increase and vice versa [15] [16]. The Active Twist Rotor (ATR) can achieve the same results as the ACF but requires more power. Unlike the ACF, an ATR does not have moving mechanical parts which allows the design to be used in much more extreme conditions, such as dust, snow or icing areas.

The Active Pitch Link (APL) is the only design that does not modify the blade; it is installed as a replacement to the traditional pitch link required to change the pitch angle of each blade. Wind tunnel testing of a hydraulically driven APL system showed great reduction of vibration [13] [17]. However, this design was never implemented into mass production due to the weight limitations, complexity and safety concerns of a hydraulic system in the rotating frame. This has led to the development of an electronically driven Active Pitch Link (APL) designed by the Rotorcraft Research Group at Carleton University. This APL design is part of a Hybrid Control concept that incorporates several active control systems. This 
concept initiated the SHARCS (Smart Hybrid Active Rotor Control Systems) project with collaborative research efforts from the National Research Council Canada (NRC), Smart Rotor Systems (SRS) Inc. and the Carleton University Rotorcraft Research Group.

The only current technology that is similar to the Carleton Rotorcraft Research Group's APL design is the active lead-lag damper developed by Georgia Tech [30]. The conceptual design of this active lead-lag damper is very similar to the Smart Spring system used in the APL prototype. A comprehensive study, including computational simulations was conducted to show that the leadlag damper would be very effective to reduce helicopter vibrations throughout the entire flight envelope. Although the results were promising, it was concluded that a practical design of such a device would be too challenging to implement. Due to the limitations expressed by the GeorgiaTech research, no prototype was developed for the active lead-lag damper.

\subsection{Hybrid Control Concept}

Actively controlled systems can adapt to reduce vibration or noise over a wide range of flight regimes, their major downfall is that they can only reduce either vibration or noise, not both. Additionally, it has been shown that one active system can alleviate one particular problem but it increases the effect of other problems [14] [16].

To address this shortcoming, the Hybrid Control concept was proposed by Feszty and Nitzsche [36]. The Hybrid Control system is based on the common theorem of Control Theory that in order to control two independent phenomena, 
two independent control systems are required. Therefore, in order to reduce vibration and noise in helicopters simultaneously, two or more independent active control systems are required. The Hybrid Control concept is based on this premise and incorporates two or more active control devices on a single rotor blade. This means one system can be optimized to reduce vibrations, while the second system can be optimized to reduce noise. In particular, this Hybrid Control concept proposes the use of both a flow control technique (i.e. ACF, ATR or ATC) in combination with a structural control system (i.e. APL). The APL controls the structural properties of the blade by actively changing the blade root stiffness, allowing for vibration reduction.

A patent for the Hybrid Control concept was filed by Feszty and Nitzsche in 2008 and is based on the combination of an active flow changing device and the APL.

\subsection{The SHARCS Project}

In order to demonstrate the Hybrid Control concept experimentally, the SHARCS (Smart Hybrid Active Rotor Control Systems) project was launched at Carleton University in 2004 . The goal of the project is to experimentally show that vibration and noise can be simultaneously reduced through the Hybrid Control concept.

The aim of this project is to include three independent active control systems on one blade. As shown in Figure 2, this design includes two blade based flow control systems, the Actively Controlled Flap (ACF) and the Actively 
Controlled Tip (ACT). In addition to these, it also includes a hub-based structural control system, the Active Pitch Link (APL).

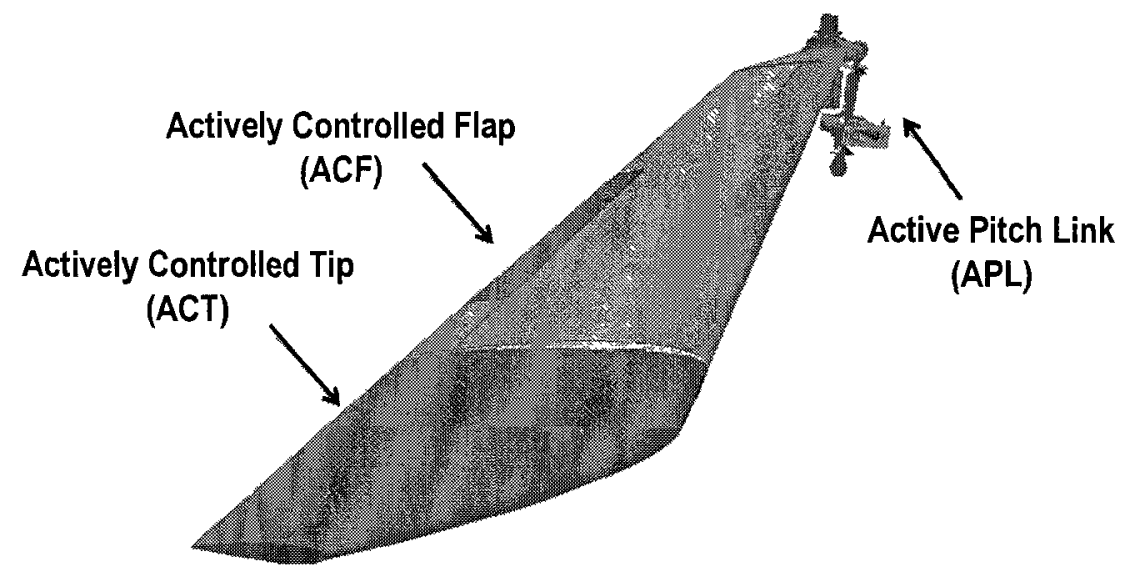

Figure 2: The SHARCS Hybrid Control concept.

Elements of this concept have been demonstrated computationally and experimentally over the past four years. Computational feasibility studies of the Actively Control Flap (ACF) have been completed by Davis and Ülker [32] and of the Active Pitch Link (APL) by Oxley et al. [34].

Whirl tower test of the Active Pitch Link (APL) and Actively Controlled Tip (ACT) have been conducted in 2008 [36], and the APL was tested in the nonrotating frame by Mander [37].

\subsection{Thesis Objective}

The main focus of this thesis is to demonstrate experimentally that the Active Pitch Link (APL) can significantly reduce vibrations transferred through the pitch link. For this, the first-ever closed-loop control tests of the APL were conducted and will be presented. The goal of this thesis is therefore to perfect the APL as a lone active control system. Merging it with the ACF or ACT to prove the Hybrid 
Control concept will be the scope of another work project building on this thesis' results.

\subsection{Thesis Structure}

The thesis consists of three main parts. First, the functionality of the APL prototype will be proven via non-rotating tests. The goal of these tests is to ensure that all design requirements were met. Second, non-rotating tests were conducted to implement a closed-loop control algorithm to actively control the APL with the objective of vibration reduction. Although computational and numerical studies have previously shown significant vibration reductions, this is the first time the closed-loop control algorithm has been implemented with a prototype APL.

Lastly, preparations for whirl tower and wind tunnel testing of the APL were completed. Baseline vibrations through a conventional pitch link were experimentally measured, which is crucial to enable further testing of the APL in the rotating frame. 


\section{Active Pitch Link (APL) Prototype Design}

Once the conceptual design of the Active Pitch Link (APL) was developed a prototype was required for experimental evaluation of the concept. The first step was a functional prototype of the Smart Spring concept and then the development and manufacturing of an APL which meets all design requirements.

\subsection{Operating Principle of Smart Spring System}

The operating principle of the APL is based on the Smart Spring concept (Figure 3) presented by Nitzsche in 1999. Figure 3 is not an exact representation of the system used in the APL but it illustrates well the general operating principle.

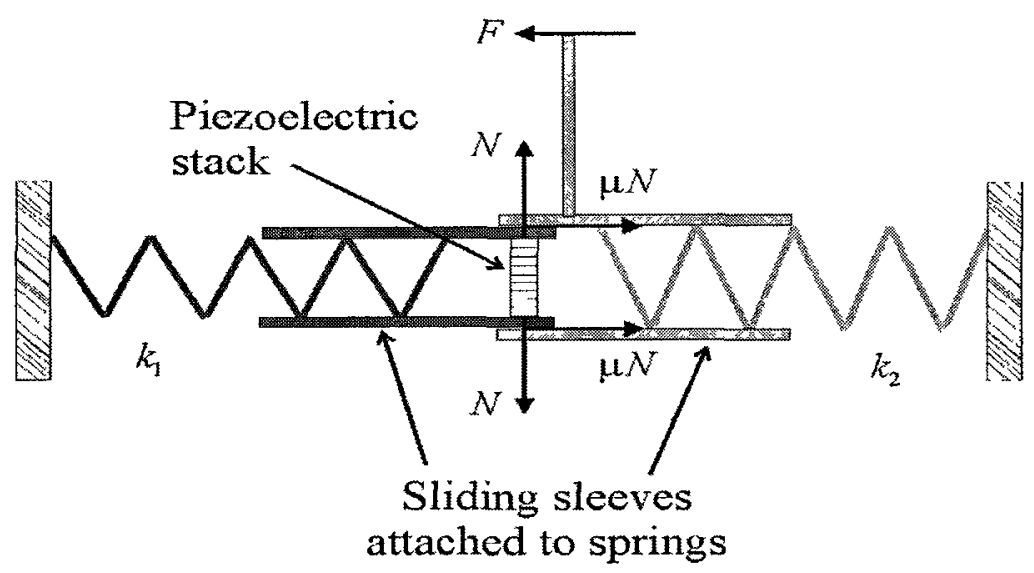

Figure 3: Sketch of Smart Spring concept.

In Figure 3, two springs, $k_{1}$ and $k_{2}$ are attached to opposing rigid walls.

The other end of each spring contains a rigidly attached sleeve. The two sleeves mate in the centre and can slide with respect to each other. An external (input) 
force $F$ is applied to the sleeve of spring $k_{2}$. A stack of piezoelectric actuators is inserted into the internal sleeve attached to spring $k_{1}$.

When the piezoelectric actuator is "OFF", the two sleeves can move freely and the resulting horizontal displacement (output) is $\delta_{\max }=F / k_{2}$. Spring $k_{2}$ is designed to be the "primary" load path of the APL. When the actuator is turned "ON" the piezoelectric stack deforms the internal sleeve causing it to apply a resultant normal force, $N$, onto the external sleeve.

A friction force, $\mu N$, is induced by the contact between the two surfaces. If this friction force is sufficiently large, the two sleeves are forced into motion together. In this case, an arrangement of two springs in series is created and a smaller horizontal output displacement $\delta_{\min }=F /\left(k_{1}+k_{2}\right)$ is obtained because the stiffness "seen" by the input force rises from the system's original $k_{2}$ to $\left(k_{1}+k_{2}\right)$. In fact, the spring designated by $k_{1}$ is driven by the resultant friction force $\mu N$ applied by the internal sleeve onto the external sleeve. This force is dictated by the input voltage to the piezoelectric stack. This spring configuration is called the "secondary" load path of the APL.

The horizontal output displacement of the system under the input force $F$ varies between the referred two extremes, $F /\left(k_{1}+k_{2}\right) \leq \delta \leq F / k_{2}$ and the total load is distributed between the primary and the secondary load paths. Due to manufacturing tolerances and piezoelectric limitations, the latter two limits may not be achievable. This is due to the fact that the maximum stroke supplied by the stack of piezoelectric elements might be insufficient to guarantee that the two sleeves move freely in the actuator "OFF" condition. It is also possible that the 
piezoelectric force is not sufficient to guarantee a locked situation between the two sleeves in the "ON" condition. However, this is not regarded as an important issue because the fundamental concept resides solely on the ability of the system to change in real-time its apparent stiffness characteristics.

Note that the APL system also changes its apparent mass because the piezoelectric stack and internal sleeve have inertial properties. However, this effect can be disregarded if the overall system is "stiffness dominated" (i.e., the harmonic disturbance force has a frequency much lower than the internal resonance frequencies of the APL). The dry friction between the sleeves also creates Coulomb damping, which cannot be neglected and adds an important stabilizing effect to the system. Since the APL actively changes both its apparent mass, stiffness and its internal damping, it is called an "impedance control" device.

Within the context of the SHARCS project, the APL replaces the conventional pitch link. Thus, the blade and the APL become an integral system, which can control the twist impedance of the blade in real-time. For this, the 1st torsional mode of the blade is targeted for the control action.

\subsection{APL Prototype Design Requirements}

There were four design requirements set by the Carleton Rotorcraft Research Group for the APL, each contributing to safe, reliable operation while reducing the vibration transmitted from the rotor blade into the fuselage. These are: 


\section{Electrical actuation:}

The system shall be driven electrically to ensure simplicity, low weight and reliability. Note that although a previously tested hydraulic active pitch link was very successful in reducing vibration, it was concluded to be inadequate for mass-production because of the weight and challenges in unreliability of the slip ring of a hydraulic system.

\section{Controllability:}

This means ensuring that there is sufficient force from the actuator to allow Individual Blade Control (IBC) characterized by the frequency range of $(\mathrm{N}-1) / \mathrm{rev}$ to $(\mathrm{N}+1) / \mathrm{rev}$, where $\mathrm{N}$ is the number of blades in the system.

3. Observeability:

It is essential to have ample monitoring systems as part of the APL design. These systems are required to monitor the vibration loads, actuator displacements and force, as well as the health of the unit itself. This real-time data is also required for closed-loop control of the system.

4. Fail-safe mode:

The last and most important design requirement of the APL is its failsafe mode. It is paramount that the APL functions as a conventional pitch link in the case of actuator failure or power loss to the system. In this case the load path must not be transferred through any springs or 
the actuators (piezoelectric actuators might be too brittle), and the APL must function as a conventional pitch link.

In addition to the four major requirements for safe operation of the APL several other design limitations were established. First, in order to determine the actuator size it was required to determine the loads that the actuator would be required to overcome. The loads acting on the APL are the same as those that act through a conventional pitch link including static, dynamic and centrifugal loading. Due to lack of experimental data the static and dynamic loads were initially estimated using CFD simulations in a forward flight case.

The CFD simulations where obtained using the SMARTROTOR code [34] with the SHARCS scaled rotor in forward flight conditions. From these simulations it was estimated that the magnitude of the static loads acting though the pitch link for this configuration is approximately $100 \mathrm{~N}$ and about a $70 \mathrm{~N}$ amplitude for the dynamic loads [35]. Based on the configuration of the system, it is estimated that the centrifugal loads are about $165 \mathrm{~g}$ 's. These loads were used to size the actuators required in the APL prototype.

The final piece of information required for the APL prototype design was the physical size requirements of the unit. The APL size was limited to a scaled hub design requiring it to be no more than $108 \mathrm{~mm}$ in length and it was required to not interfere radial with the hub and its components.

\subsection{APL Prototyping}

Over the past ten years, three prototype Active Pitch Links were developed. The first prototype, developed in 2003 , was a large scale system to prove the 
Smart Spring concept, Figure 4 (a). This prototype is approximately $1 \mathrm{~m}$ in length, and was used to confirm the Smart Spring concept is feasible as described in the operating principle and did not meet all the design requirements.

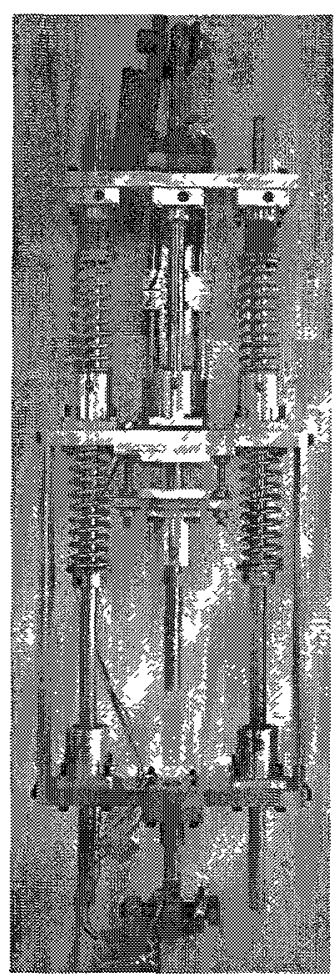

(a)

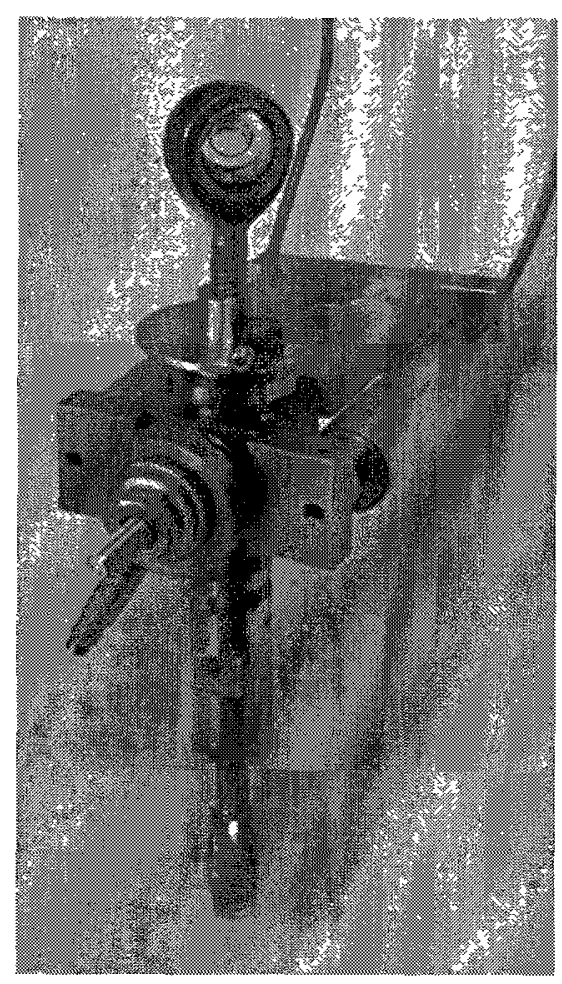

(b)

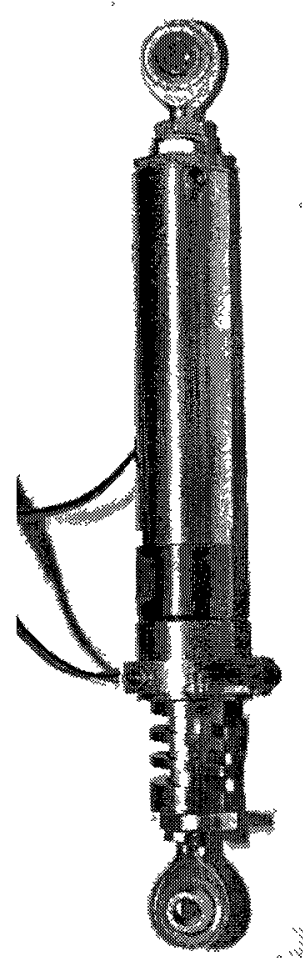

(c)

Figure 4: APL prototypes: (a) $1^{\text {st }}$ generation - 2003 (b) $2^{\text {nd }}$ generation - 2006 (c) $3^{\text {rd }}$ generation -2011 .

The second generation APL was designed and manufactured in 2006 and is shown in Figure 4 (b). After testing this unit in both the non-rotating frame and whirl tower tests [36] a more effective APL prototype was designed and built in 2011, Figure 4 (c).

The third generation APL is the most current APL prototype developed and testing of this prototype is the focus of the research presented in this thesis. All 
further information discussed in this thesis is in regards to the third APL prototype.

In this APL prototype design, the overall system stiffness can be varied between $k_{1}$ ("soft" link) and $k_{2}$ ("solid" link), instead of the ranges of $k_{2}$ and $k_{1}+k_{2}$ as in Figure 3. This design is compact with adjustable preload settings and a total mass of $0.196 \mathrm{~kg}$. It also incorporates a friction force clamp independent from centrifugal loads.

\subsection{Control Algorithm Characteristics}

The controller for this APL is called "semi-active" or "indirect-active" because all control energy is directed to change the dynamic properties of the structure (the blade impedance) rather than to generate mechanical work against external aerodynamic forces. For this reason, the power consumption is low in comparison to other Individual Blade Control (IBC) concepts such as the Active Twist Rotor (ATR), where the piezoelectric elements need to act against the total aerodynamic moment applied on the blade. As a comparison, to reach its objectives, the APL system needs about $100 \mathrm{~V}$ peak-to-peak control voltage, about $3-5 \%$ of the value required by the ATR. The manufacturing and maintenance costs of an APL system are also very low when compared to those of an ATR. Maintenance is also easy since the friction elements are easily reachable and replaceable.

The closed-loop control algorithm, discussed later, self-compensates for a possible change in damping characteristics of the system due to the wear of contacting parts or temperature increases. The most important trait of this system 
is that the modal characteristics of the blade's $1^{\text {st }}$ elastic torsion mode shape, especially its frequency (due to the active changes in the APL apparent stiffness) and damping ratio (due to the APL internal friction) are controllable.

\subsection{Spring Stiffness Selection}

Selecting the "soft spring" stiffness $\left(k_{1}\right)$ of the APL is crucial for optimal performance. The APL is designed to alter the first torsional mode and therefore the stiffness required for the "soft spring" mode is dictated by the blade's fan plot. The method of selecting the spring stiffness from a blade's fan plot is described in detail in references [36] and [37]. For this experimental test campaign, a range of springs with varying stiffness were manufactured in-house to determine the optimal spring stiffness required, Figure 5.
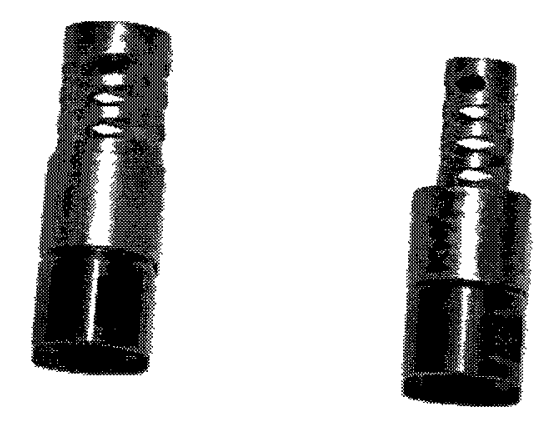

Figure 5: APL changeable springs ( $163 \mathrm{kN} / \mathrm{m}$ and $256 \mathrm{kN} / \mathrm{m}$ ).

The springs were designed and manufactured by Smart Rotor Systems (SRS) Inc. They are made of 4140 steel, including heat treatment using an oil quench technique as well as shot peening to minimize residual stresses. Three springs were manufactured with stiffness ranging from $80 \mathrm{kN} / \mathrm{m}$ to $256 \mathrm{kN} / \mathrm{m}$. All 
experiments outlined in this thesis were achieved using the $80 \mathrm{kN} / \mathrm{m}$ spring since this showed optimal results for $1 /$ rev vibration reduction.

\subsection{Actuator Selection}

The actuators for this APL design were selected based on the design requirements outlined in Section 2.2. A Piezomechanik HPSt 150/14-10/50 piezoelectric ring actuator was selected with a maximum block force of $4,500 \mathrm{~N}$, maximum displacement of $45 \mu \mathrm{m}$ and maximum frequency of $200 \mathrm{~Hz}$.

This APL also incorporates one default Hall effect sensor (Honeywell, SS495) to facilitate "observability" of the device. This sensor is mounted externally and is used to measure the spring displacement. 


\section{Non-rotating Experiments}

In order to test the functionality of the APL, it was first tested in the nonrotating frame. The aim of these tests was to ensure that the device functions under the expected static and dynamic loads as well as to develop the closedloop control algorithm.

The test campaign was divided into three stages, with the following objectives:

Stage 1: Determine the maximum static and dynamic load the APL can withstand while maintaining a fail-safe mode. i.e. the APL can hold in the case of power loss or actuator failure.

Stage 2: Determine the APL's stiffness curve. This is a plot of the APL's resultant stiffness as a function of the piezoelectric actuator input voltage when a dynamic input load is applied.

Stage 3: Closed-loop control tests to explore the APL's capability to reduce the vibration transmitted though the APL.

\subsection{Test Set-up}

All non-rotating tests were done using the same experimental test set-up described in this section. The only exception is the maximum static load test described in Section 3.2.1.

A unique test apparatus was constructed specifically to mimic the dynamic loading expected to act through a pitch link during rotation (not including the centrifugal loads). A 3D CAD drawing of the apparatus is shown in Figure 6. This 
apparatus is capable of producing dynamic loads of varying amplitude and frequency axially through the APL.

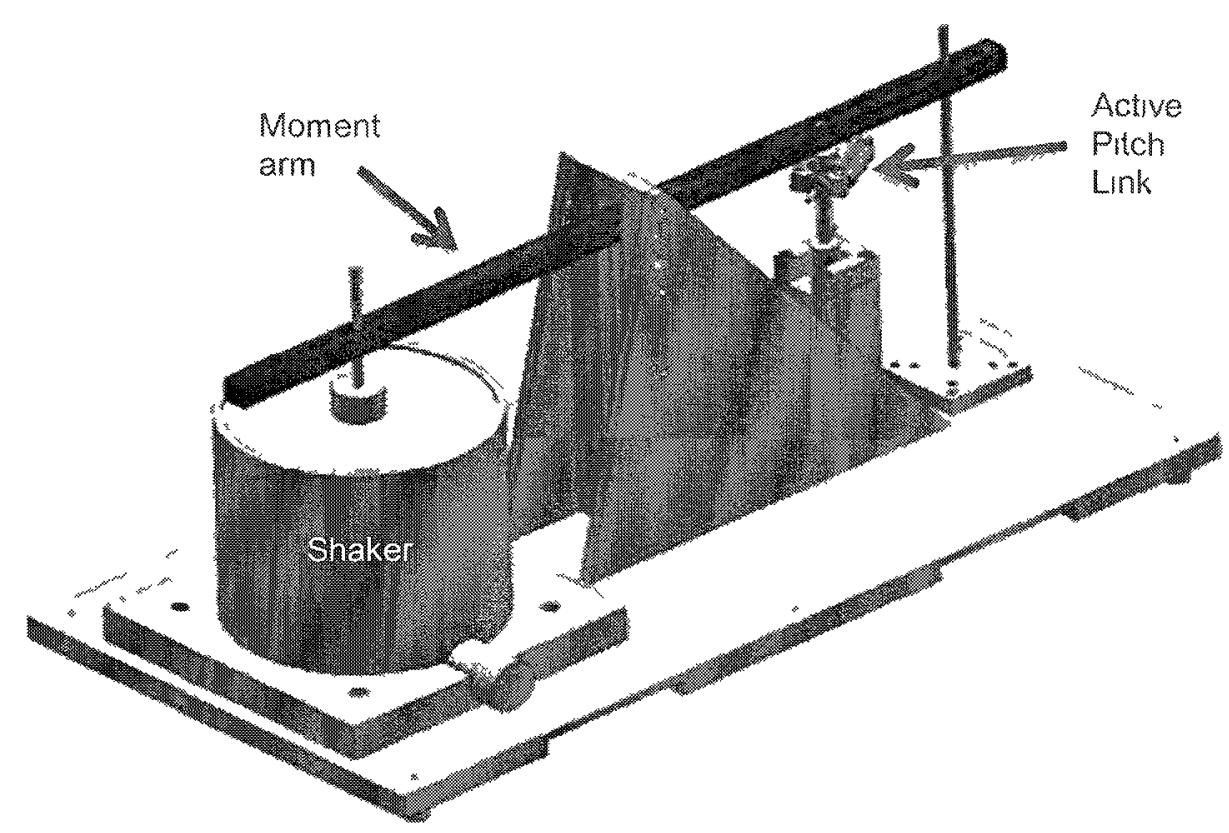

Figure 6: 3D CAD drawing of non-rotating test apparatus.

As shown on the test apparatus, Figure 7, a moment arm transmits loads from a shaker (Bruel \& Kjaer, Model 4808) into the APL. Ball joint rod ends were used to ensure that only axial loading is transmitted through the APL. The input to the shaker was controlled using XPC TargetBox/Simulink. Appendix F includes a point form outline for setting up the hardware and software required to control the test set-up using xPC TargetBox/Simulink. 


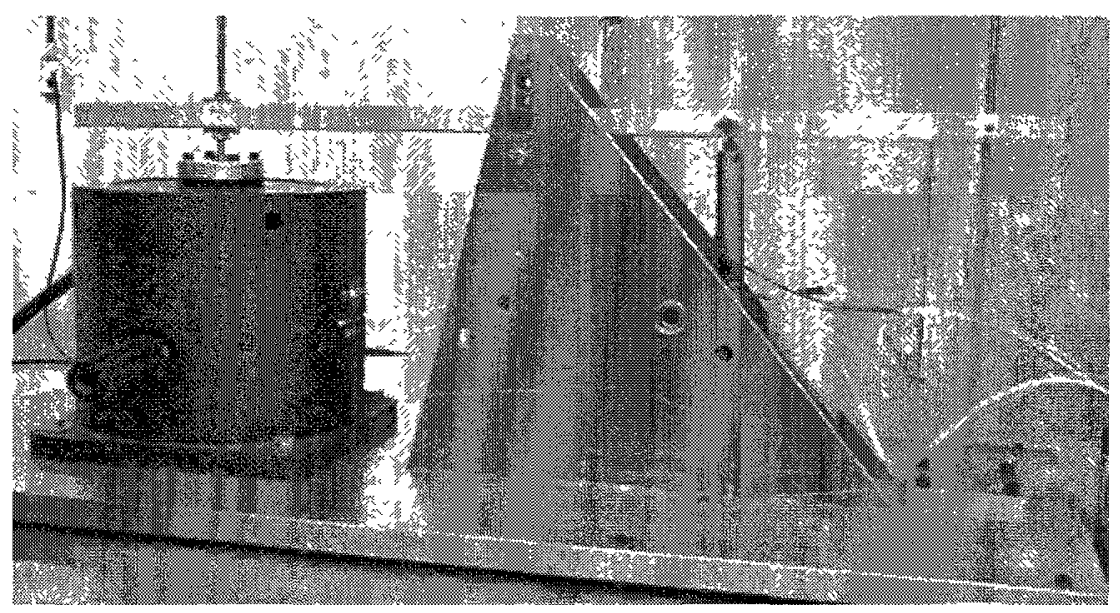

Figure 7: Test apparatus for non-rotating dynamic tests of APL.

During the non-rotating tests, two measurements were done. The first measurement was required to monitor the vibration reduction performance of the APL, thus loads transmitted through the link are measured. Strain gauges are mounted on a bracket at the bottom of the APL, as shown in Figure 8 . A half bridge is installed on the bracket using $350 \mathrm{Ohm}$ strain gauges. This bracket mimics the location of the swash plate on a helicopter and a reduction of loads transmitted into this bracket translates to a reduction of loads transmitted to the helicopter fuselage. The strain gauge measurements were also used for the closed-loop control law.
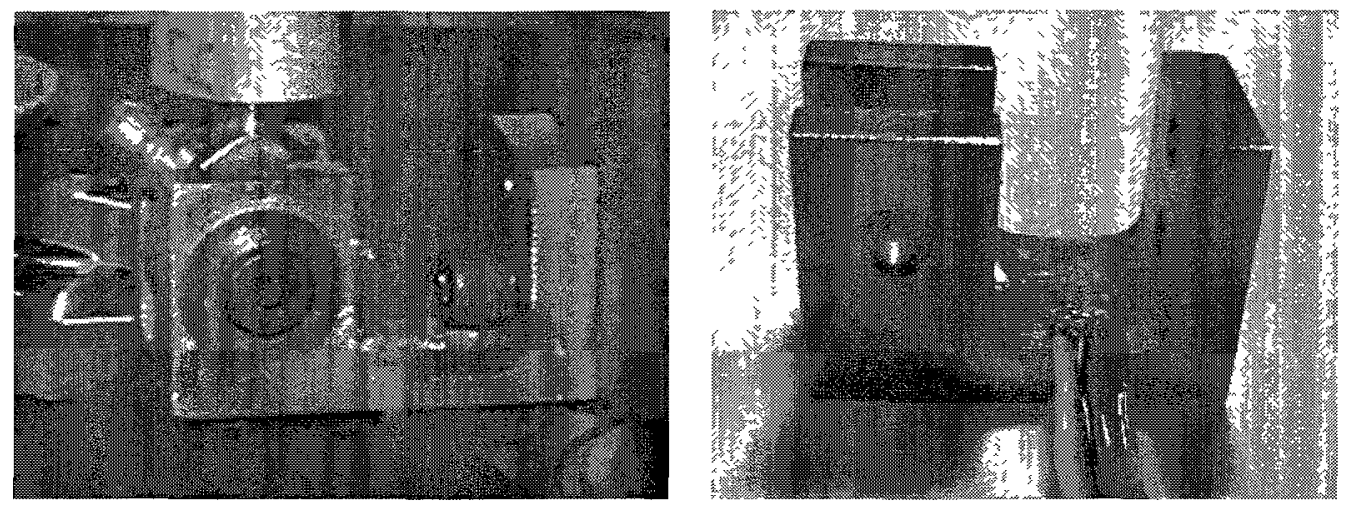

Figure 8: APL bottom bracket with strain gauges for output load measurement. 
Secondly, a Hall sensor (Honeywell, SS495A) was used to measure the displacement of the spring on the APL. The Hall sensor is mounted externally on the APL spring as shown in Figure 9. This data was used to monitor the APL's functionality and to calculate the resultant stiffness of the system.

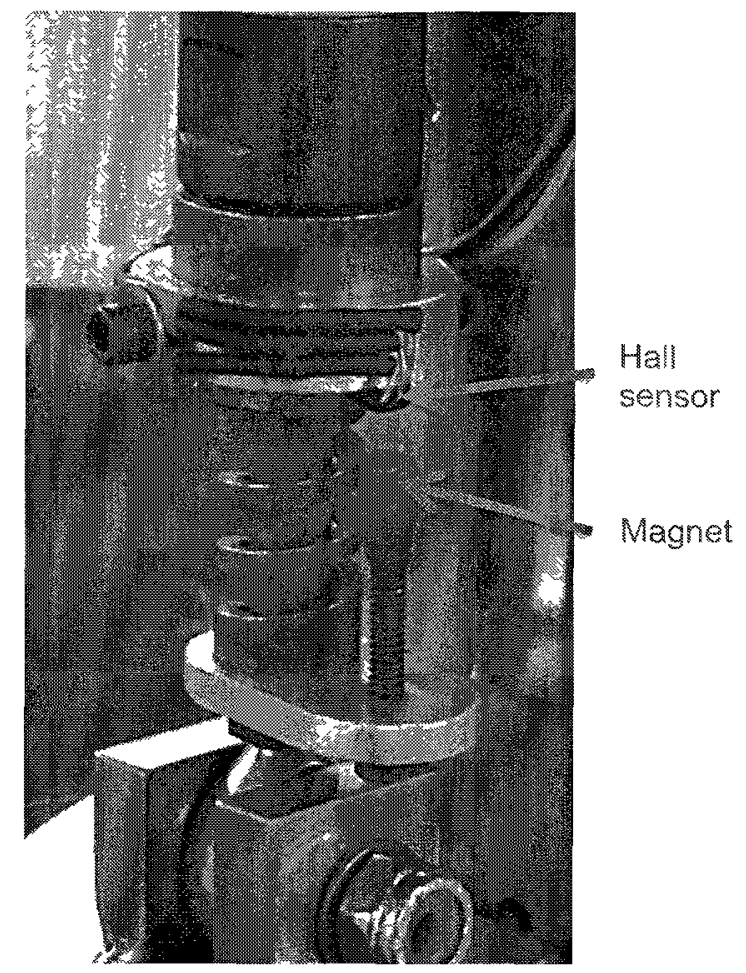

Figure 9: Hall sensor mounted external to spring on APL.

The data from both the Hall sensor and strain gauges were collected using XPC TargetBox/Simulink. During all non-rotating dynamic tests, data was collected at $7,143 \mathrm{~Hz}$ sampling frequency.

\subsection{Maximum Load Capacity of APL}

One of the most important features of the APL is its fail-safe design. This design ensures that in the case of power failure or actuator failure the APL reverts to a traditional solid pitch link. This means that all load is transferred 
through the "solid link" of the APL. Although the APL was designed to operate under axial loading up to $150 \mathrm{~N}$, experimental testing was required to confirm that it can hold in its fail-safe condition under static and dynamic loading of this magnitude.

\subsubsection{Maximum Static Load Capacity}

In order to test the maximum static load the APL can withstand, a load cell and press were used as shown in Figure 10. For this test static load was applied to the APL using the press while the load was measured via a load cell located at the base of the APL.

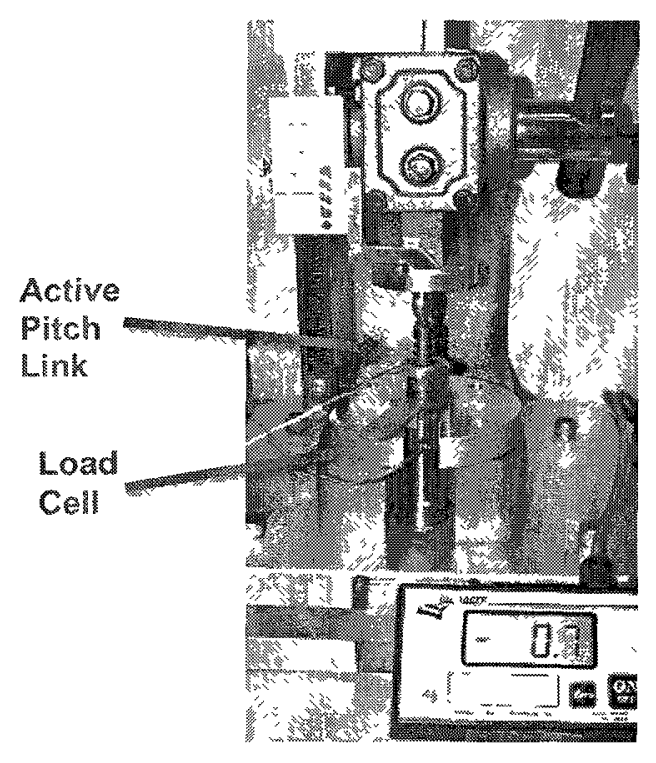

Figure 10: Static press and load cell.

The press used in this set-up is a generic off-the-shelf press with custom modifications. The first major modification is the addition of a load cell manufactured by Longacre Racing Products Inc. This load cell has a precision of $\pm 0.1 \mathrm{lb}$. , calibrated by the manufacture and a capacity of $350 \mathrm{lb}$. The second 
modification is the addition of a micrometer to measure the vertical displacement of the press, with a precision of $\pm 0.0001 \mathrm{~m}$.

\section{Test Procedure}

In order for the APL to function in its fail-safe mode, there should be no displacement of the spring when load is applied axially to the system when no power is supplied to the piezoelectric actuator.

To confirm the fail-safe load limit, increasing (static) axial load was applied incrementally to the APL mounted in the press (Figure 10) until displacement of the spring was measured by the external Hall sensor (Figure 9). When spring displacement was detected, the applied load was manually recorded as the maximum static load that the APL can hold in its fail-safe mode. The same procedure was completed ten times and the average load was calculated.

It should be noted that the maximum static load of the APL can be changed based on the preload settings of the APL during assembly. All testing presented in this research was done with the same preload settings. Note that changing the preload settings may cause changes to all results presented.

\section{Test Results}

Through repetitive testing as described above, the average static load (from ten tests) that the APL can withstand before spring displacement was found to be $245 \mathrm{~N}$. This exceeds the predicted static pitch link loads from CFD (100 N) and confirms the APL's fail-safe mode operation for static loads. Based on the 
accuracy of the load cell and the human interaction required, it is estimated that the error of this load is approximately $\pm 5 \mathrm{~N}( \pm 1 \mathrm{lb}$.).

\subsubsection{Maximum Dynamic Load Capacity}

The fail-safe mode of the APL is required for dynamic loading, in addition to static loading. This was experimentally tested using the non-rotating dynamic test set-up (Figure 7) described in Section 3.1. The goal of this test was to determine the maximum amplitude of dynamic loading that can be applied to the APL before any spring displacement is detected by the external Hall sensor.

\section{Test Procedure}

Before installing of the APL into the test set-up, the strain gauges were calibrated using hanging masses. This method gives a direct calibration factor between the strain gauge reading and the load applied in the vertical direction.

For this calibration, masses were hung vertically from the bracket, imitating an axial load applied through the APL. Masses were added incrementally, then removed incrementally and the strain gauge value was recorded at each step using XPC TargetBox/Simulink. The same procedure was repeated five times and a linear calibration factor was determined for each set of data. The average calibration factor was determined to be $44 \mathrm{~N} / \mathrm{V}$ and was used to determine the load being transmitted through the APL into the bracket.

After the strain gauge calibration, the APL was mounted into the shaker test set-up. A periodic axial loading was applied to the APL while no voltage was supplied to the piezoelectric actuator. All tests were performed with a sinusoidal 
input load at a frequency of $25 \mathrm{~Hz}$ (which corresponds closely to $1 / \mathrm{rev}$ vibration at the nominal $1,550 \mathrm{rpm}$ of the SHARCS scaled rotor).

The amplitude of the applied load was increased until displacement of the spring was detected by the external Hall sensor. At the point of spring displacement, the amplitude of the applied load was automatically recorded (using xPC TargetBox/Simulink) as the maximum dynamic load the APL can hold in its fail-safe mode. The same testing procedure was completed ten times and the average maximum dynamic load was determined.

\section{Test Results}

Through repetitive testing as described above, the average dynamic load that the APL can withstand before spring displacement was found to be $39 \mathrm{~N}$ at a frequency of $25 \mathrm{~Hz}$. This value is less than the predicted dynamic pitch link loads from CFD $(70 \mathrm{~N})$, but confirms the APL can function in its fail-safe mode when a load of $39 \mathrm{~N}$ or less is applied. Based on the automatic data collection method, and the strain gauge calibration it is estimated that the error of this value is about $\pm 1 \mathrm{~N}$.

Note the accuracy of the maximum dynamic load is estimated to be more accurate than the maximum static load due to the measurement methods. The static press was calibrated to measure a much larger range of loads, whereas the strain gauges for the dynamic load test are more sensitive and calibrated over a much smaller load range. 


\subsection{Stiffness Curve of APL}

The main purpose of using an APL is to change the torsional stiffness of a blade by modifying the pitch link stiffness. To show that the APL can predictably change the system stiffness, measurement of the stiffness curve was required.

This experimental stiffness curve was created using a sinusoidal input load since it mimics the periodic loading expected during rotational testing of the APL. Applying a static load for these tests would not be an accurate representation of how the APL will function during rotational testing.

Note that the control law algorithm presented in this thesis depends only on the two extremes of the stiffness curve. The full range of controllability of the APL's stiffness is essential for further development of the control law.

\subsubsection{Theoretical Stiffness Curve}

Based on the $2^{\text {nd }}$ generation APL design and construction, a theoretical stiffness curve was developed as shown in Figure 11. This figure outlines the change in APL stiffness as a result of the change in input voltage to the piezoelectric actuator. 


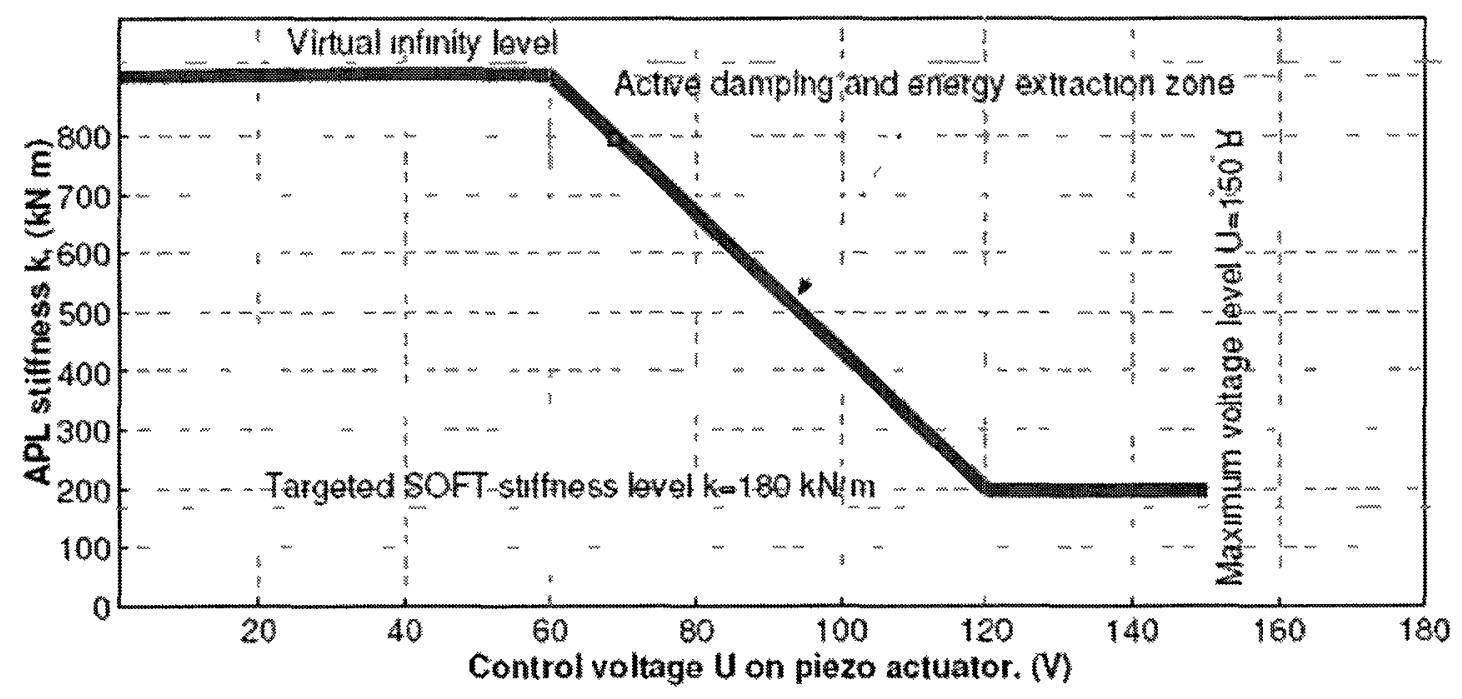

Figure 11: Theoretical change in APL stiffness [36].

The theoretical stiffness curve shows that there are three modes of operation for the APL and they are controlled by the input voltage to the piezoelectric actuator. The first is the "solid link" mode which is theoretically achieved with an input voltage in the range of $0-60 \mathrm{~V}$. In this mode the stiffness of the APL is virtually infinity and it acts as a traditional solid pitch link.

The second mode of operation is the "transition" range, where the APL stiffness varies linearly from its maximum to its minimum value. This mode is controlled by an input voltage in the range of $60-120 \mathrm{~V}$. Although this transition mode is not used for current research, it is essential for future development of the closed-loop control law.

The last mode of operation is the "soft link" mode, controlled by an input voltage of $120-150 \mathrm{~V}$. In this mode, the load path is carried though the APL's spring resulting in the desired "soft spring" stiffness of $180 \mathrm{kN} / \mathrm{m}$. 
Based on experimental testing of the $2^{\text {nd }}$ generation APL [37], the desired "soft spring" stiffness does not directly dictate the stiffness of the spring installed in the APL. An accurate estimate of the required spring stiffness was determined to be very difficult, and this is the reason for experimentally testing several spring stiffnesses as outlined in Section 2.5. The desired "soft spring" stiffness of the $3^{\text {rd }}$ generation APL is $180 \mathrm{kN} / \mathrm{m}$ as indicated on the theoretical stiffness curve, Figure 11.

\subsubsection{Experimental Stiffness Curve}

\section{Test Set-up}

In order to experimentally determine the stiffness curve of the APL, a dynamic load was applied with a magnitude of $37 \mathrm{~N}$ and a frequency of $15.7 \mathrm{~Hz}$ using the shaker test set-up described in Section 3.1. This input load remained constant for the entire test and was measured using the strain gauges mounted on the end bracket of the APL. The strain gauges were previously calibrated as outlined in Section 3.2.2.

The two measurements required to experimentally determine the APL stiffness are the magnitude of the input load, $F$, (which remained constant during these tests) and the magnitude of the APL spring displacement, $x$. With these two measured values the experimental stiffness, $k$, of the APL is determined using Equation 1. (Neglecting the stiffness of the solid metal parts/links in the $A P L)$.

$$
k=F / x
$$


Calibration of the external Hall sensor was required to accurately measure the spring displacement. This calibration was completed using the static press test set-up described in Section 3.2.1. Note that this contains a micrometer that enables to measure vertical displacement. With the APL inserted in the static press, incremental displacements were applied to the unit, compressing the spring. At each incremental displacement, both the Hall sensor voltage as well as the micrometer measurement were recoded. This same procedure was completed three times and the average calibration factor was used. For this particular test the calibration factor was determined to be $2.8 \mathrm{~mm} / \mathrm{V}$. The Hall sensor data was collected using XPC TargetBox/Simulink.

Note that the Hall sensor calibration was repeated every time the APL was disassembled/reassembled or the Hall sensor/magnet was moved.

\section{$\underline{\text { Test Matrix }}$}

The APL stiffness curve is a plot of the calculated resultant stiffness as a function of the piezoelectric input voltage. To create this plot, a constant dynamic load $(F)$ of $37 \mathrm{~N}, 15.7 \mathrm{~Hz}$ was applied axially to the APL. This was done repeatedly for several different piezoelectric input voltages. Table 2 outlines that data was collected for ten input voltages ranging between 15-150 V. Note that no spring displacement data could be collected when the piezoelectric actuator voltage was zero, since the APL functioned here as a solid pitch link with an effective stiffness of infinity. 
Table 2: Stiffness curve test matrix.

\begin{tabular}{|c|c|}
\hline Data Point & $\begin{array}{c}\text { Piezoelectric } \\
\text { Actuator Voltage [V] }\end{array}$ \\
\hline 1 & 15 \\
\hline 2 & 30 \\
\hline 3 & 45 \\
\hline 4 & 60 \\
\hline 5 & 75 \\
\hline 6 & 100 \\
\hline 7 & 115 \\
\hline 8 & 130 \\
\hline 9 & 145 \\
\hline 10 & 150 \\
\hline
\end{tabular}

For each data point the time history of the spring displacement (measured by the Hall sensor) was recorded for at least one second using XPC TargetBox/Simulink. This data was used to determine the magnitude of spring displacement, $x$, for each corresponding input voltage. Each data point was tested independently five times to ensure consistency and repeatability.

\section{Effects of Friction Clamp Initial Conditions}

The APL was designed to use a friction clamp to vary the stiffness of the system. It is known that the force required to overcome a frictional force is much less for already moving parts than for stationary parts. For this reason, it was assumed that the initial conditions of the friction clamp are very important when determining the experimental stiffness curve of the APL. In order to show the effect of the initial conditions of the friction clamp (i.e. moving or stationary) the experimental stiffness curve was developed twice.

This means that the test matrix described above was measured twice using two different initial conditions: 1) The two parts of the friction clamp were 
stationary relative to each other (zero spring displacement) and 2) the two parts of the friction clamp were moving relative to each other (maximum spring displacement). The procedure for testing with these two initial conditions is similar and is summarized in Figure 12 and Figure 13. The only difference between the two stiffness curves are the input voltage to the piezoelectric actuator before data is recorded (i.e. $t=-0.5$ to 0 seconds). Note the spring displacements shown in Figure 12 and Figure 13 are only a representation of the expected displacements and are not based on actual experimental data. For this reason there are is no absolute scale provided for the spring displacement.

Figure 12 summarizes the testing procedure for the first initial condition, data point $2(30 \mathrm{~V})$. At time $t=-0.5$ seconds the input voltage to the piezoelectric actuator was set to zero, and the periodic input load on the APL was applied. For 0.5 seconds there was no spring displacement, since the APL was functioning in its "solid link" mode, and the two parts of the friction clamp were stationary relative to each other. At time $t=0$ seconds the input voltage to the piezoelectric actuator was changed to $30 \mathrm{~V}$. As can be seen, the spring displacement at this point is no longer zero since the normal force applied to the frictional surfaces is no longer sufficient. At time $t=0$, the time history of the spring displacement (Hall sensor) was recoded for 1 second. This is the data used to determine the experimental APL stiffness for a piezoelectric input voltage of $30 \mathrm{~V}$ for the $1^{\text {st }}$ initial condition. 

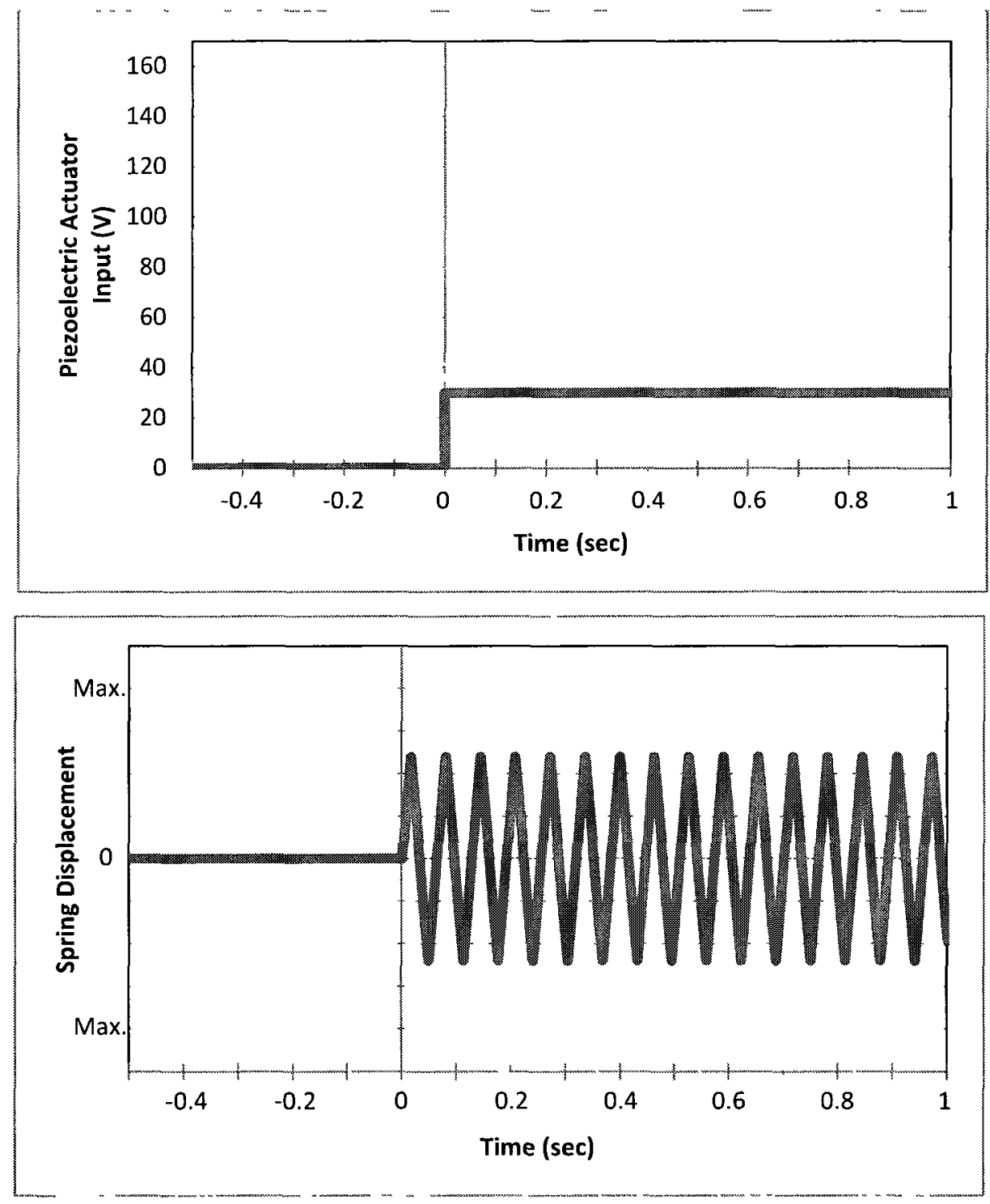

Figure 12: Stiffness curve test procedure for $1^{\text {st }}$ initial condition - stationary (data point 2).

The test procedure for the second initial condition is similar and summarized in Figure 13. At time $t=-0.5$ seconds the input voltage to the piezoelectric actuator was set to $150 \mathrm{~V}$, and the periodic input load on the APL was applied. For 0.5 seconds the spring was allowed to displace freely and the two part of the friction clamp move relative to each other. At time $t=0$ seconds the 
input voltage to the piezoelectric actuator was changed to $30 \mathrm{~V}$. As shown in Figure 13 , at $t=0$ the spring displacement is now limited due to the lower input voltage. At time $\mathrm{t}=0$, time history data of the spring displacement (Hall sensor) was recoded for 1 second. This is the data used to determine the experimental APL stiffness for a piezoelectric input voltage of $30 \mathrm{~V}$ for the $2^{\text {nd }}$ initial condition.
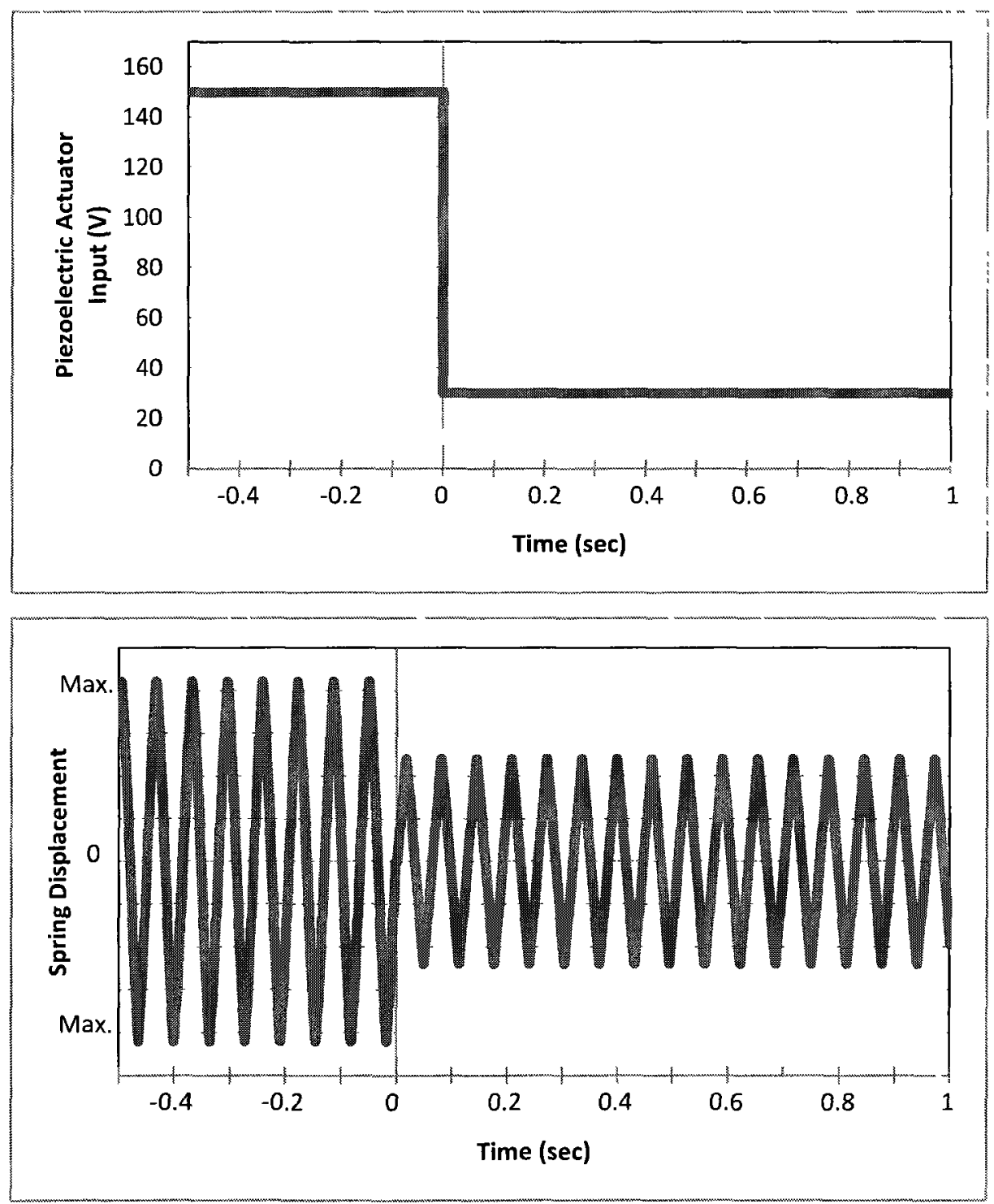

Figure 13: Stiffness curve test procedure for $2^{\text {nd }}$ initial condition - movement (data point 2). 


\section{Stiffness Curve Data Analysis and Results}

The data from each test point, for each initial condition were analyzed in the same manner. The analysis procedure will be described for one particular data point from the first initial condition test.

Figure 14 shows the experimental time history data of the APL spring for a piezoelectric input voltage of $150 \mathrm{~V}$. To determine the APL stiffness, the average maximum displacement of the spring was required. This was found by calculating the average amplitude of the displacement peaks (in compression) using a Matlab script file titled "averagepeaks.m" shown in Appendix A.

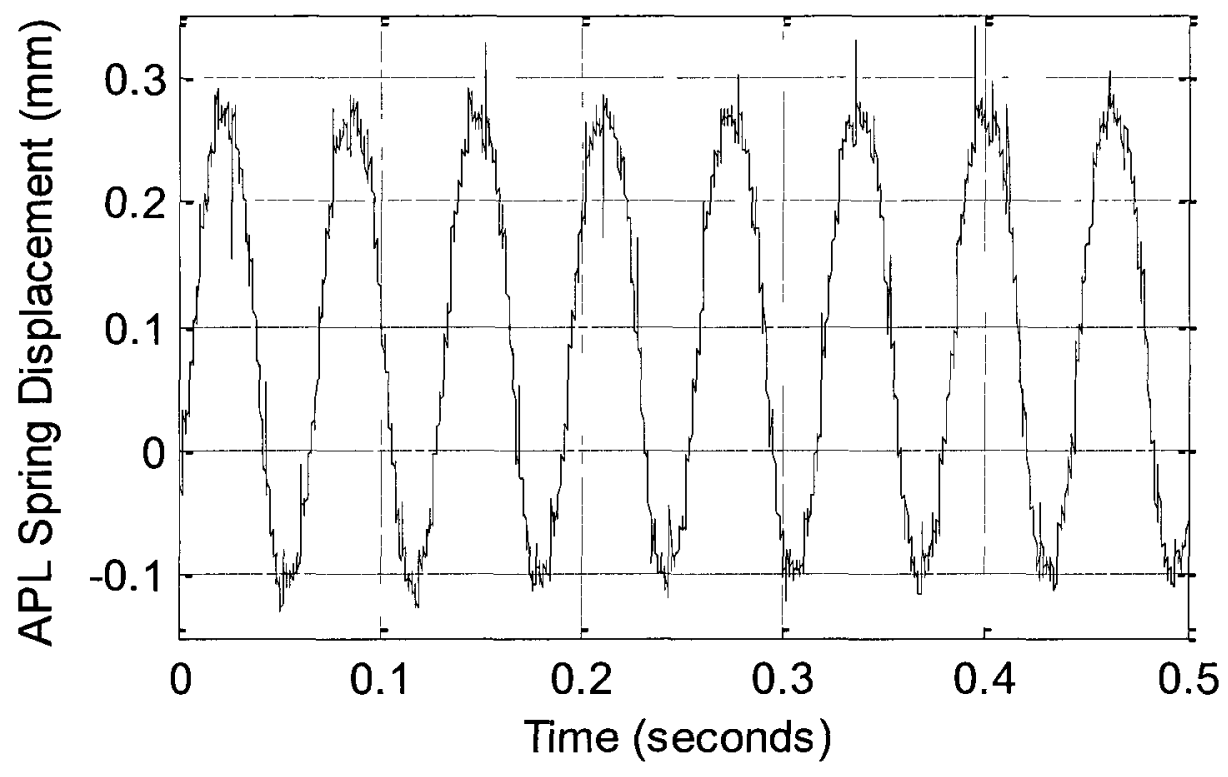

Figure 14: Spring displacement time history $1^{\text {st }}$ initial condition, $150 \mathrm{~V}$ input voltage.

Given the average spring displacement, $x$, and the magnitude of the axial load, $F$, on the APL, the stiffness of the system was calculated using Equation 1. The APL stiffness corresponding to each input voltage was calculated using the 
Matlab script file "StiffnessCurve.m", Appendix B. This file plots the stiffness curve of the APL corresponding to the data for each initial condition test.

The stiffness curves for both initial conditions are shown in Figure 15. Data was collected and plotted for five separate tests to confirm the trend. The absolute values for each point were within a range of approximately $400 \mathrm{kN} / \mathrm{m}$ of each other, confirming consistency.

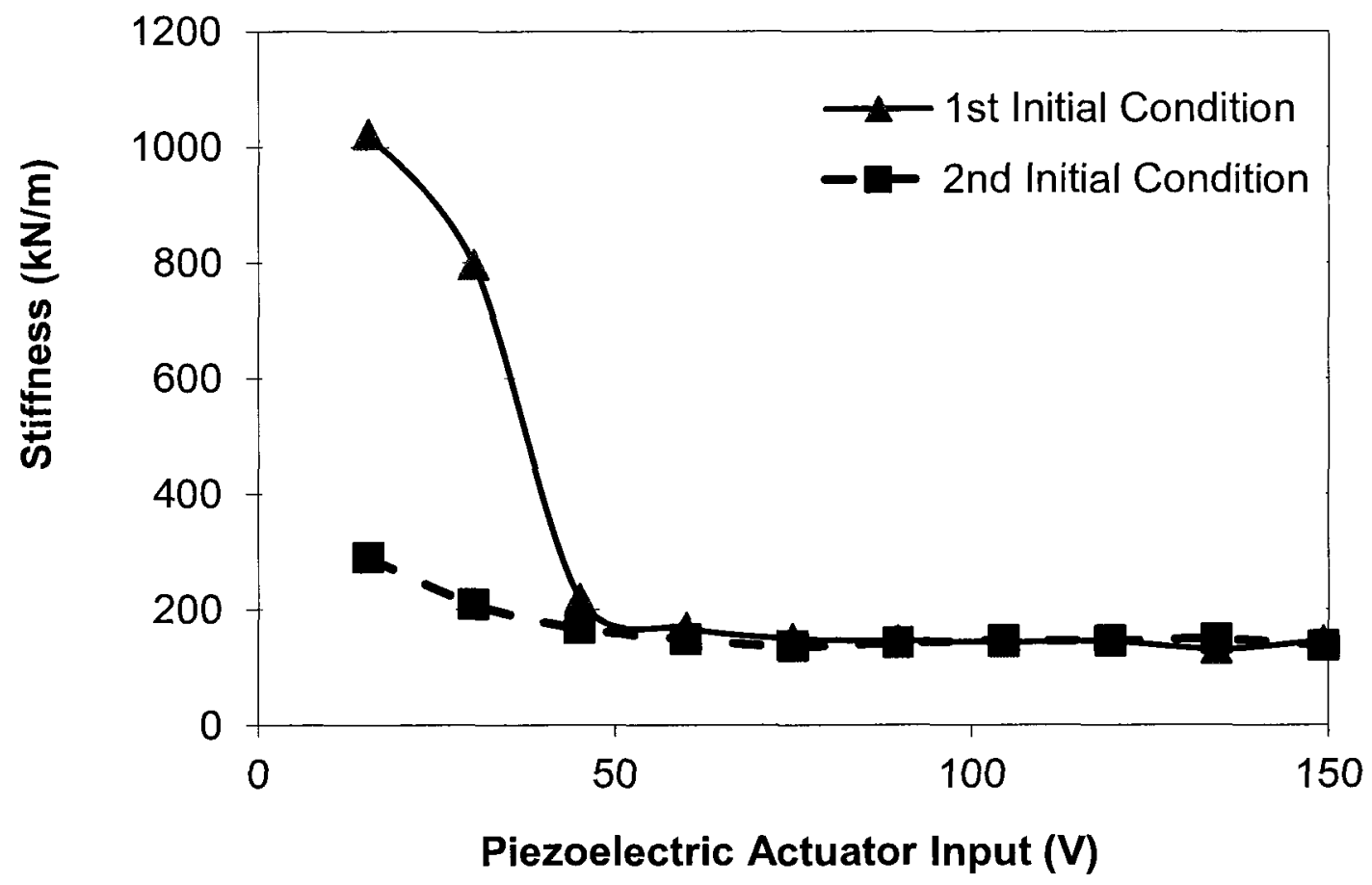

Figure 15: APL resultant stiffness curve.

This stiffness curve confirms that the resultant stiffness of the APL can be controlled by the piezoelectric actuator voltage. For the $1^{\text {st }}$ initial condition, the stiffness of the APL can be set to any value between $140 \mathrm{kN} / \mathrm{m}$ to $1,100 \mathrm{kN} / \mathrm{m}$. It should be noted that this curve is very similar to the theoretical curve presented 
in Section 3.3.1, except the "soft spring" stiffness is $140 \mathrm{kN} / \mathrm{m}$ rather than the desired $180 \mathrm{kN} / \mathrm{m}$.

The stiffness curve for the $2^{\text {nd }}$ initial condition demonstrates that the resultant stiffness is indeed affected by the initial conditions of the friction clamp. For the $2^{\text {nd }}$ initial condition the theoretical linear portion is not as pronounced, and there is less range to control the stiffness of the APL. For this initial condition the APL stiffness can only be set to a value between $140 \mathrm{kN} / \mathrm{m}$ to $300 \mathrm{kN} / \mathrm{m}$ when limited to an input voltage of $15-150 \mathrm{~V}$.

This data does confirm that the APL stiffness can be changed and controlled by the input voltage to the piezoelectric actuator. It provides a better understanding of how the change in APL stiffness can be used to further develop the control law beyond the research presented. These results show that the "soft spring" stiffness is the same, $140 \mathrm{kN} / \mathrm{m}$, no matter which initial condition the friction clamp experiences.

As will be shown later, the closed-loop control law presented in this research is based on a state-switch controller that uses only the two extremes of the stiffness curve (i.e. those of the "solid link" mode and of the "soft spring" mode). Therefore, although the initial conditions of the friction clamp determine the shape and range of the stiffness curve, the initial conditions should not change the performance of the control law presented in this thesis.

Also note that these results are unique to the preload settings of the APL at the time of assembly. Changing the preload settings will change the resultant stiffness curve too. 


\subsection{Closed-loop Control Testing of APL}

Previous computational research has shown that the APL can reduce vibrations transmitted though the pitch link by up to $60 \%$ [38] when a state-switch control algorithm is implemented. The present research is the first time that this closed-loop control law has been implemented experimentally using the APL prototype. This algorithm is used to control the activation of the APL to reduce vibrations.

\subsubsection{Control Law Theory}

The closed-loop control law theory was developed by Nitzsche and Harold for a base excited Smart Spring system [39] as the one shown in Figure 16. This system represents how the APL operates. The spring labeled $k_{3}$ represents the rotor blade stiffness, $k_{1}$ is the "solid link" mode (stiffness of virtually infinity) and $k_{2}$ is the "soft spring" mode. The goal of the APL is to reduce the motion/vibration transmitted from mass $m_{b}$ into mass $m_{c}$. The force $F(t)$ represents the vibration created due to aerodynamic loading of the blade during forward flight. The vibration experienced by mass $m_{c}$ represents the vibrations transmitted to the swash plate on the helicopter. Reduction of the motion/vibration of mass $m_{c}$ is achieved with the use of the APL closed-loop control law. 


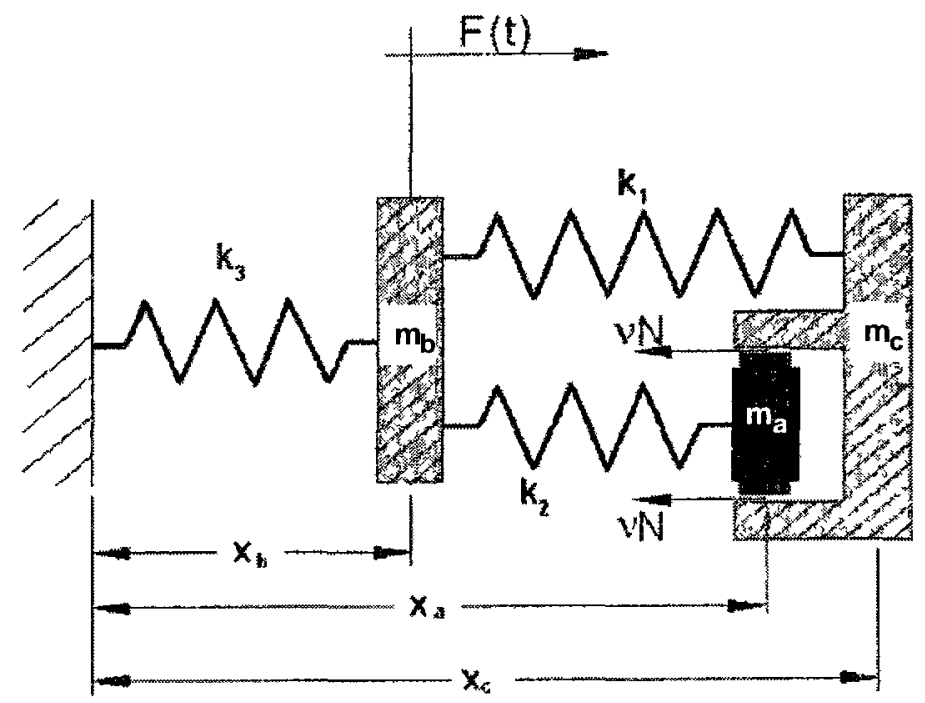

Figure 16: Base-excited Smart Spring system [39].

This control law reduces the magnitude of the output vibration transmitted to $m_{c}$ by extracting kinetic energy from the system through the Smart Spring design. The developed control law is a basic state-switch algorithm, which requires real-time inputs to determine if the piezoelectric actuator should be "ON" $(150 \mathrm{~V})$ or "OFF" $(0 \mathrm{~V})$. During the development of the control law, it was determined that two real-time measurements are required to determine the state of the actuator. The first is the displacement of mass $m_{c}$ relative to mass $m_{b}$. The second measurement is the absolute displacement of mass $m_{c}$.

The state of the actuator is not based on the absolute measured values, but rather on a comparison between the absolute and relative displacements. The following rules outline when the actuator should be "ON" or "OFF" based on realtime measurements (detailed development of this control law theory can be found in reference [40]): 
- If the relative displacement and the absolute displacement are in the same direction the actuator should be turned "OFF".

- If the relative displacement and the absolute displacement are in opposite directions the actuator should be turned "ON".

In general terms, the control states that when masses $m_{c}$ and $m_{b}$ are moving in the same direction the actuator should be "OFF". If they are moving in opposite directions the actuator should be "ON", forcing the movement of mass $m_{c}$ to be reduced due to the movement of mass $m_{b}$, thus reducing the magnitude of vibration.

The APL and this control law are designed to reduce vibrations from only one specific input frequency. This design is to ensure that only the unwanted vibration transmitted through the pitch link is reduced while the $1 /$ rev control of the rotor blade is still maintained. This is a fundamental design requirement since the installation of the APL cannot disturb the controls for flight.

The frequency of vibration that the APL reduces depends on the mechanical/physical properties of the APL. This includes the APL's "soft spring" stiffness and the apparent mass of the APL in the "soft spring" mode. These values can be changed based on the preload settings of the APL during assembly. All experiments presented were done using consistent parameters. Results may vary if the APL has different preload settings.

\subsubsection{Simulation Results}

The state-switch controller was numerically simulated using Matlab/Simulink to confirm its performance as a closed-loop controller. 
Successful vibration reduction was shown through both time history data and FFT analysis [40].

A separate computational study was also performed using the SMARTROTOR 3D aeroelastic rotor code [34]. This simulation implemented the Smart Spring system as a sub-loop of the main aeroelastic calculations. This study implemented the same state-switch control law theory to extract kinetic energy from the system, thus reducing the output vibrations of the APL. This simulation proved successful and reduced vibrations close to $60 \%$ [34]. These results show that the APL control law can optimally reduce the vibration at one specific frequency while not affecting other frequencies. This is important since it shows that the APL will not interfere with the control of the helicopter.

Note that no previous experimental testing of this control law has been completed with an APL prototype.

\subsubsection{Experimental Implementation of Control Law}

After careful analysis of the control law theory as well as the APL system it was determined that for this experiment only one real-time measurement is required to successfully implement the control algorithm. The one measurement required is the absolute direction of the output displacement of the APL (mass $m_{c}$ in Figure 16). Due to the nature of the system, the relative and absolute directions of displacement are coupled, and therefore the control algorithm only requires one measurement.

The closed-loop control algorithm was implemented using an Arduino Duemilanove microcontroller (Figure 17). This microcontroller has 14 digital 
input/output pins, 6 analog inputs, and can be powered by a USB connection or $5 \mathrm{~V}$ power supply. It has $16 \mathrm{~KB}$ of memory for storing data. This microcontroller is re-programmable through use of the Arduino software, which is a $\mathrm{C}++$ based programming interface.

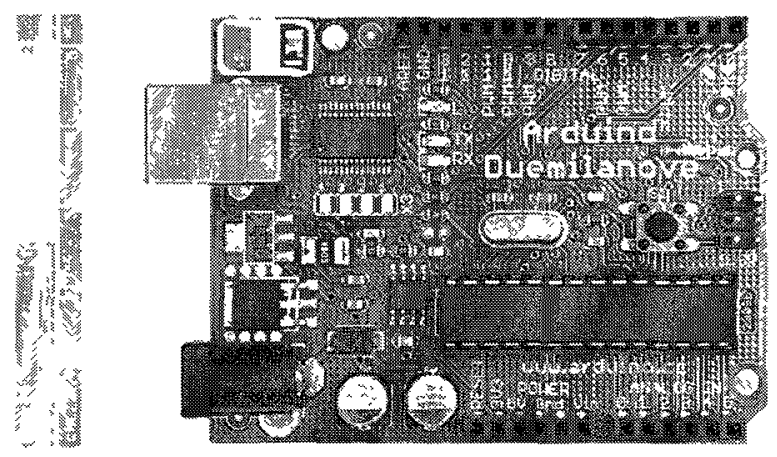

Figure 17: Arduino Duemilanove microcontroller.

The closed-loop control algorithm used for experimental testing is given in Appendix C. This code contains two control methods for development purposes, but all results presented were completed using the second control logic method. For more details comments are provided in the code (Appendix C).

For operation of the closed-loop control, the only real-time input required is the strain gauge data from the APL end bracket (Figure 8). The control law signal conditions an amplified version of the strain gauge signal. Signal conditioning is done by use of a low pass filter. This code tracks the phase of the strain gauge signal, i.e. whether the displacement at the end of the APL is in the positive or negative direction. Based on the real-time phase tracking, the code predicts the next point at which the piezoelectric actuator should be switched "OFF". This code also includes time shifting of the switching activation time 
based on the signal conditioned time-error created. The only output of the microcontroller is a $0 \mathrm{~V}$ or $3 \mathrm{~V}$ signal sent to the piezoelectric actuator amplifier. This signal is then amplified to a $0 \mathrm{~V}$ or $150 \mathrm{~V}$ input to the actuator.

In this control algorithm the default mode of the APL is "ON", allowing the friction clamp to move freely. The control law will dictate when the APL should clamp or turn "OFF". Note that if there is a power failure or damage to the actuator the APL will turn "OFF" reverting to a solid pitch link (i.e. to the fail-safe mode).

Due to the use of only one real-time measurement, the control algorithm requires two parameter settings that are determined experimentally. The first parameter is the length of time the APL remains "OFF" once it is activated. This parameter is implemented as the percentage of time the APL remains "OFF" for a half cycle of the periodic loading. Therefore, this value can range from $0 \%$ (APL always supplied 150V) to $100 \%$ (APL always supplied OV). The second parameter sets the phase shift between the real-time filtered data and when the APL will activate (turn "OFF"). This parameter is defined as a percentage of time for a half cycle of the input load. If the parameter is set to $0 \%$ there will be no time shift and a setting of $100 \%$ will time shift the activation by a half cycle. More details are provided as comments in the code (Appendix C).

\subsubsection{Test Set-up}

Experimental testing of the APL closed-loop control law was done using the same non-rotating test set-up described in Section 3.1 with the shaker and moment arm used to apply axial loading to the APL. 
Figure 18 is a schematic representation of how the real-time data is collected and used. The strain gauge data measured at the end of the APL is amplified using a P3 strain indicator (Vishay Micro-Measurements). This signal is split and sent to the Arduino microcontroller and the xPC TargetBox/Simulink. As described in Section 3.4.3, the microcontroller uses this real-time data to determine if the piezoelectric actuator should be "ON" (150 V) or "OFF" $(0 \mathrm{~V})$. This signal is sent to a Piezomechanics amplifier, then to the actuator.

The XPC TargetBox/Simulink system is used to monitor and record the realtime data of the strain gauges, the Hall sensor and the input voltage being supplied to the piezoelectric actuator. The only output signal being sent from the xPC TargetBox/Simulink is the shaker input (the periodic input force).

The Arduino microcontroller is programmed to activate the control algorithm only when an external button is held. This prevents the control law from continuously determining the input voltage for the piezoelectric actuator. This is important since each test requires one second of data with the control law off (the APL functions as a solid pitch link) followed by another second with the control law on. This allows for a direct comparison of the vibration reduction due to the implementation of the APL control law. 


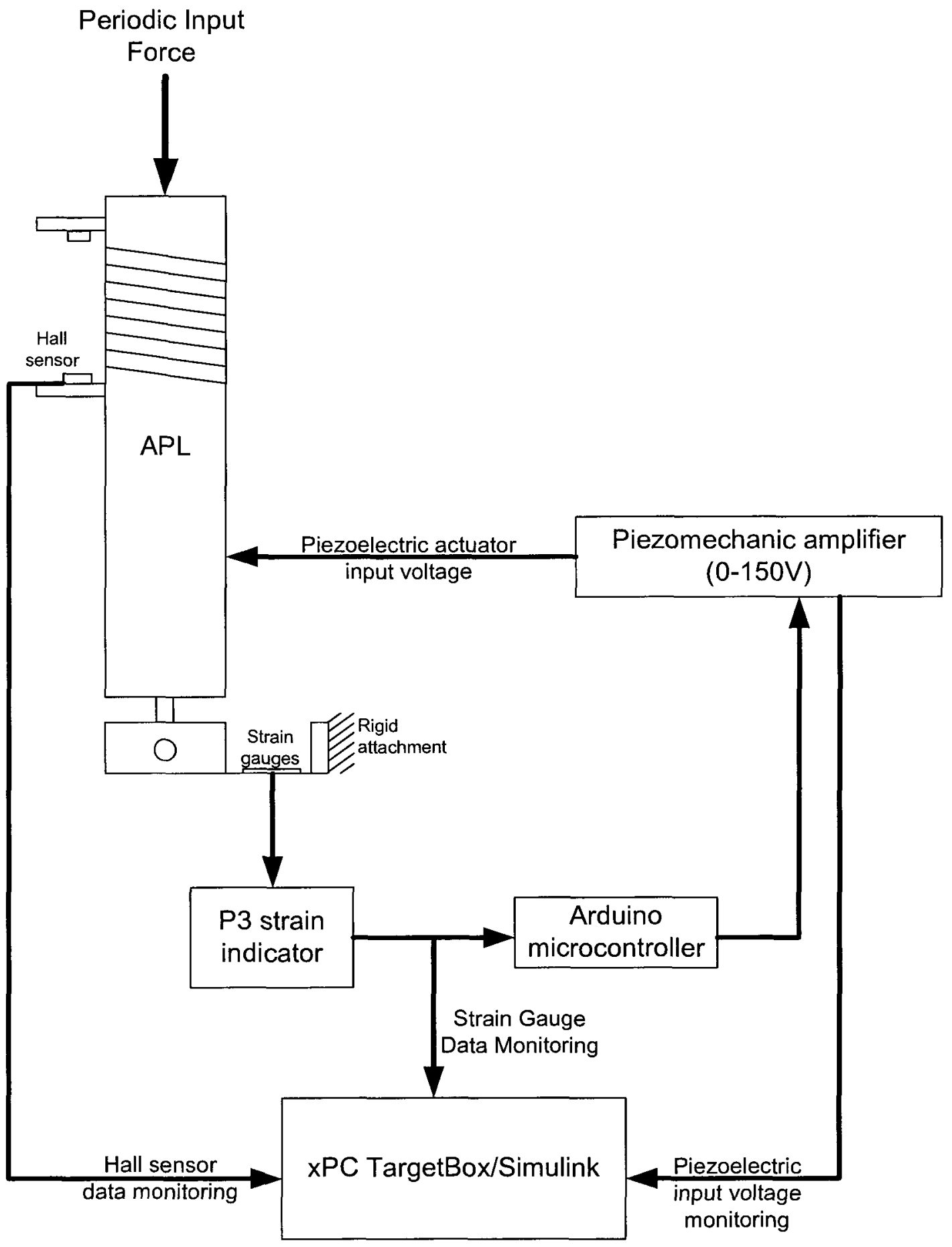

Figure 18: Schematic of test set-up for closed-loop control experiment. 


\subsubsection{Test Matrix}

Two sets of test were required to demonstrate the optimal abilities of the closed-loop control law when implemented with the APL prototype. The first set of tests were required to determine the optimal combination of the two programmable parameters of the control algorithm described in Section 3.4.3. To do this, a constant axial input load was applied to the APL $(37 \mathrm{~N}$ at $25 \mathrm{~Hz}$ frequency) and a total of 20 different parameter combinations were tested, as outlined in Table 3. Each data point was measured during five separate tests. The vibration reduction was determined for each of these five tests and the average was taken.

Table 3: Control law parameters determination - test matrix of 20 data points.

\begin{tabular}{|c|c|c|c|c|c|}
\hline Data Point & \multicolumn{5}{|c|}{ Parameter 1: off time (\%) } \\
\hline $\begin{array}{c}\text { Parameter 2: } \\
\text { Phase Shift (\%) }\end{array}$ & $\mathbf{2 0}$ & $\mathbf{3 5}$ & $\mathbf{5 0}$ & $\mathbf{6 5}$ & $\mathbf{8 0}$ \\
\hline $\mathbf{0}$ & 1 & 2 & 3 & 4 & 5 \\
\hline $\mathbf{2 5}$ & 6 & 7 & 8 & 9 & 10 \\
\hline $\mathbf{5 0}$ & 11 & 12 & 13 & 14 & 15 \\
\hline $\mathbf{7 5}$ & 16 & 17 & 18 & 19 & 20 \\
\hline
\end{tabular}

Once the optimal combination of the control law parameters was determined, the second set of tests were conducted using only these parameter values. The second set of tests were done to show that the APL vibration reduction is limited to a specific input load frequency. This test is to ensure that the APL can controllably reduce only a targeted frequency while limiting changes at other input frequencies (i.e. ensure control of the rotorcraft is still maintainable while the APL is reducing vibrations transferred though the pitch link into the fuselage). 
This set of tests was done by maintaining a constant force but varying the frequency of the input load applied to the APL. The vibration reduction at each frequency was determined. Each test was done with the same input load (37 N). A total of five input frequencies were tested: $13.3 \mathrm{~Hz}, 16.7 \mathrm{~Hz}, 20.8 \mathrm{~Hz}, 23.3 \mathrm{~Hz}$ and $25.0 \mathrm{~Hz}$. For each frequency the same test was done five times and the average vibration reduction was calculated.

Data was collected the same way for both sets of tests: axial loading is applied to the APL while the control law is off and real-time data is collected by the XPC TargetBox/Simulink for 0.8 seconds. During this time, the piezoelectric actuator voltage is $0 \mathrm{~V}$. After 0.8 seconds, the control law is turned on and data recording is continued for another second. This provides 1.8 continuous seconds of real-time data allowing for a direct comparison of the output loads with the control law off and then on.

\subsubsection{Data Analysis and Results}

For each data point, the same data was collected for 1.8 seconds: strain gauge (APL output load), Hall sensor (spring displacement) and piezoelectric actuator input voltage. Figure 19 is an example of the time history data collected for one data point. This plot shows that for the first 0.8 seconds of the test the APL is not active (therefore the spring displacement is zero) and the output loads of the APL are visible. At 0.8 seconds into the test, when the APL control law is turned on, the input voltage of the piezoelectric actuator begins switching between $0 \mathrm{~V}$ and $150 \mathrm{~V}$ and spring displacement is visible. This time history also shows a reduced magnitude in the output loads from the APL. Although Figure 
19 is for one particular data point, every data point tested had the same trend, the only difference being the magnitude at which the APL output load was reduced.

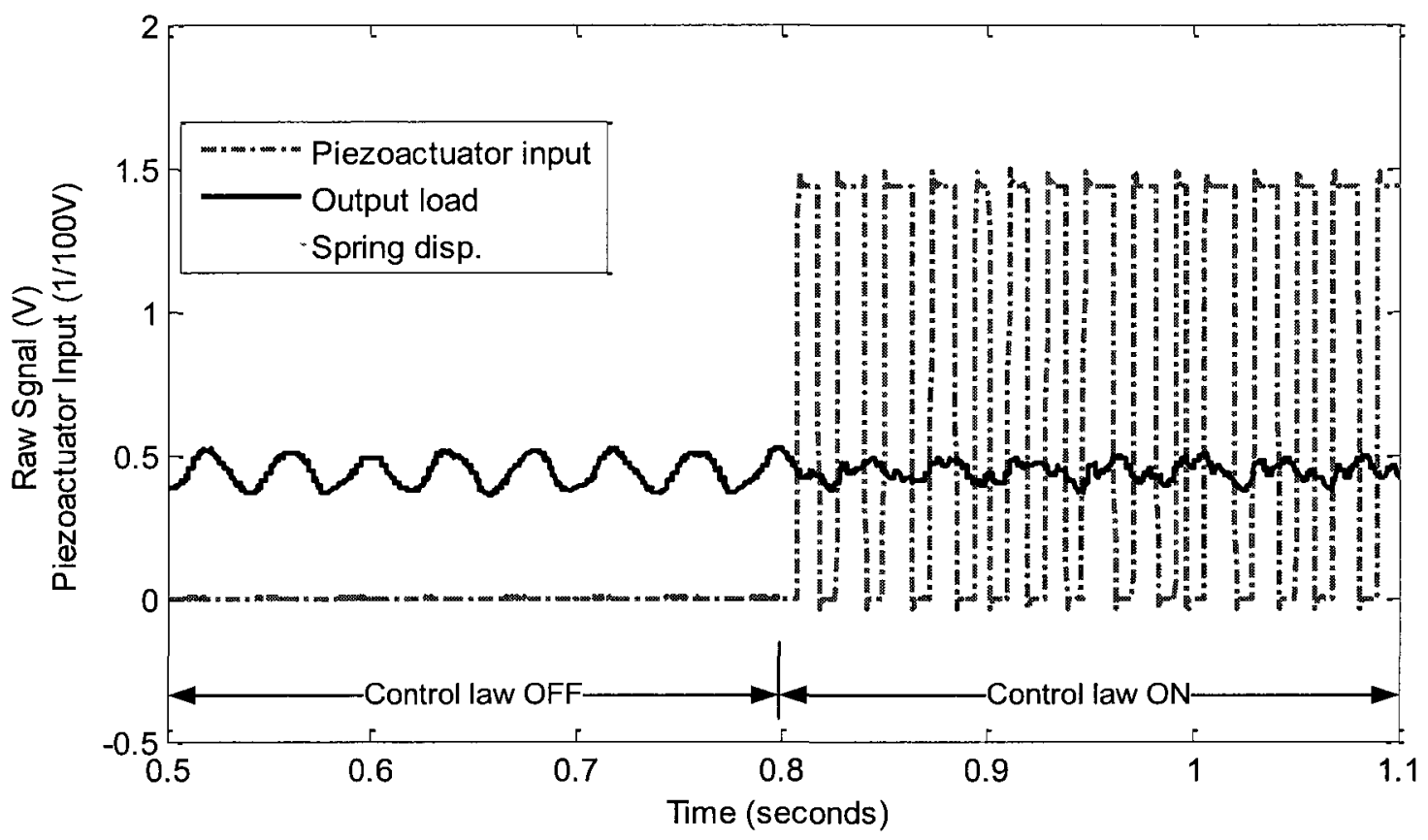

Figure 19: Time history data for closed-loop control experiment, input load: $37 \mathrm{~N}, 25 \mathrm{~Hz}$.

The reduction in vibration was determined by analyzing the strain gauge data collected from the end of the APL (the same data used for the closed-loop control algorithm). Figure 20 is a plot of the same strain gauges data presented in Figure 19 and better illustrates the reduction in the APL's output loads due to the implementation of the closed-loop control law. 


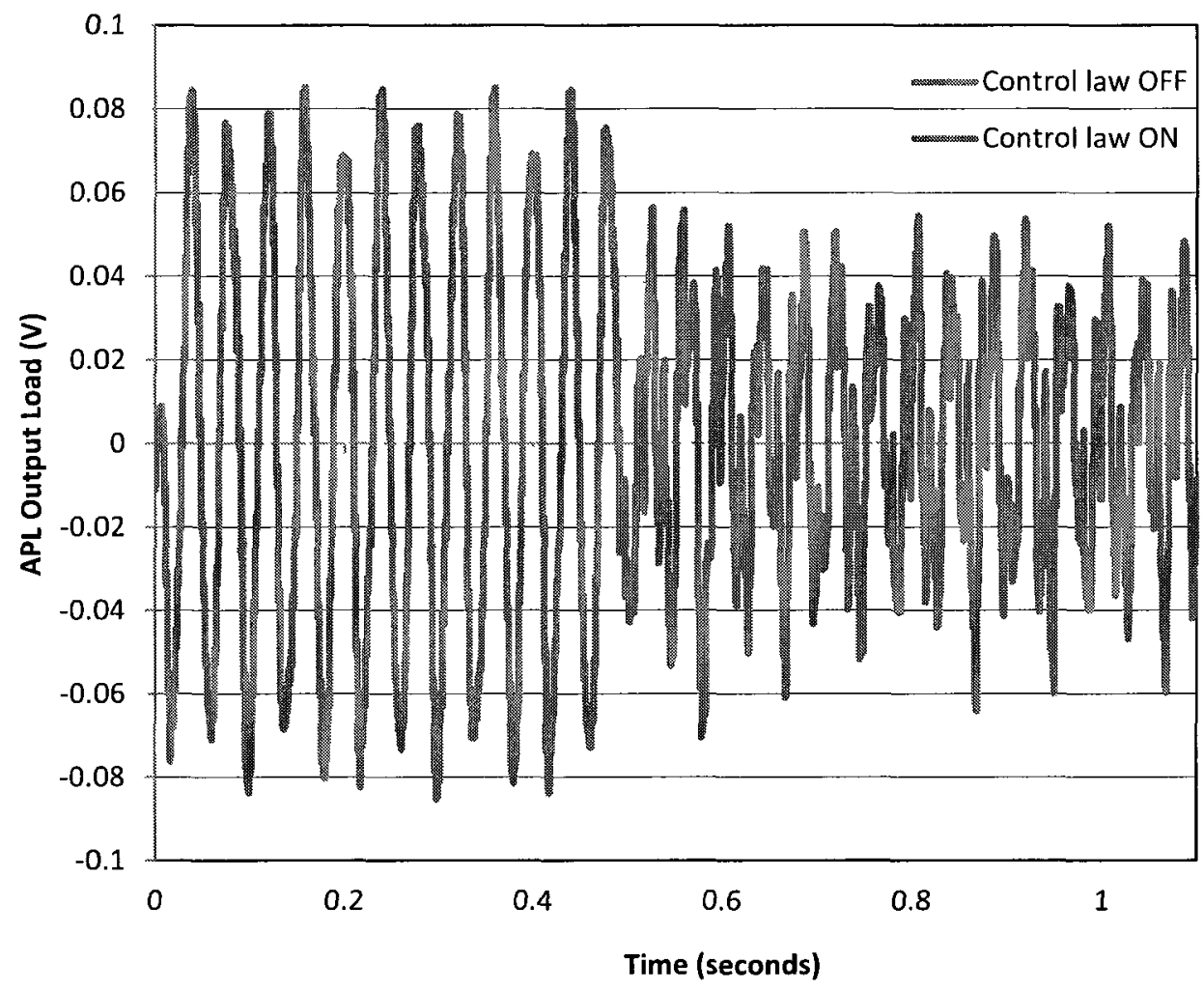

Figure 20: Time history of APL output load for closed-loop control experiment.

In order to determine the amount of vibration reduction achieved through the implementation of the control law, an FFT analysis was performed on the strain gauge data in Figure 20. This data represents the load being transferred from the pitch link into the swash plate on a helicopter. A separate FFT analysis was performed on the first 0.8 seconds of data and the last 1 second of data using the Matlab script file "DataProcess.m" (Appendix D). Figure 21 shows a comparison of the FFT analysis done for the time history data of Figure 20. This FFT analysis shows a large reduction in the magnitude of the peak at $25 \mathrm{~Hz}$ (the input load frequency). The percentage of vibration reduction was calculated based on the difference between these two peaks. 


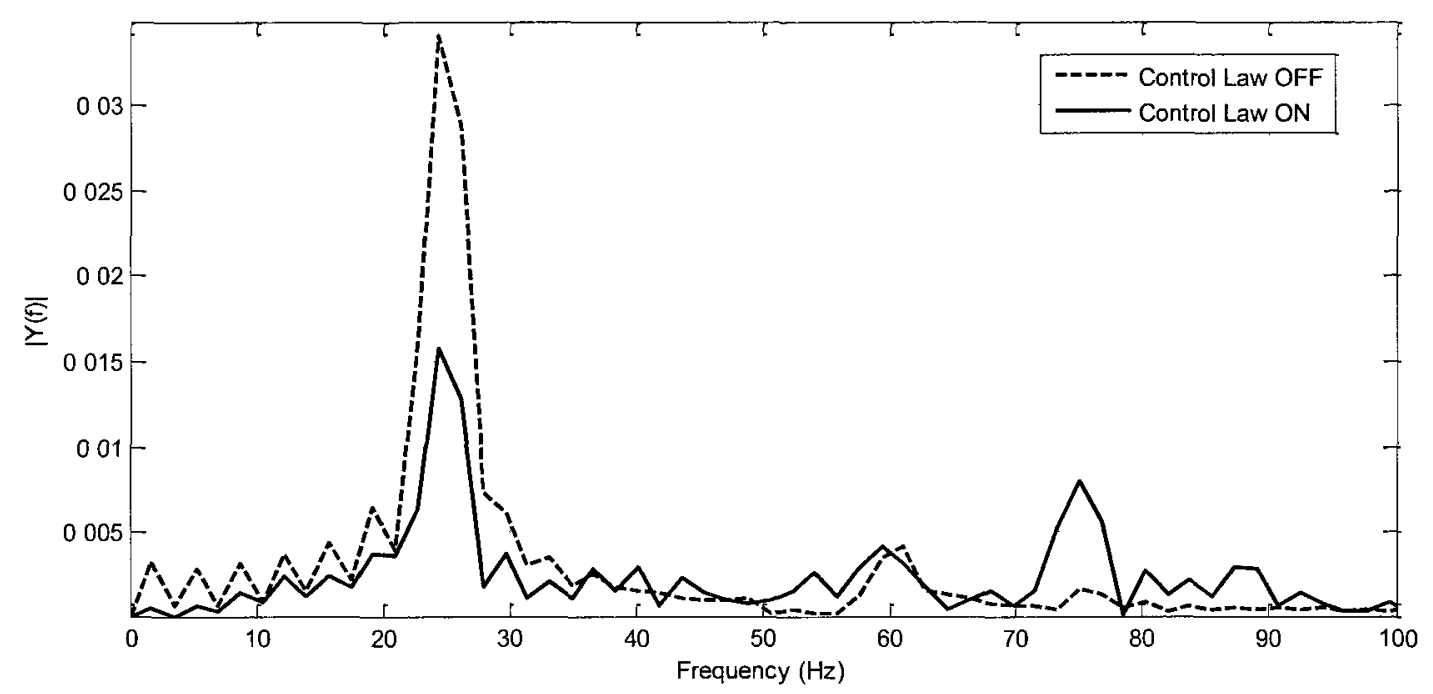

Figure 21: FFT analysis of APL output load, input load: $37 \mathrm{~N}, 25 \mathrm{~Hz}$.

It should be noted that due to the implementation of the closed-loop control law, an additional peak at $75 \mathrm{~Hz}$ was developed in the FFT. This additional peak shows that the magnitude of the vibration at $25 \mathrm{~Hz}$ was reduced by distributing the vibration to other frequencies. This confirms previous computational results [34].

As described in Section 3.4.5 the first set of tests completed for the closed-loop control law were done to determine the two parameter settings required in the control algorithm. Data was collected for each of the 20 parameter combinations outlined in Table 3, and analyzed as described above with an FFT procedure. For each data point, the same test was conducted five times, and the average percent of vibration reduction was determined. The scatter between the results of the five tests gave results within a range of $10 \%$ of the average. Table 4 summarizes the vibration reduction achieved by each parameter combination. 
Table 4: Vibration reduction achieved for each parameter combination for closed-loop control algorithm.

\begin{tabular}{|c|c|c|c|c|c|}
\hline $\begin{array}{c}\text { Vibration } \\
\text { Reduction (\%) }\end{array}$ & \multicolumn{5}{|c|}{ off_time (\%) } \\
\hline Phase Shift (\%) & $\mathbf{2 0}$ & $\mathbf{3 5}$ & $\mathbf{5 0}$ & $\mathbf{6 5}$ & $\mathbf{8 0}$ \\
\hline $\mathbf{0}$ & 37 & 50 & 58 & 53 & 40 \\
\hline $\mathbf{2 5}$ & 37 & 48 & 46 & 35 & 27 \\
\hline $\mathbf{5 0}$ & 22 & 22 & 21 & 20 & 23 \\
\hline $\mathbf{7 5}$ & 23 & 38 & 35 & 39 & 33 \\
\hline
\end{tabular}

This data shows that the best parameter combination is to have zero phase shift and to turn the actuator "OFF" (supply $0 \mathrm{~V}$ ) for $50 \%$ of each half cycle, once it has been initiated in the control law. These parameters were used for all further testing completed with the control law. (Note the data presented in Figure 19, Figure 20 and Figure 21 was collected using this optimal parameter combination).

The second set of tests was required to determine the effectiveness of the control law implementation for a range of input load frequencies. The magnitude of the input load remained constant $(37 \mathrm{~N})$ and five frequencies were tested: $13.3 \mathrm{~Hz}, 16.7 \mathrm{~Hz}, 20.8 \mathrm{~Hz}, 23.3 \mathrm{~Hz}$ and $25.0 \mathrm{~Hz}$. For each frequency time history data was collected for five separate tests and an FFT analysis was completed for each. The average reduction in vibration at each frequency was determined, and is plotted in Figure 22. The scatter between the results at each frequency gave results within a range of $10 \%$ of the average.

This data shows that the effectiveness of the control law changes based on the input load frequency. It highlights that the APL is designed to optimally reduce vibrations only at a specific frequency. This is important since the APL 
must not interfere with the controls of the helicopter. This frequency, at which the APL reduces vibration best, depends on the physical properties of the system, including the stiffness of the spring mounted in the APL. If this spring stiffness is changed, the vibration reduction at each frequency will be different.

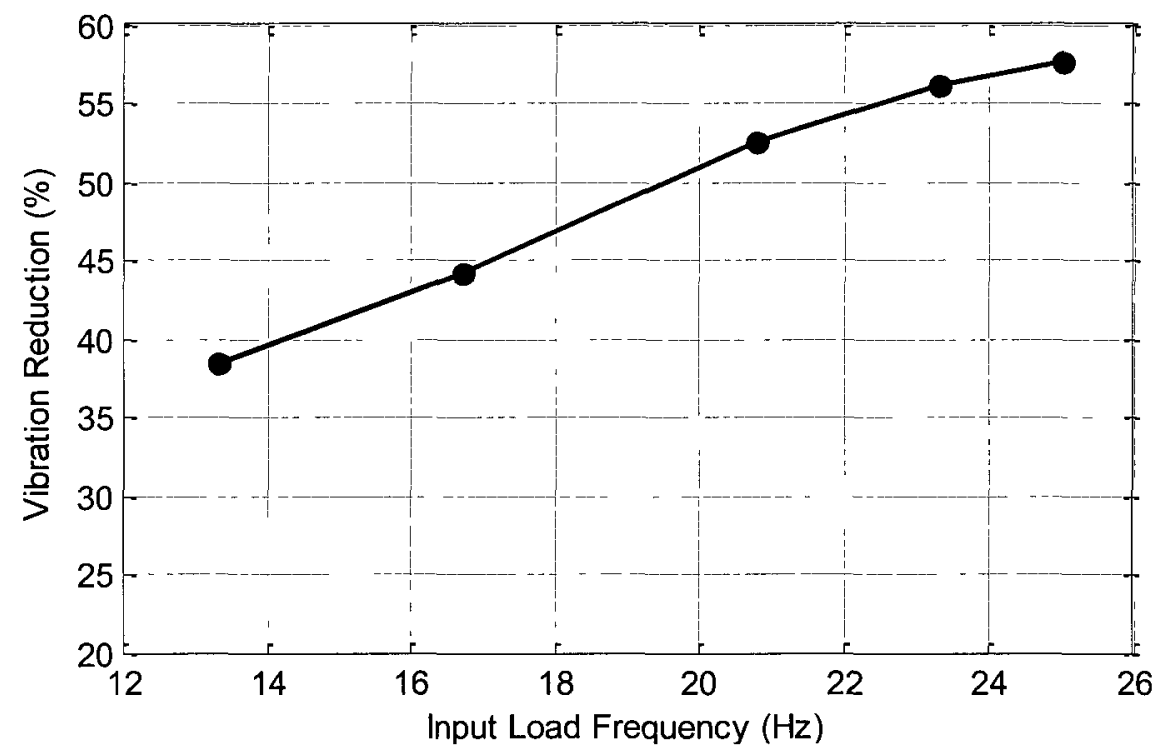

Figure 22: Vibration reduction due to APL closed-loop control law.

It was important to confirm that the vibration reduction was in fact a direct result of the implementation of the control law. If the APL was allowed to act solely in its "soft spring" mode (continuously $150 \mathrm{~V}$, rather than switching) the spring would absorb kinetic energy reducing the output vibrations. To confirm that the $60 \%$ reduction in vibration (at $25 \mathrm{~Hz}$ ) is due to the control law, a third set of tests was conducted. The same procedure was followed to collect 1.8 seconds of continuous data, except at 0.8 seconds, rather than turning the control law on, a constant $150 \mathrm{~V}$ was supplied to the piezoelectric actuator (allowing the APL to 
function in its "soft spring" mode). As with the previous test, this test was completed using a constant magnitude of input load $(37 \mathrm{~N})$ and a change in frequency. Each frequency was tested five times, and the average vibration reduction was determined through FFT analysis. Figure 23 summarizes the reduction of vibration due to the "soft spring" mode of the APL.

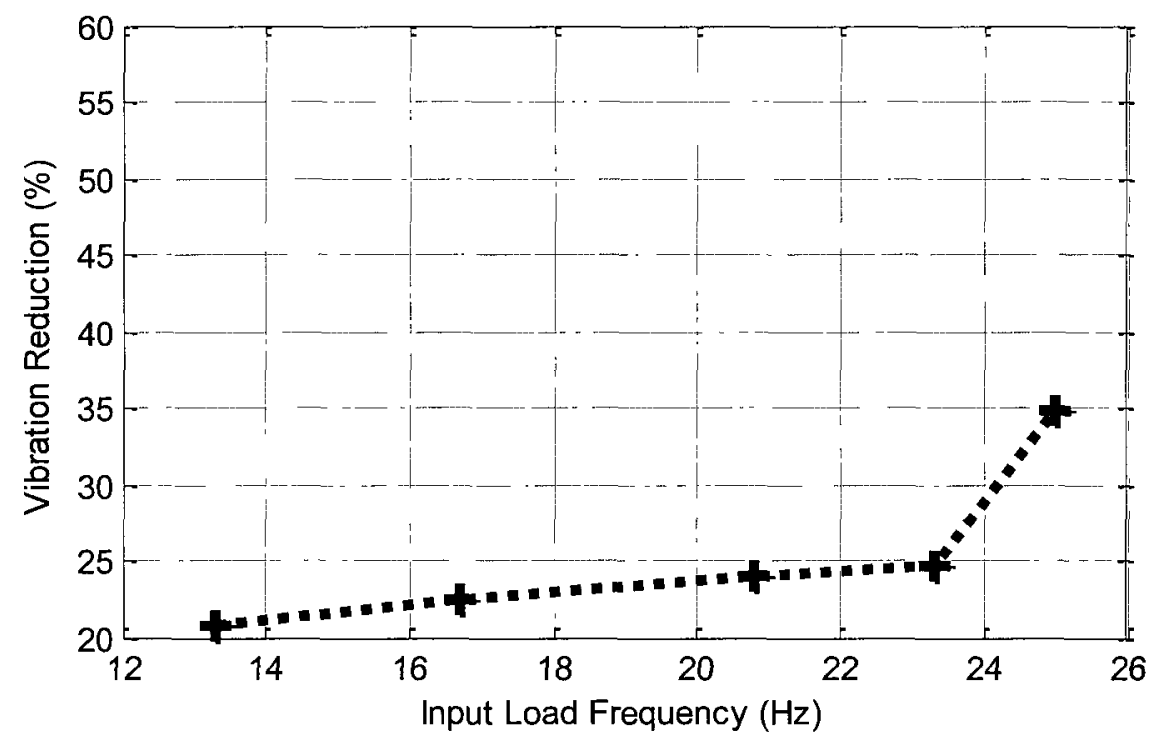

Figure 23: Vibration reduction due to "soft spring" mode only.

Figure 23 shows that although the "soft spring" mode of the APL in fact reduces vibration transferred through the pitch link, the closed-loop control law reduced the vibration by an additional $20-35 \%$ at each frequency. This confirms that the control law is functioning as expected.

The data presented for this closed-loop control law experiment proves that the prototype APL can reduce vibrations transferred though the pitch link up to almost $60 \%$, at a specific frequency. This also confirms the computational studies previously conducted. 
Note that these results are for a specific preload setting and spring stiffness of the APL. Changing any of these properties will change the performance of the APL. 


\section{Whirl Tower Test Preparations}

The ultimate goal of the SHARCS research program is to demonstrate the capabilities of the APL in scaled wind tunnel and/or flight tests. Before starting such testing, the closed-loop control law with the APL prototype must be tested in a whirl tower to ensure its functionality during rotation and high centrifugal loading.

While the experimental testing of the APL in non-rotating frame was conducted, a whirl tower facility was designed and built by the Carleton Rotorcraft Research group. The Carleton Whirl Tower is the first such facility in Canada and contains state-of-the-art technology. Since aerodynamic loading only creates vibration in forward flight (or decent) the whirl tower facility also requires a method to generate vibrations.

\subsection{The Carleton Whirl Tower Facility}

In partnership with Smart Rotor Systems (SRS) Inc. and the National Research Council Canada (NRC), the Carleton Whirl Tower facility (Figure 24) was constructed at the M-22 building of the Institute for Aerospace Research of the NRC in Ottawa, ON.

The whirl tower houses a $60 \mathrm{HP}, 575 \mathrm{~V}, 3$ phase, 1,800 rpm motor, which is controlled via a variable frequency drive/transformer (VFD). The motor drives the rotor shaft directly with the use of an elastomeric coupler. 

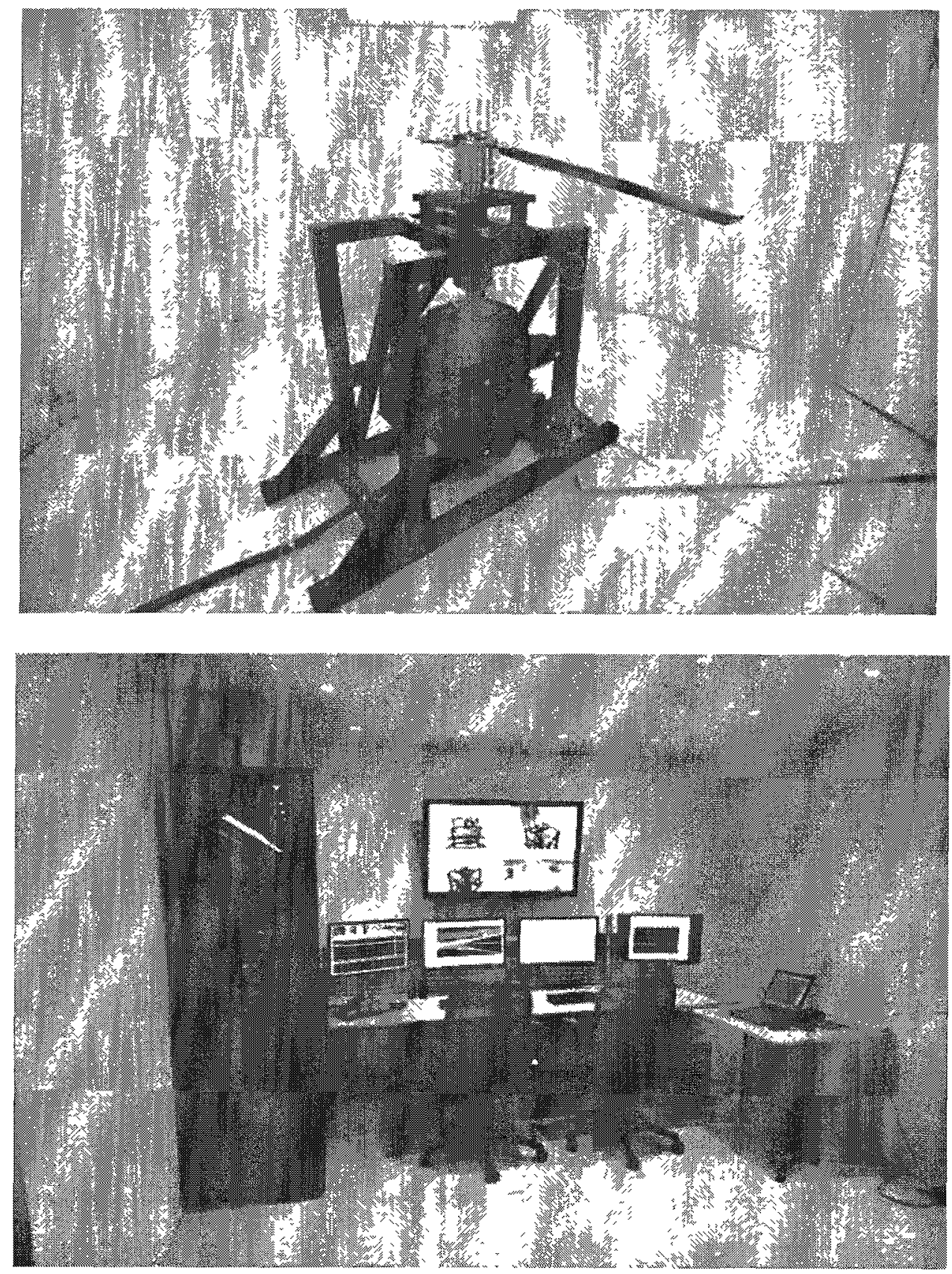

Figure 24: The Carleton Whirl Tower facility's test chamber and control room.

The tower was built within a $4.5 \mathrm{~m}$ diameter protective enclosure. The protective walls were constructed out of Armorcore level 3 panels, a glass-fibre based protective panel developed for withstanding gunshots. The facility includes 
operator safety features such as automatic motor shut-down if the door of the test chamber is opened. The whirl tower and surrounding area is monitored by live video surveillance to ensure safety of people and the facility during operation. The motor VFD and all required power supplies are located on the exterior of the protective walls.

The facility includes a custom 1-blade articulated hub manufactured to facilitate the APL prototype (Figure 25). This articulated hub was designed to house a $1.1 \mathrm{~m}$ radius aeroelastically scaled carbon-fibre blade. This blade was designed, manufactured and fully instrumented by the Carleton Rotorcraft Research group [41]. Strain gauges are installed in the interior of the blade to monitor stress during rotation, Figure 26 . The rotor hub houses both a wireless telemetry system as well as an 8 channel slip ring assembly from Shleifring. The wireless system consists of 2 Microstrain V-link nodes, each capable of transmitting data from 8 differential and 8 strain gauge channels wirelessly.

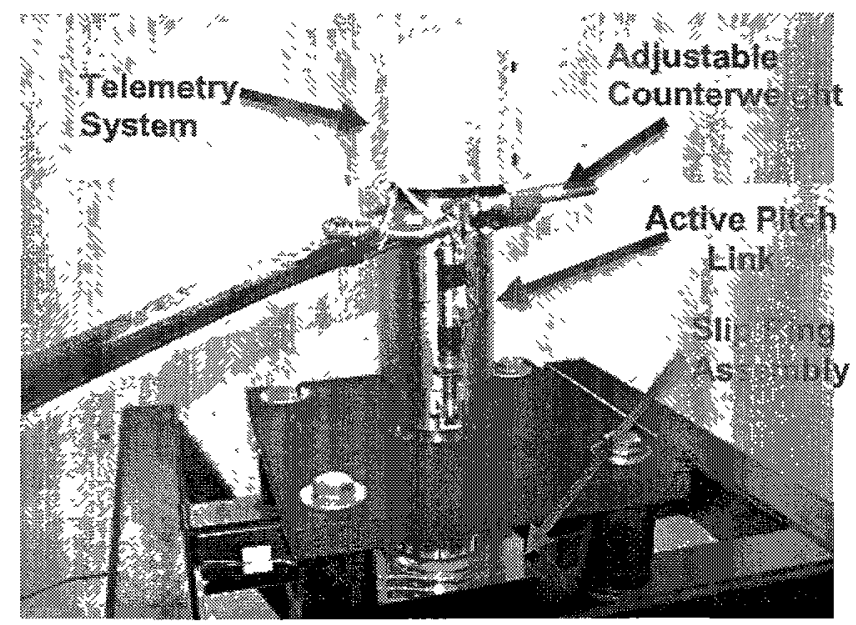

Figure 25: The 1-bladed fully articulated hub assembly. 


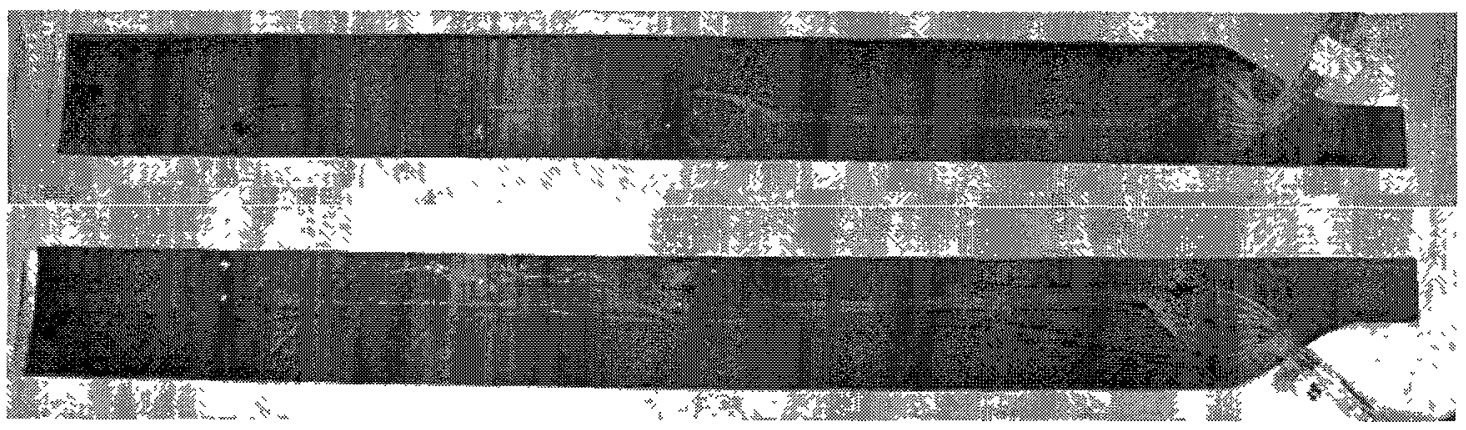

Figure 26: SHARCS aeroelastically scaled carbon-fibre blade before assembly, internally installed strain gauges.

This whirl tower facility has been fully commissioned and has several hours of operation at full speed $(1,550 \mathrm{rpm})$. This whirl tower was designed to ensure that any natural frequencies of the frame are above the operating range of the facility.

\subsection{Baseline Vibratory Loads of Pitch Link in Whirl Tower}

In order to test the APL in the whirl tower, it is required to generate vibratory loads representative of the vibrations expected in forward flight. Since the whirl tower can aerodynamically represent hover only, vibration could possibly be introduced into the system by use of an active flow control system on the blade (such as Active Twist or Actively Controlled Flap).

It was assumed that the aerodynamic interference between the blade and the whirl tower test stand likely generates some baseline vibrations. If these loads are similar to the predicted CFD results (Section 2.2) in terms of amplitude and frequency, they could be used to test the APL. Therefore, it was necessary to measure the baseline vibratory loads through the pitch link. 
This test was done using the whirl tower facility in the same configuration that the APL will be tested, but with a conventional solid pitch link as shown in Figure 27. Since there is no swash plate in this hub design, the pitch link is connected to an L-bracket at the bottom of the hub. Strain gauges were installed on this bracket and calibrated to measure the loads transmitted axially though the pitch link (the same bracket was used in the non-rotating tests, i.e. Figure 8). The data from the strain gauges were collected using the MircoStrain Wireless V-link system.

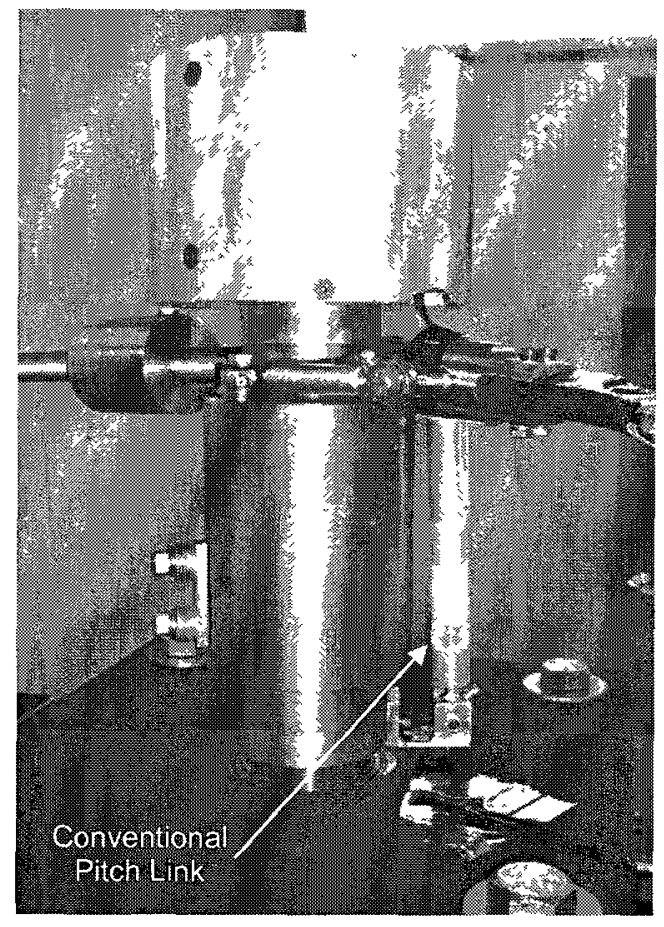

Figure 27: Solid pitch link in hub assembly.

It is assumed that the pitch link loads are a function of both the blade pitch angle, as well as the rotational speed of the system. Therefore, data was collected for varying pitch angles and rotational speeds. For convenience, the pitch angle was measured at the blade root. The twist distribution of the 
SHARCS blade is shown in Figure 28. The three root pitch angles tested were +2.75 degrees, 0 degrees and -2.75 degrees. Measurements were done at the following rotational speeds: $800,1,000,1,250,1,400$ and $1,550 \mathrm{rpm}$ for each angle setting.

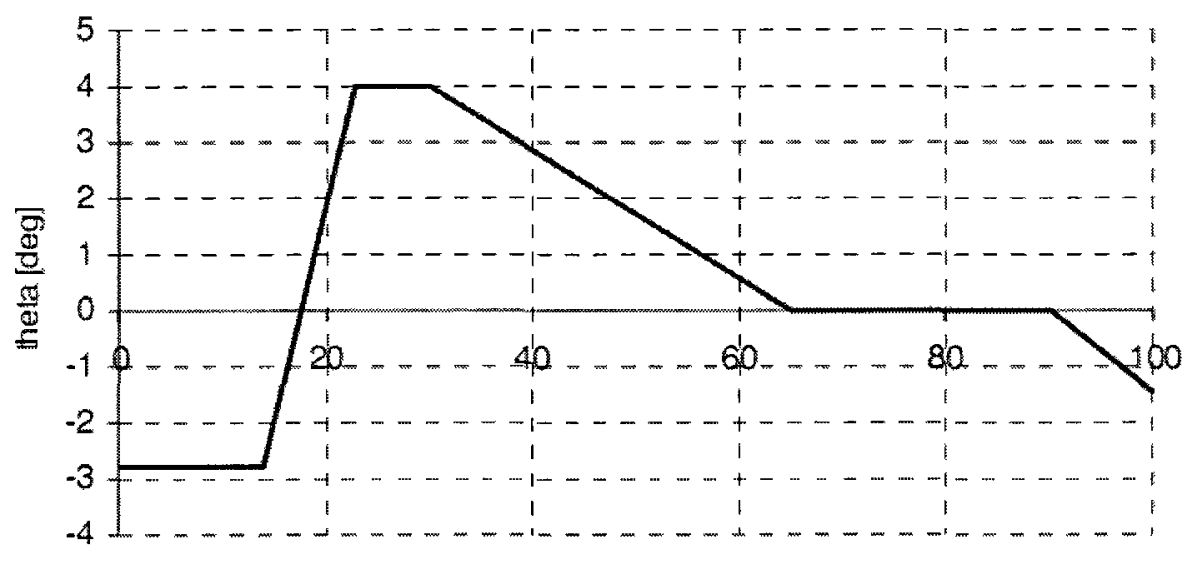

$$
r / R[\%]
$$

Figure 28: SHARCS blade twist distribution.

Figure 29 shows the time history of the pitch link loads at each rotational speed with a 0 degree root pitch angle. It can be seen that as the rotational speed is increased, the mean static load and dynamic load acting through the pitch link increases. 


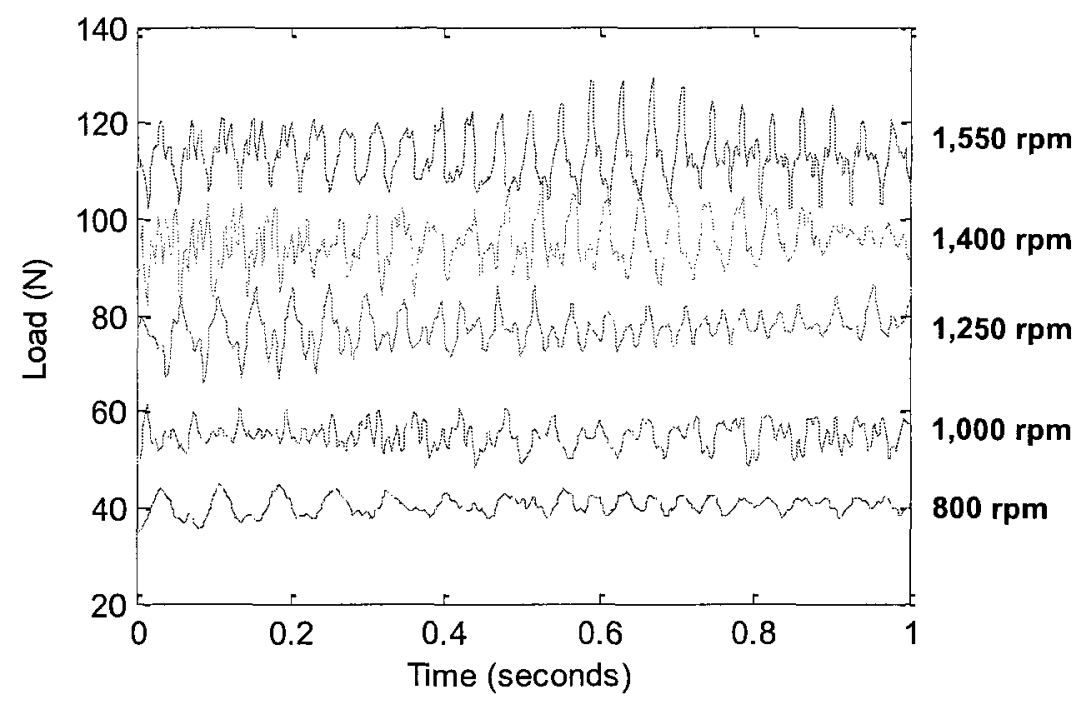

Figure 29: Baseline vibratory load through the pitch link for 0 degree root pitch angle at various rotational frequencies.

The change in mean static load as a function of rotational speed is summarized in Figure 30 (a). This data shows a clear trend exists between the mean static load and the rotational speed. Figure 30 (b) summarizes the mean amplitudes of the dynamic baseline vibratory loads. This data also shows that there is a trend between the amplitude of the dynamic loading experienced by the pitch link and the rotational speed. 


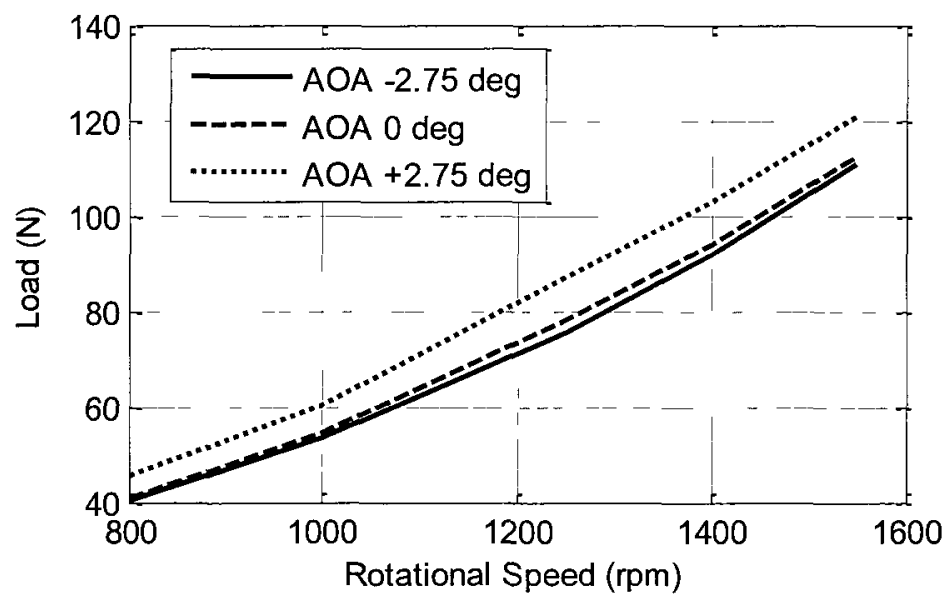

(a)

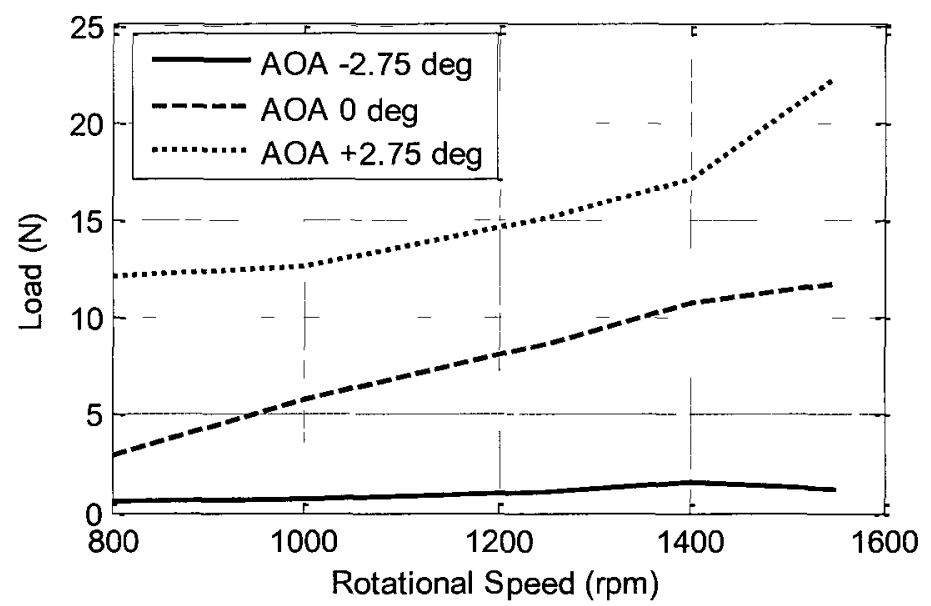

(b)

Figure 30: Mean (a) static and (b) dynamic baseline vibratory loads through the pitch link.

To determine the cause of the rotational pitch link loads, an FFT analysis of the dynamic loads was done. Figure 31 shows an FFT of the dynamic loads though the pitch link at 0 degree root pitch angle. This analysis shows that the frequency of the dynamic load is always close to $1 /$ rev, confirming that the source of vibrations is aerodynamic interference. This is most likely due to the asymmetric design of the frame that houses the motor. The same trend was evident at all other root pitch angles tested. 


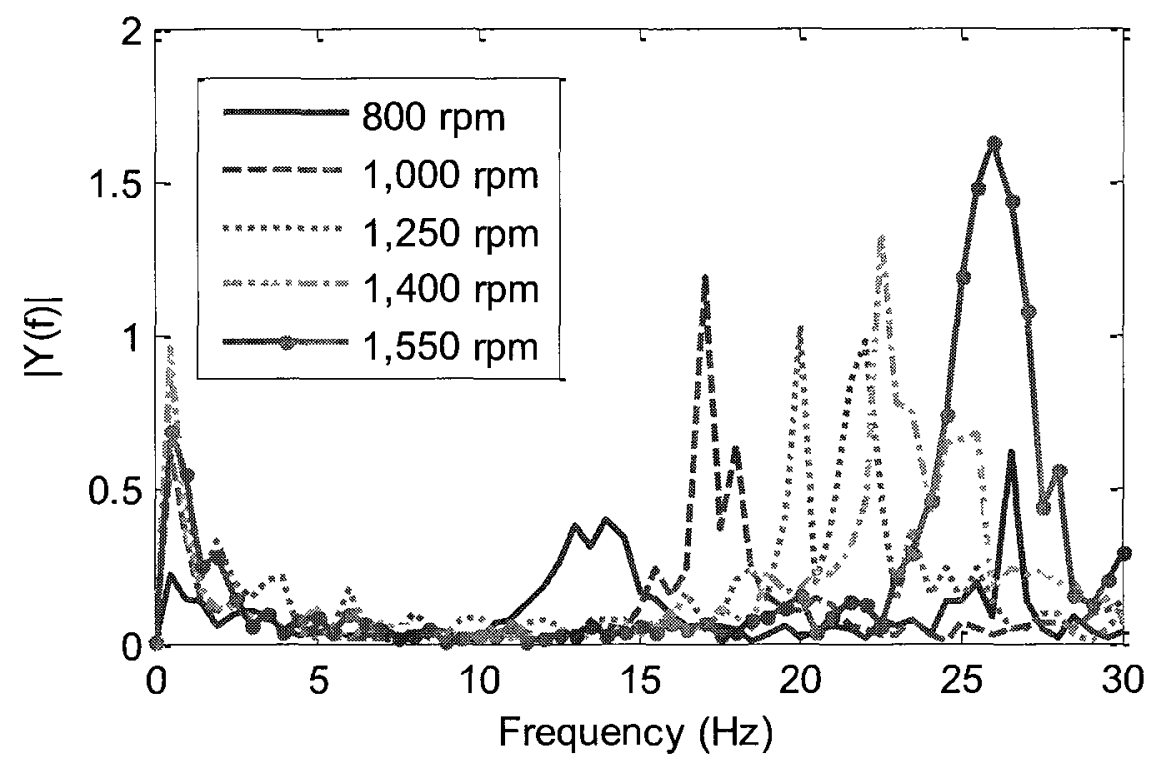

Figure 31: FFT analysis of baseline vibratory pitch link loads.

As can be seen, the baseline vibratory loads of the whirl tower facility show some similarity to the pitch link loads determined from CFD for a representative forward flight case (Section 2.2). While the CFD results exhibit about $100 \mathrm{~N}$ static load with about $70 \mathrm{~N}$ amplitude for dynamic load, this experiment yielded $120 \mathrm{~N}$ static load and $20 \mathrm{~N}$ dynamic load. The frequencies are comparable, both occurring at around $1 /$ rev.

This means that for preliminary testing of the APL in the rotating frame, the baseline vibratory loads could be used as the input load to the APL. These loads are periodic, at the right frequency and with the same order of magnitude of load.

\subsection{APL Whirl Tower Tests}

Whirl tower testing of the APL prototype has begun. Similar to the nonrotating test, the first step is to ensure the APL can function in its fail-safe mode during rotation. Currently, the ON-OFF conditions of the APL have been verified 
in the rotating frame i.e. the APL can function in the "solid link" and "soft link" modes. Once the fail-safe mode, and all functionality tests of the APL have been completed in the rotating frame, the closed-loop control of the APL will be tested. Figure 32 shows the APL as it is installed in the whirl tower for testing. This testing will be completed as part of research conducted by new members of the Carleton Rotorcraft Research Group.

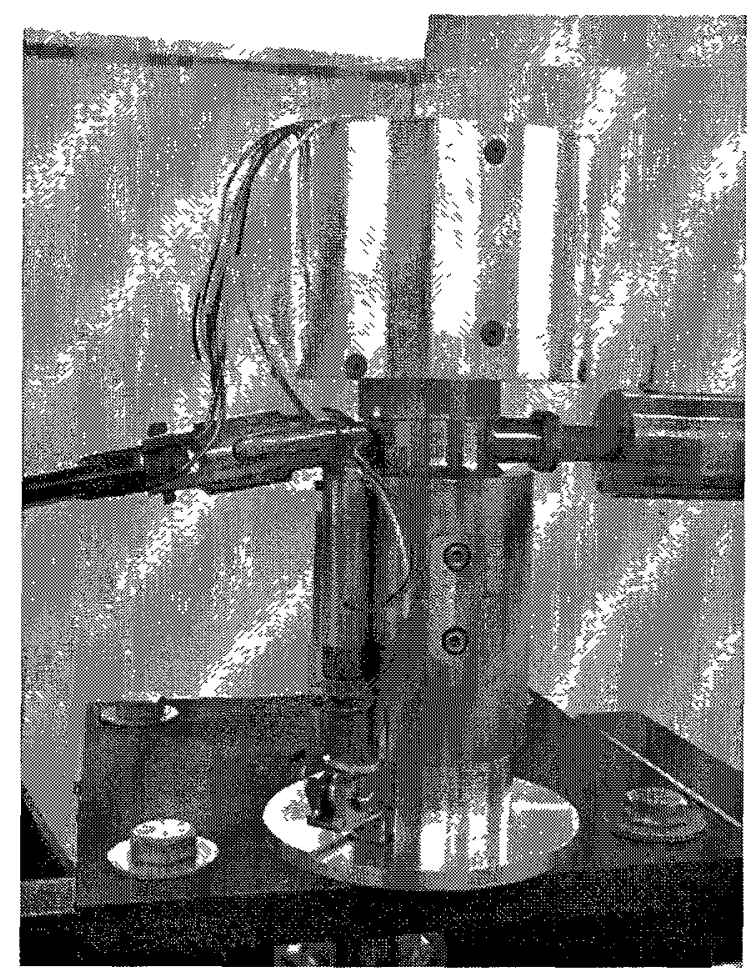

Figure 32: The APL installed for functionality and closed-loop control tests in the rotating frame. 


\section{Wind Tunnel Test Preparations}

The ultimate goal of the SHARCS project is to demonstrate the Hybrid Control concept in wind tunnel testing. This should allow demonstration of the capabilities of the APL under forward flight conditions. The goal of the wind tunnel test is to show a significant reduction of the rotor induced vibration because of the Active Pitch Link (APL).

In collaboration with the Institute for Aerospace Research (NRC-IAR), a Bell 412 tail-rotor assembly will be used to test the APL during forward flight conditions. This rotating test set-up is housed in the NRC $3 \mathrm{~m} \times 6 \mathrm{~m}$ open-circuit propulsion wind tunnel located in Ottawa, ON.

In order to test the APL in this wind tunnel set-up, an APL prototype had to be designed and manufactured to fit this particular assembly. First, this APL must be designed to physically fit the test set-up dimensions. Secondly, the APL must be designed with properties to specifically reduce vibrations for these blades. This requires knowledge of the rotor blades torsional stiffness/modal properties, as well as the pitch link loads experienced during forward flight conditions.

In preparation for APL wind tunnel tests, an experimental modal analysis of the system was performed. As well, the static and dynamic loads acting through the pitch link were experimentally measured. These results will be presented in this chapter. 


\subsection{NRC Bell 412 Tail-rotor Wind Tunnel Test Set-up}

The Institute for Aerospace Research (NRC-IAR) provided access to their $3 \mathrm{~m} \times 6 \mathrm{~m}$ open-circuit propulsion wind tunnel (Figure 33) and their Bell 412 tailrotor assembly test set-up. Table 5 provides a brief summary of some important characteristics of this wind tunnel.

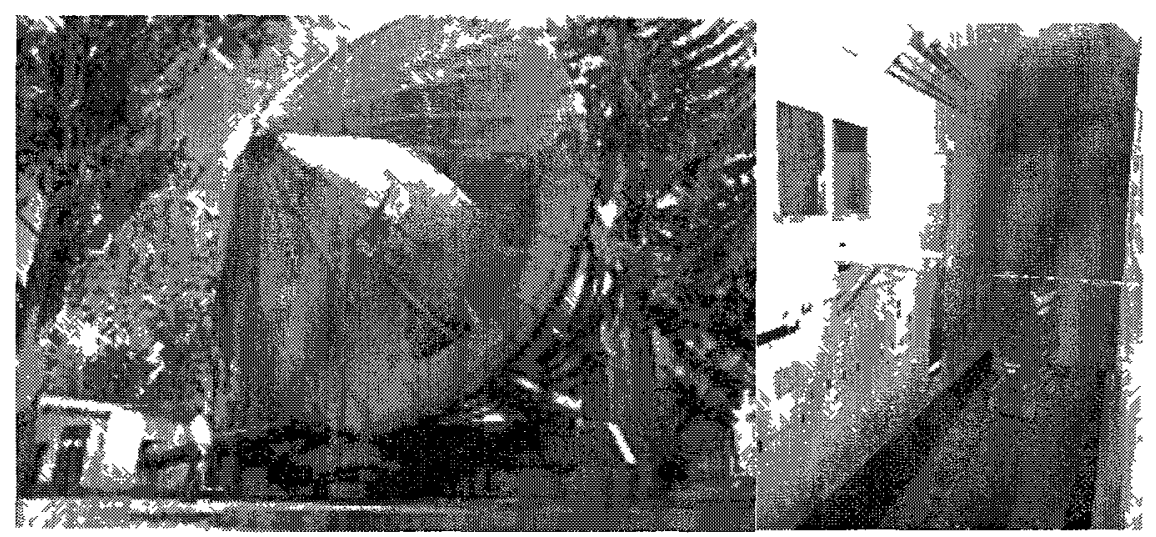

Figure 33: NRC $3 \mathrm{~m} \times 6 \mathrm{~m}$ open-circuit propulsion external fan and test section with the Bell 214 tail-rotor set-up.

Table 5: Properties of NRC $3 \mathrm{~m} \times 6 \mathrm{~m}$ open-circuit propulsion wind tunnel Tunnel geometry

\begin{tabular}{|r|l|}
\hline Test section & $\begin{array}{l}3.1 \mathrm{~m} \text { wide } \times 6.1 \mathrm{~m} \text { high } \mathrm{x} \\
12.2 \mathrm{~m} \text { long }\end{array}$ \\
\hline Test section area & $18.9 \mathrm{~m}^{2}$ \\
\hline
\end{tabular}

Tunnel characteristics

\begin{tabular}{|r|l|}
\hline Fan power & $750 \mathrm{~kW}$ (Electric) \\
\hline Max. speed & $40 \mathrm{~m} / \mathrm{s}$ (Electric) \\
\hline Speed uniformity & $\pm 0.5 \%$ \\
\hline
\end{tabular}

Data system and instrumentation

\begin{tabular}{|r|l|}
\hline Software & $\begin{array}{l}\text { test specific MatLab \& } \\
\text { LabView }\end{array}$ \\
\hline Flow visualization & $\begin{array}{l}\text { PIV, Acoustic Array, PSP, } \\
\text { laser light sheet, smoke, } \\
\text { surface oil, fluorescent }\end{array}$ \\
\hline
\end{tabular}


The tail-rotor assembly contains many original service parts of a Bell 412 helicopter, although some custom pieces were required. The blades in the set-up were taken out of service due to various issues, including service time and fatigue stresses. Custom parts include the yolk (i.e. the pitch link end attachment point which can be manually moved to adjust the pitch angle) and pitch link assembly. Figure 34 compares the NRC test set-up and the tail-rotor assembly of a Bell 412 helicopter in service. It can be noted that the NRC assembly has a simpler set-up, but the blade and pitch link attachments are almost identical. 


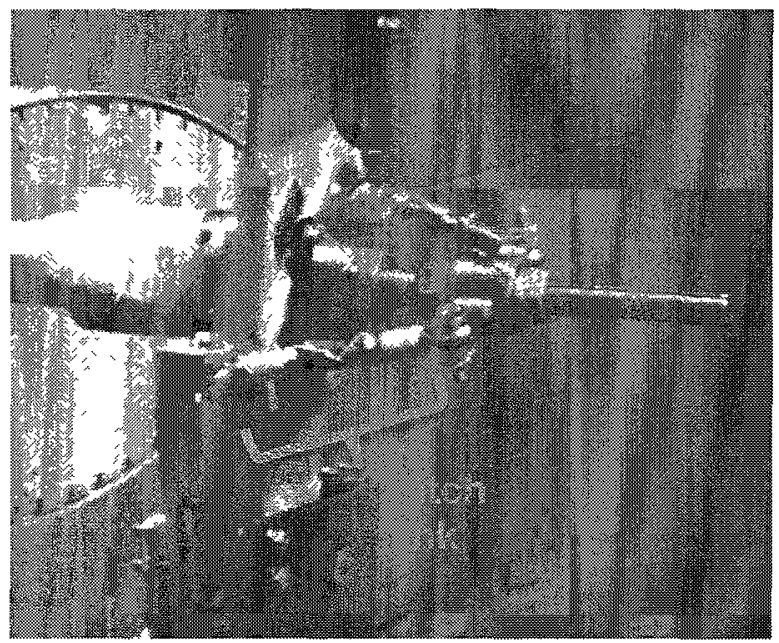

(a)

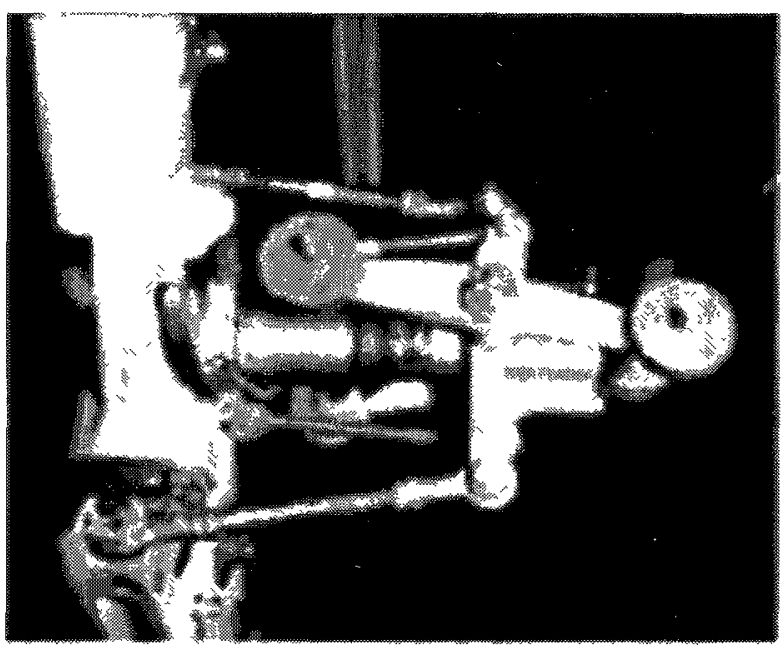

(b)

Figure 34: Comparison of (a) NRC test set-up to (b) in service rotor.

Two sets of instrumentation were installed on the test set-up in order to collect required data. Additional instrumentation was installed by NRC-IAR for operation purposes. (NRC fully instrumented the blades with strain gauges. The raw strain gauge data from wind tunnel tests are available in Appendix $F$. This data could be used to develop an experimental fan plot). Only the instrumentation required for APL wind tunnel pitch link loads are outlined here. 
A full bridge of $350 \mathrm{Ohm}$ strain gauges were installed on the yoke of the tail-rotor assembly (Figure 35). These gauges measure the bending strain induced onto the yoke due to the loads transmitted though the pitch link. The loads measured at this location are analogues to the loads being transmitted through the pitch link into a swash plate.

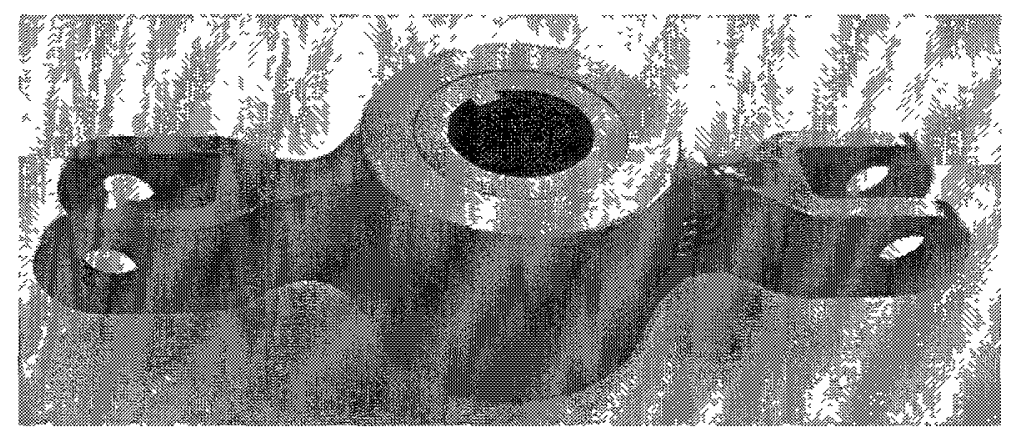

Figure 35: Instrumented yoke before installation.

The shaft was balanced before the tail-rotor assembly was mounted and again once the entire tail-rotor assembly was installed. Blade tracking was performed to ensure the blades were rotating in the same plane. A brief explanation of this process is provided in Appendix $\mathrm{F}$.

\subsection{Required Information for New APL Design}

In order to design an APL for this tail-rotor assembly, the APL "soft spring" stiffness needs to be estimated by use of a fan plot. (Details about this procedure are outlined in references [4] and [37]). A modal analysis was completed using LMS software/hardware to estimate the first points on a fan plot for this test setup. A complete fan plot was created through numerical extrapolations. 
In order to ensure that the APL will function in its fail-safe mode during wind tunnel tests, both the magnitude of static and dynamic loads acting through the pitch link are required.

\subsubsection{Modal Analysis and Numerically Extrapolated Fan Plot}

A modal analysis of the NRC Bell 412 tail-rotor assembly was completed with the use of LMS hardware/software. This system is specifically designed to perform modal analysis through the use of accelerometers and an impact hammer or shaker.

Multiple tests were performed to ensure accurate results. Table 6 outlines the modal analysis results for the first four modes.

Table 6: Modal analysis of Bell 412 tail-rotor.

\begin{tabular}{|c|c|}
\hline Frequency (Hz) & Mode Shape \\
\hline 28.3 & $1^{\text {st }}$ flapping \\
\hline 84.0 & $2^{\text {nd }}$ flapping \\
\hline 126 & $2^{\text {nd }}$ flapping \& $1^{\text {st }}$ torsion \\
\hline 155 & $1^{\text {st }}$ torsion \\
\hline
\end{tabular}

Using this modal analysis data a fan plot was created using a numerical extrapolation technique outlined in reference [42]. A Matlab function, "FanPlot()" (Appendix E) was used to developed the numerically extrapolated fan plot. This fan plot, shown in Figure 36, can be used to estimate the required "soft spring" stiffness of an APL for this test set-up. 


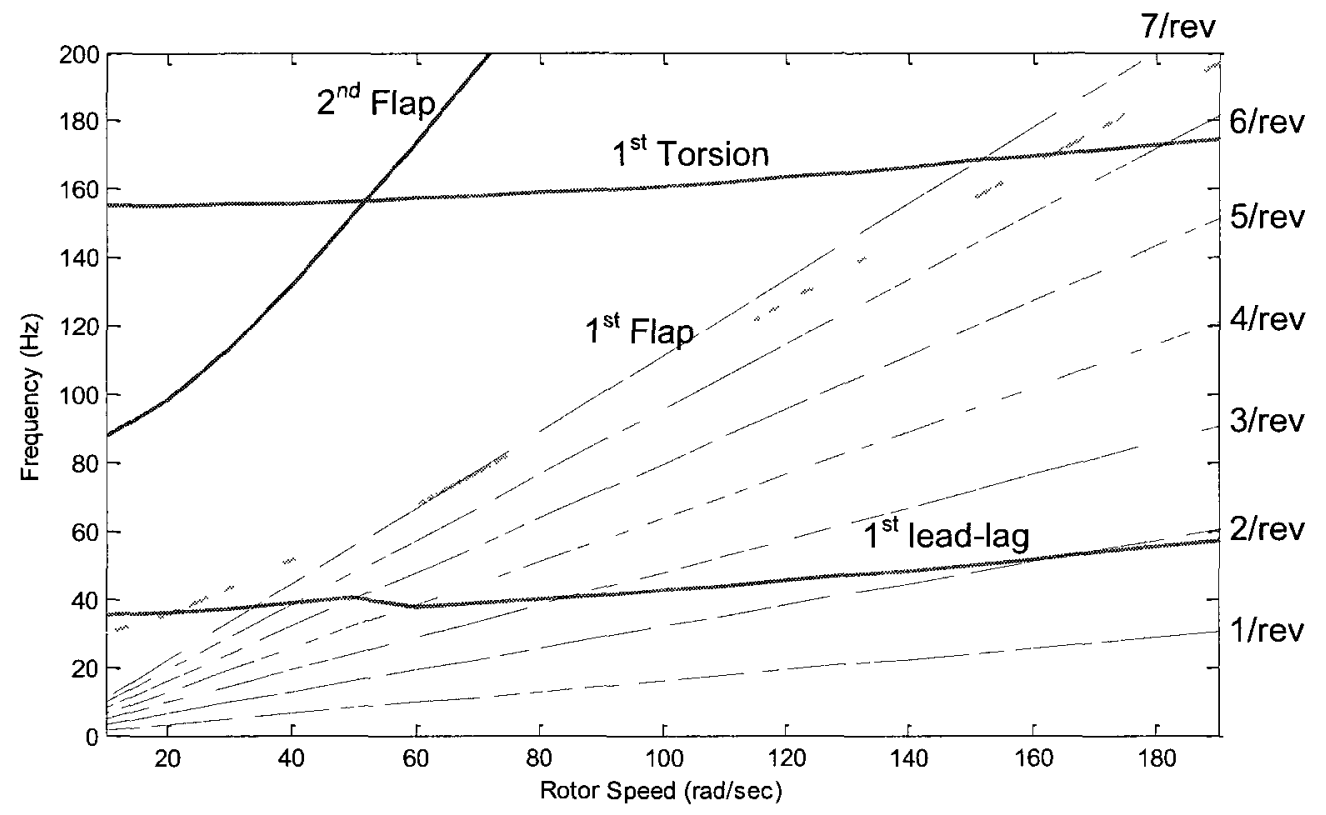

Figure 36: Numerically extrapolated fan plot for Bell 412 tail-rotor.

\subsubsection{Experimentally Determined Pitch Link Loads during Rotation}

The loads experienced by the pitch link installed in the Bell 412 tail-rotor assembly were measured with strain gauges mounted on the yoke. Measuring the loads at this point is analogous to measuring the output loads of the APL as described for the non-rotating tests. The loads measured at this point represent the loads that are transmitted though the pitch link to the swash plate on a helicopter. The aim of the APL is to reduce the magnitude of these dynamic loads. The real-time measurement from these strain gauges is also the same information that is required to implement the closed-loop control algorithm.

The pitch link loads were measured for various forward flight speeds and rotor speeds. The pitch angle of the blade was constant at 3.6 degrees for all 
tests. Figure 37 summarizes the mean dynamic and static pitch link loads at various rotor and wind speeds.

This experimental data shows that the APL must withstand up to $200 \mathrm{~N}$ of static loading, and a magnitude of $600 \mathrm{~N}$ of dynamic loading at $1000 \mathrm{rpm}$. The APL must be designed with a fail-safe mode to withstand these loads.

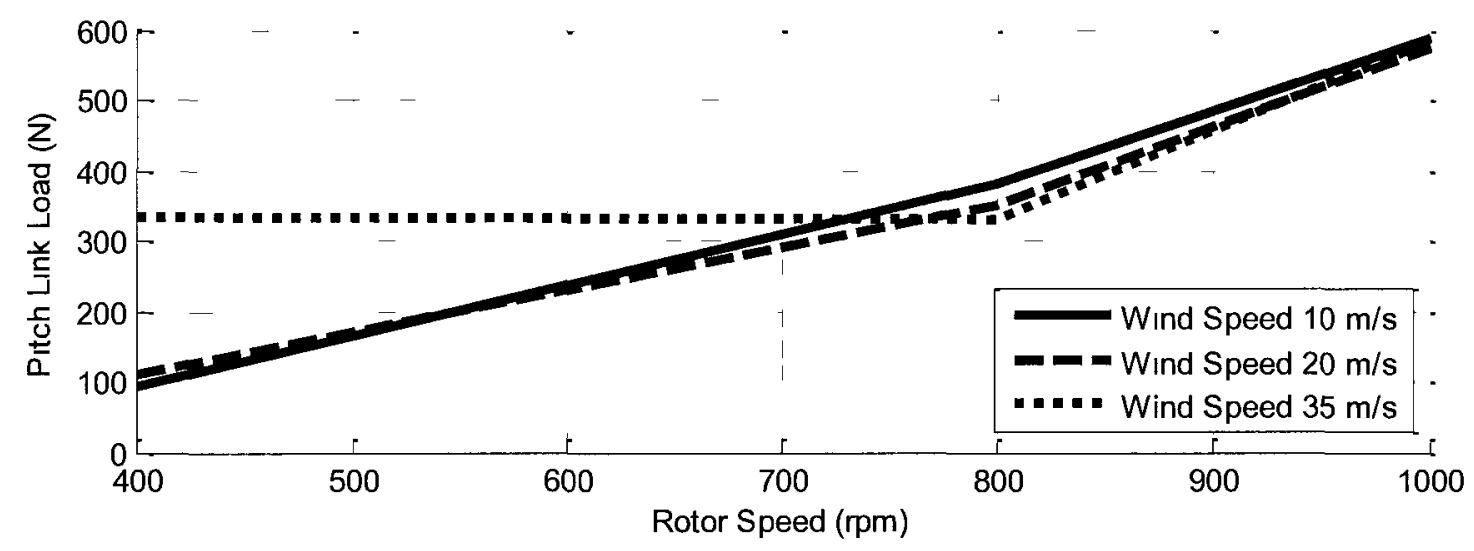

(a)

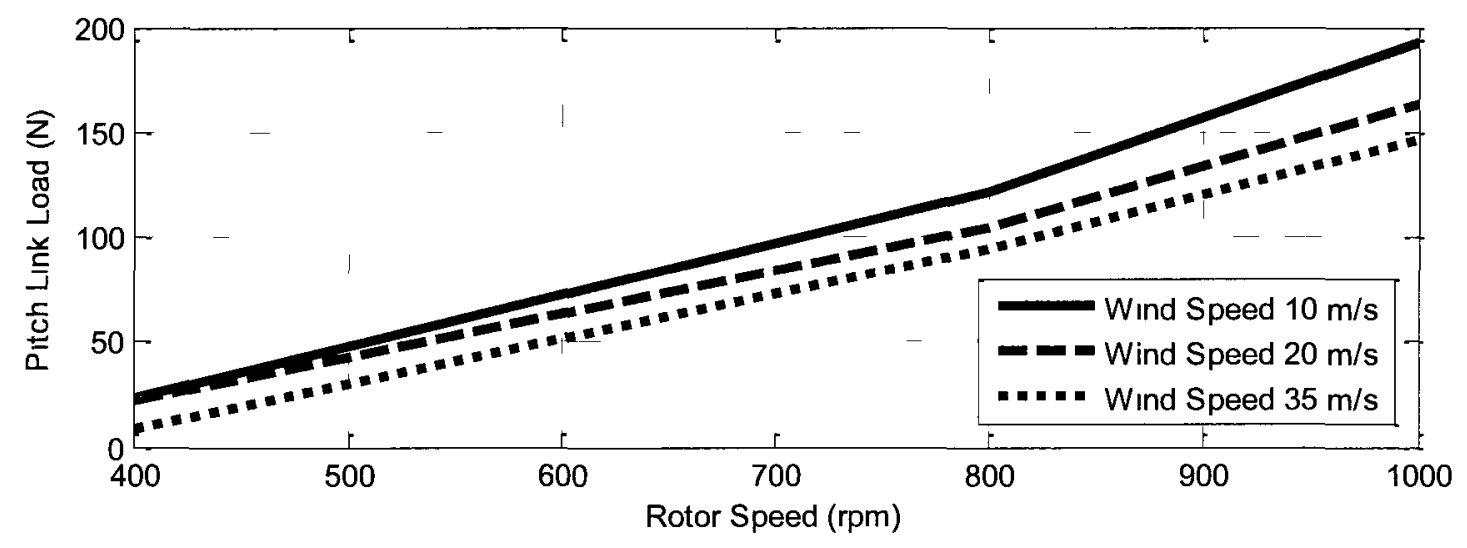

(b)

Figure 37: Mean (a) dynamic and (b) static pitch link loads in forward flight. 


\section{Conclusions and Future Work}

The APL prototype was designed and manufactured as part of the SHARCS project with a goal to demonstrate the Hybrid Control concept developed by Feszty and Nitzsche. Carleton University's APL is the only built prototype of a stiffness control device. The most current APL prototype was tested to ensure it meets all design requirements, such as its fail-safe mode and abilities to control stiffness. All design requirements were confirmed through experimental testing in the non-rotating frame.

Numerical and computational simulations implied that the APL reduces vibrations acting through the pitch link up to $60 \%$. Experimental implementation of the proposed closed-loop control algorithm proved that in non-rotating tests the APL achieves close to this $60 \%$ reduction in vibrations transferred through the pitch link. It was clearly confirmed that this reduction is due to the implementation of the control law and not just the addition of a spring in the system. The results for the closed-loop control test presented in this thesis are the first experimental tests to prove the capabilities of the APL.

These closed-loop control tests of the APL confirm that this system can be used to change the root stiffness of a single helicopter blade, in real-time. These tests also show that the APL can be tuned to optimally reduce vibrations at a specific frequency. This is very important to ensure the helicopter controls are not disturbed with the installation of the APL. 
In order to realize the ultimate goal of the SHARCS project the APL must be tested first in the rotating frame (whirl tower) and then in forward flight conditions (wind tunnel). The above tests are required to prove that the current closed-loop control algorithm can be maintained in the rotating frame and wind tunnel testing.

When the current control algorithm is confirmed in rotating tests, the suggested next step is to refine the closed-loop control theory to include the use of the full range of stiffness capabilities of the APL. This range is shown through the experimental stiffness curve and may allow for even more vibration reduction.

Once the vibration reduction abilities of the Active Pitch Link (APL) are fully tested, refined and implemented it will not only be a major accomplishment in the helicopter/flight industry but can be adapted to enhance may environment issues and programs such as wind turbines. 


\section{APPENDICES}

\section{Appendix A: Determining magnitude of average peaks (averagepeak.m).}

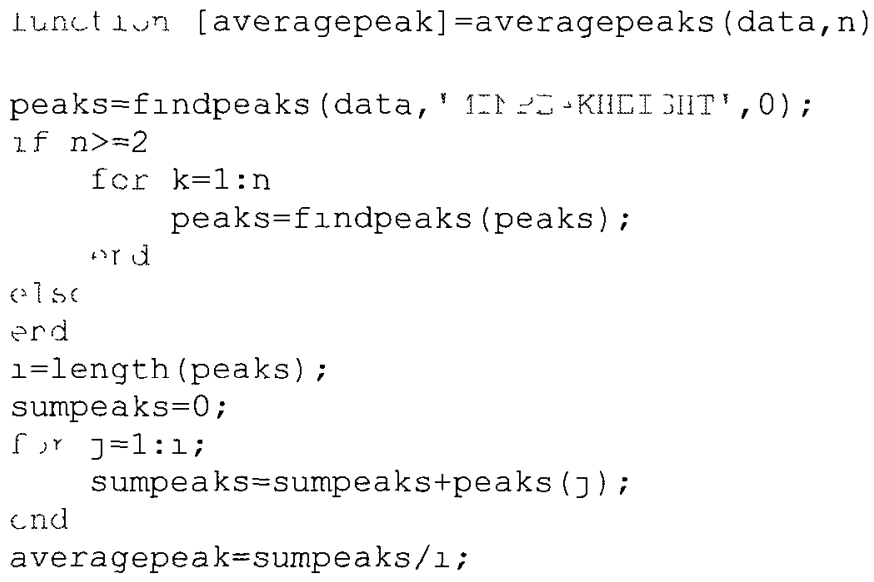

\section{Appendix B: Stiffness curve (StiffnessCurve.m).}

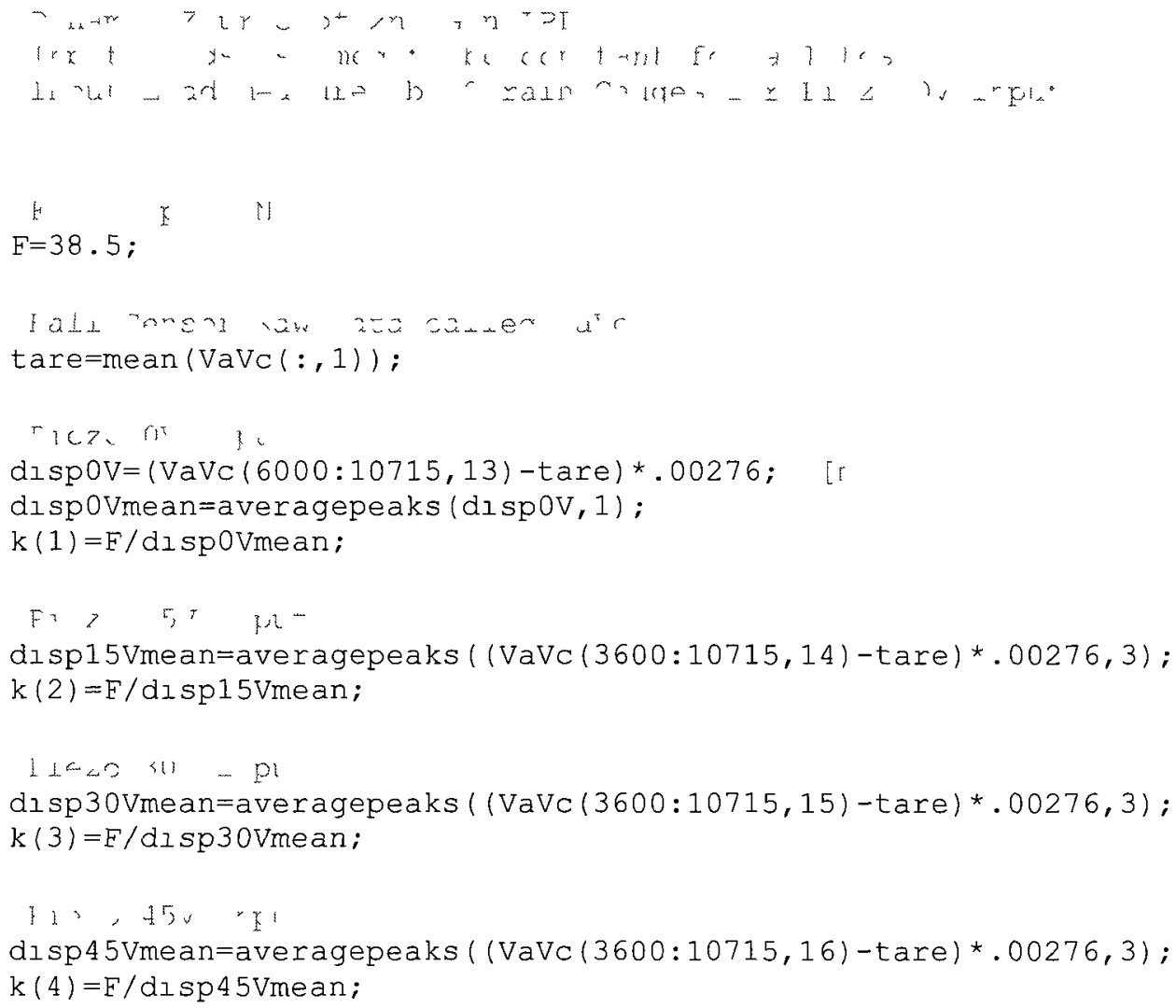




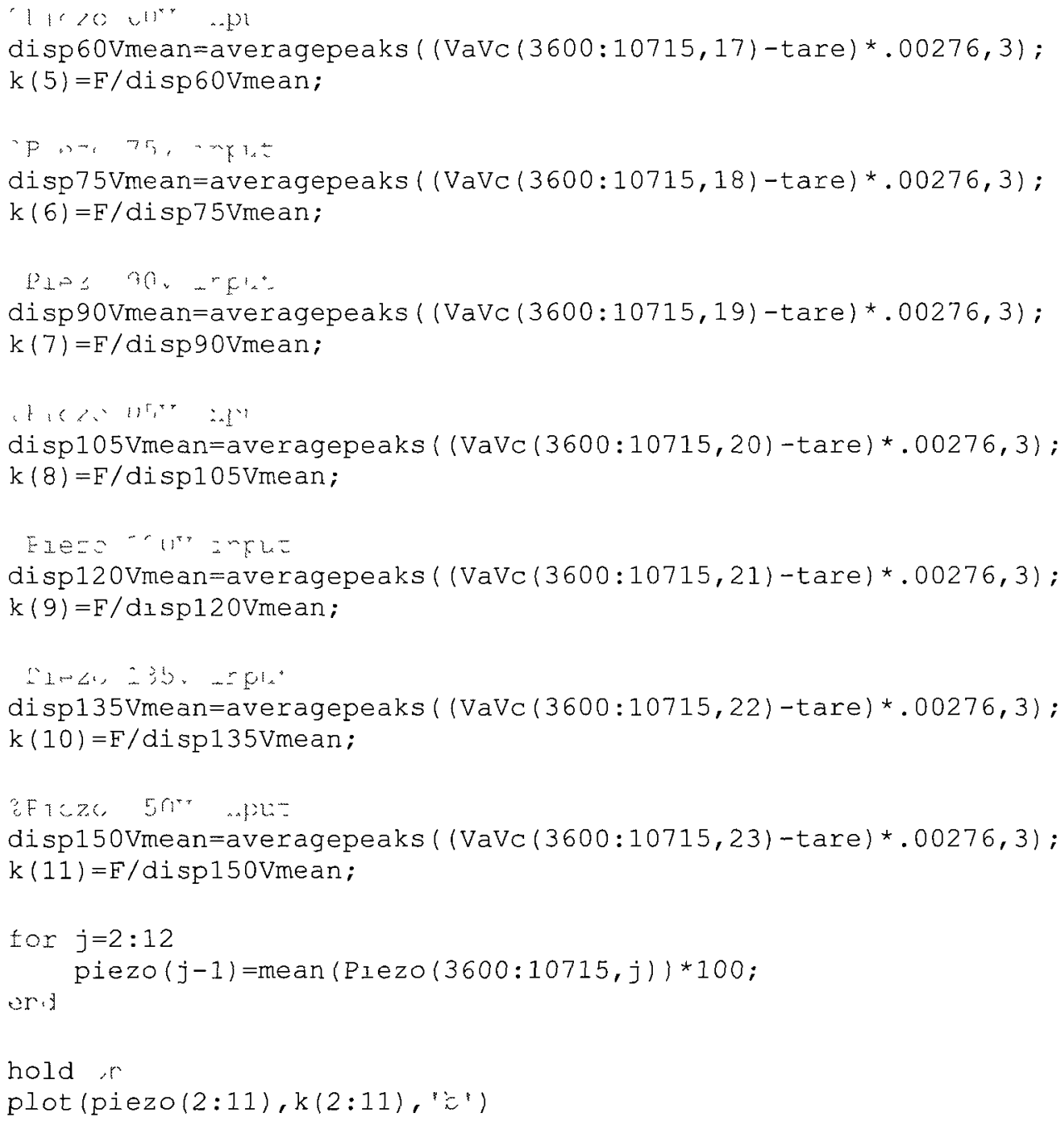




\section{Appendix C: Closed-loop control algorithm for Arduino microcontroller (APLControlLaw2.pde).}

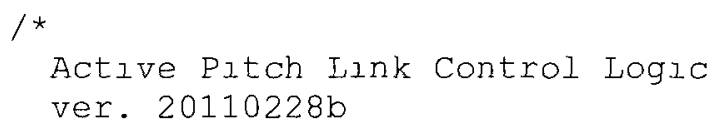

Change Log:

$20110228 \mathrm{a}$ :

-Added output smoothing based on last 4 peaks rather than Just 1 . 20110228b:

-Change to smoothing logic and lowerıng of minımum peak amplitude threshhold.

-NOTE: ALL on percent SHOULD BE TAKEN TO MEAN off percent. (1e the length of time the plezoactuator is supplied OV) *

// Select whether to operate in Mode 1 or Mode 2 at complle time \#define logic mode 2

// Mode 2 options

\#defune pulse_per_cycle 2 // Actıvate once per cycle, or twlce (rlsing and falling)

\#define on percent $50 / 100$ // define $\frac{\circ}{0}$ of perıod to activate as integer fraction

\#define phase shıft $0 / 100$ // define phase shift of actıvatıon WRT signal as intēger fraction, note:

// when actıvatıng twice per cycle, the phase shift and on percent are based on half cycle time

// 16MHz clock divider optıons: $0,8,32,64,128,256,1024$, any other value will default to 128 


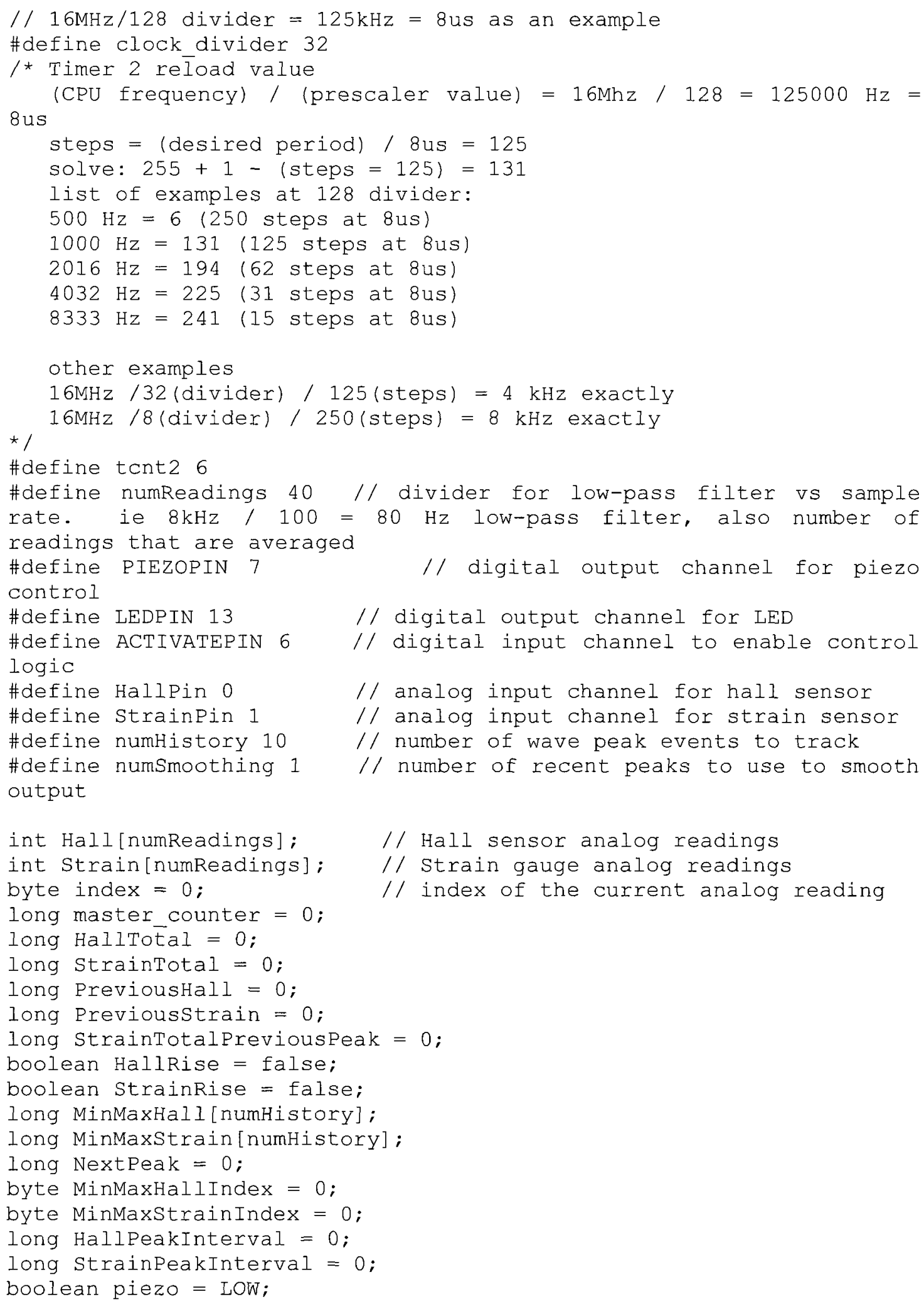




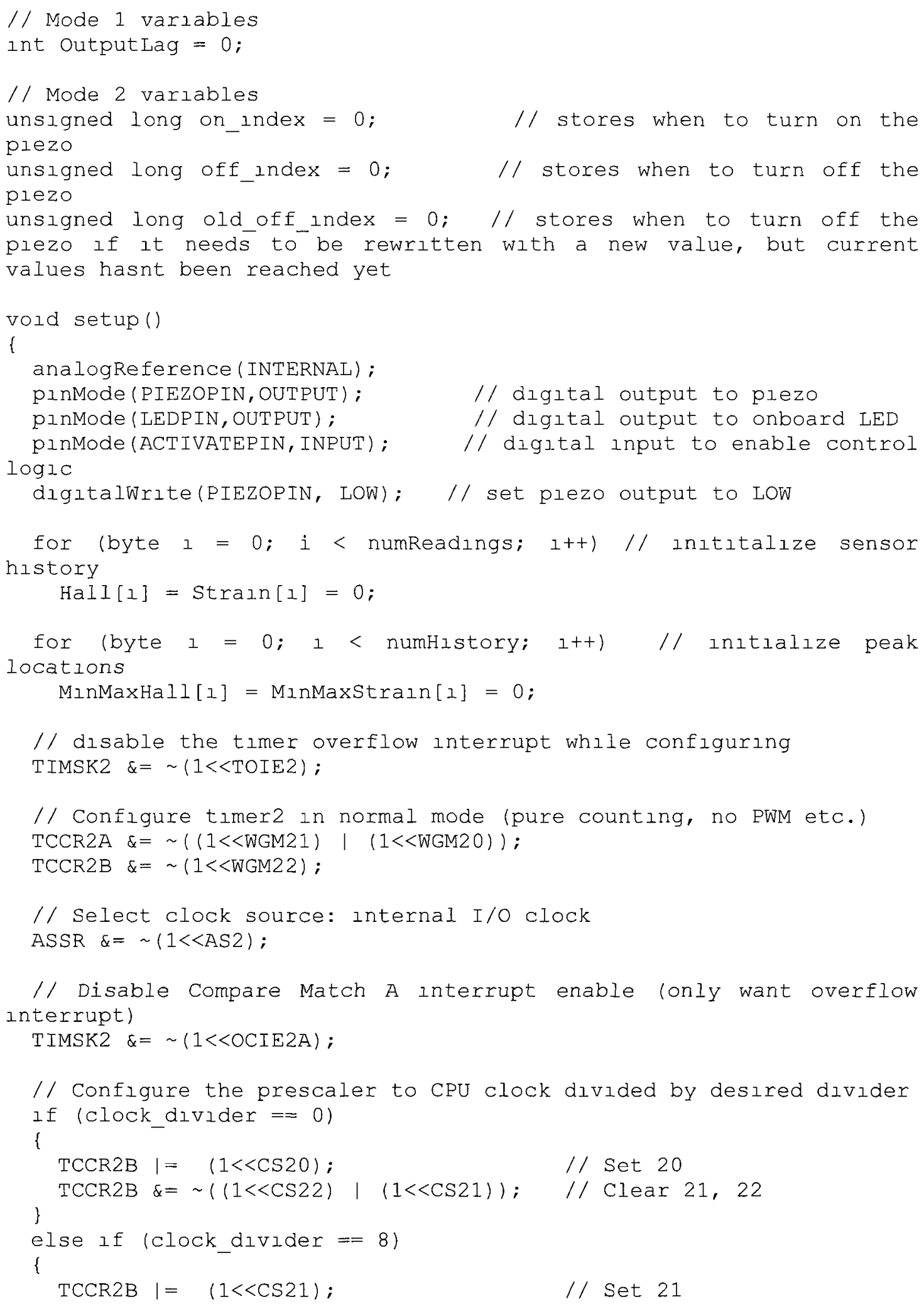




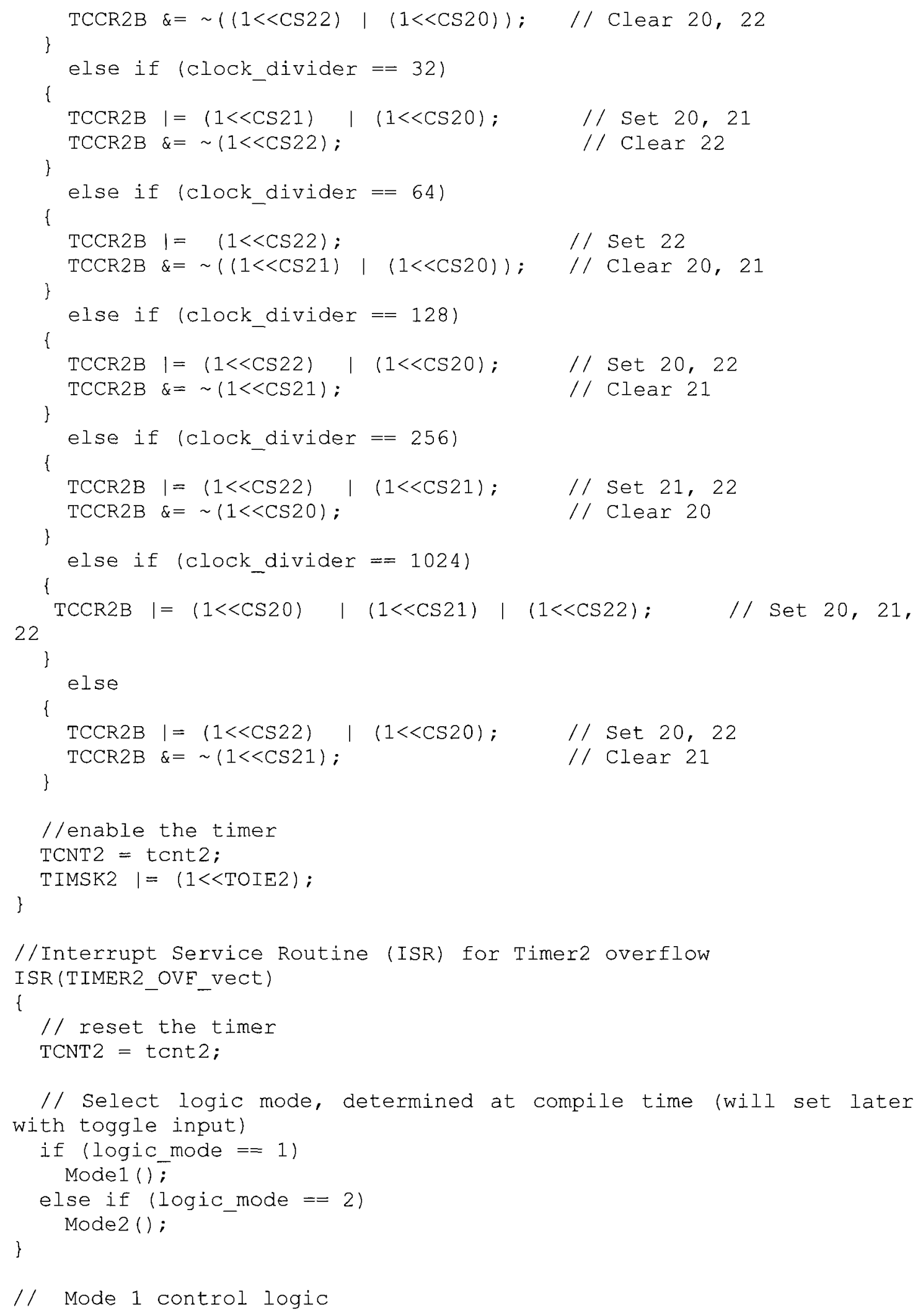

// Mode 1 control logic 


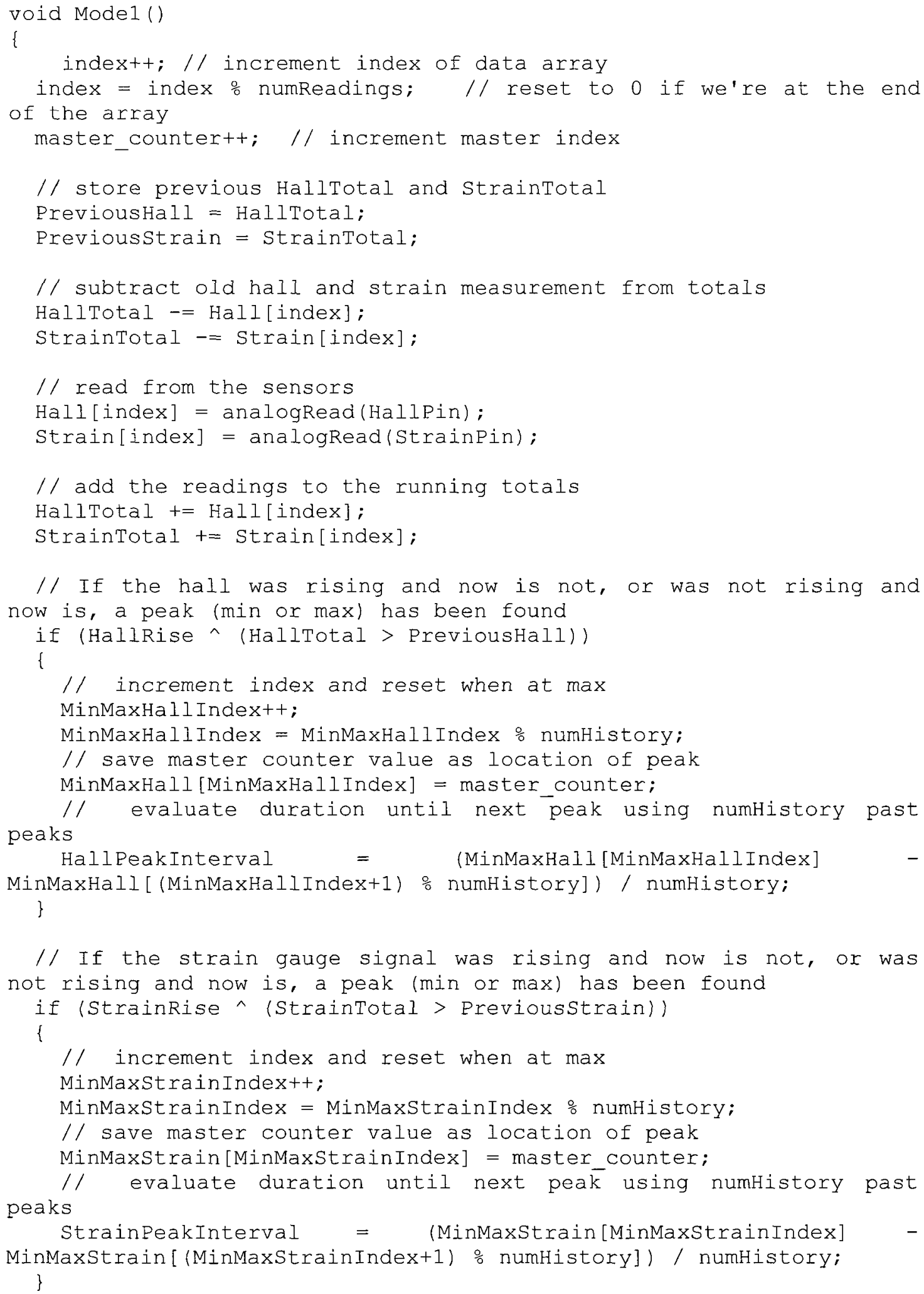


$/ /$ evaluate if current signals are rising or not

HallRise = HallTotal > Previoushall;

StrainRise = StrainTotal > PreviousStrain;

// If digital input indcates activating control

if (digitalRead(ACTIVATEPIN))

1

$/ /$ if the current measurement point is predicted to be a peak for either the hall or strain signal (using historical information), then switch the logic.

if ('master_counter $==$ (MinMaxHall[MinMaxHallindex] + HallPeakInterval - (numReadings/2))) ^ (master counter = (MinMaxStrain[MinMaxStrainIndex] + StrainPeakIñterval (numReadings/2))))

piezo = HallRise != StrainRise; // set logic to oposite of current recommended state (since prediction is that the logic state should now change)

$/ /$ if piezo is recommended to be on

if (piezo)

\{

zero again

if (OutputLag $<0) / /$ if it was off set the output filter to

OutputLag $=0$;

if (OutputLag $==2$ ) $/ /$ if 3 consecutive 'on' signals have

been received then activate

\{

digitalWrite (PIEZOPIN, piezo);

\}

digitalWrite(LEDPIN, piezo);

if (OutputLag < 3) // continue to increment OutputLag until $<=-3$ and then just leave it there

OutputLag++;

\}

$/ /$ if piezo is recommended to be off

if (!piezo)

if (OutputLag $>0) / /$ if it was on set the output filter to zero again

OutputLag $=0$

if (OutputLag $=-2$ ) // if 3 consecutive 'off' signals have been received then deactivate

l

digitalWrite(PIEZOPIN, piezo);

\}

digitalWrite(LEDPIN, piezo);

if (OutputLag > -3) // continue to degrement OutputLag until

$>=3$ and then just leave it there

OutputLag--;

\}

\}

\} 
$/ /$ Mode 2 control $\log 1 \mathrm{C}$

vold Mode2 ()

\{

Indext+; // increment index of data array

index = Index $\frac{\circ}{5}$ numReadings; $/ /$ reset to 0 if we're at the end

of the array

master_counter++; // increment master Index

// store previous stralnTotal

Previousstraln = StrainTotal;

// subtract old strain measurement from totals

StrainTotal $-=$ Strain[index];

// read from the strain sensor

Straın[ındex] = analogRead(StraınPın);

// add the reading to the running total

StrainTotal $+=$ Strain[Index];

$/ /$ static byte detect $=0$;

// If the strain gauge signal was rising and now 1 s not, or was not rising and now is, a peak (min or max) has been found

if ((StrainRise $\wedge$ (StrainTotal > Previousstrain)) \&\& (abs (StraınTotal - StraınTotalPrevıousPeak) > (15 * numReadıngs)))

\{

StrainTotalPreviousPeak = StrainTotal;

// increment index and reset when at max

MinMaxStrainIndex++;

MinMaxStraınIndex = MınMaxStraınIndex $\frac{\circ}{\circ}$ numHistory;

// save master counter value as location of peak

MinMaxStrain[MinMaxStrainIndex] = master_counter; peaks

// evaluate duratıon untıl next peak using numHistory past

StrainPeakInterval $=$ (MinMaxStraın[MinMaxStraınIndex] MınMaxStraın[(MınMaxStraınIndex+1) \% numHıstory]) / numHıstory;

// calculator next peak position based on previous selected number peaks

NextPeak $=0$;

for (Int 1 = numsmoothing; $1 ; 1--$ )

NextPeak $+=$ MinMaxStrain[(MinMaxStraınIndex $-1+1) \div$

numHıstory] + (StrainPeakInterval * 1 );

NextPeak $/=$ numbmoothing;

$1 /$ Correct for low pass filter time error

NextPeak $-=$ numReadıngs $2 / 5$;

$1 *$ detect $=8$;

digltalWrite(PIEZOPIN, HIGH); // set outputs on dıgltalWrite(LEDPIN, HIGH); *

\} 


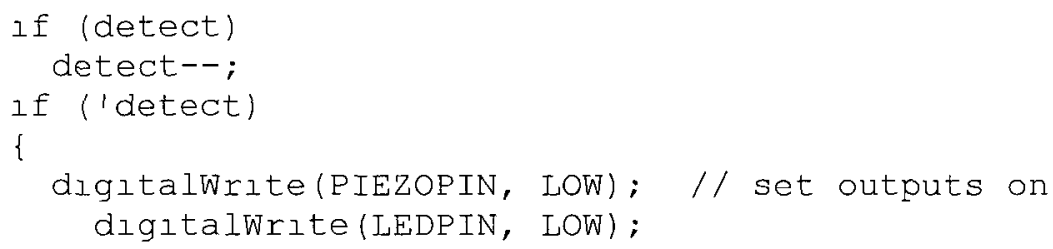




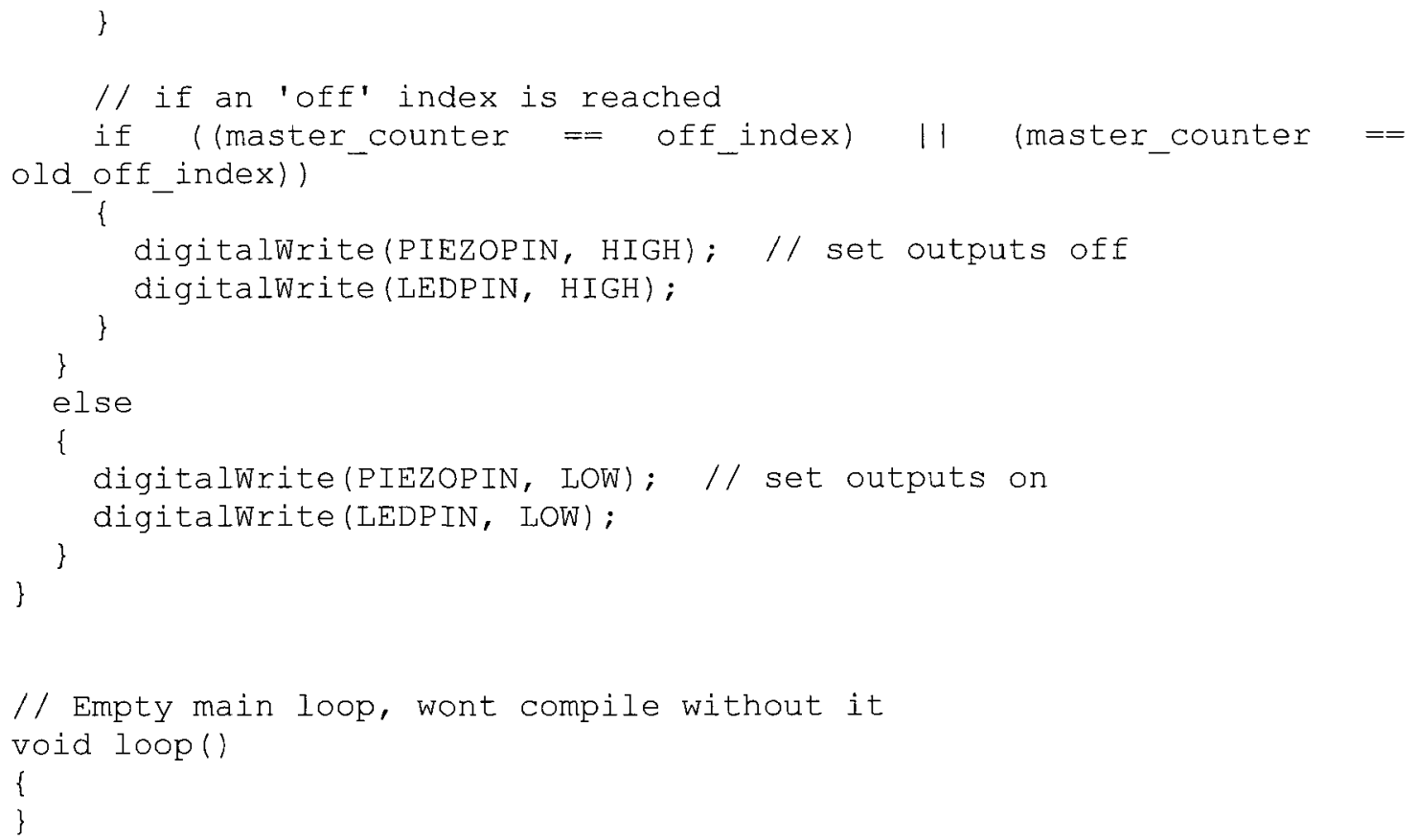

// Empty main loop, wont compile without it void loop()

I

\} 


\section{Appendix D: FFT data process analysis (DataProcess.m).}

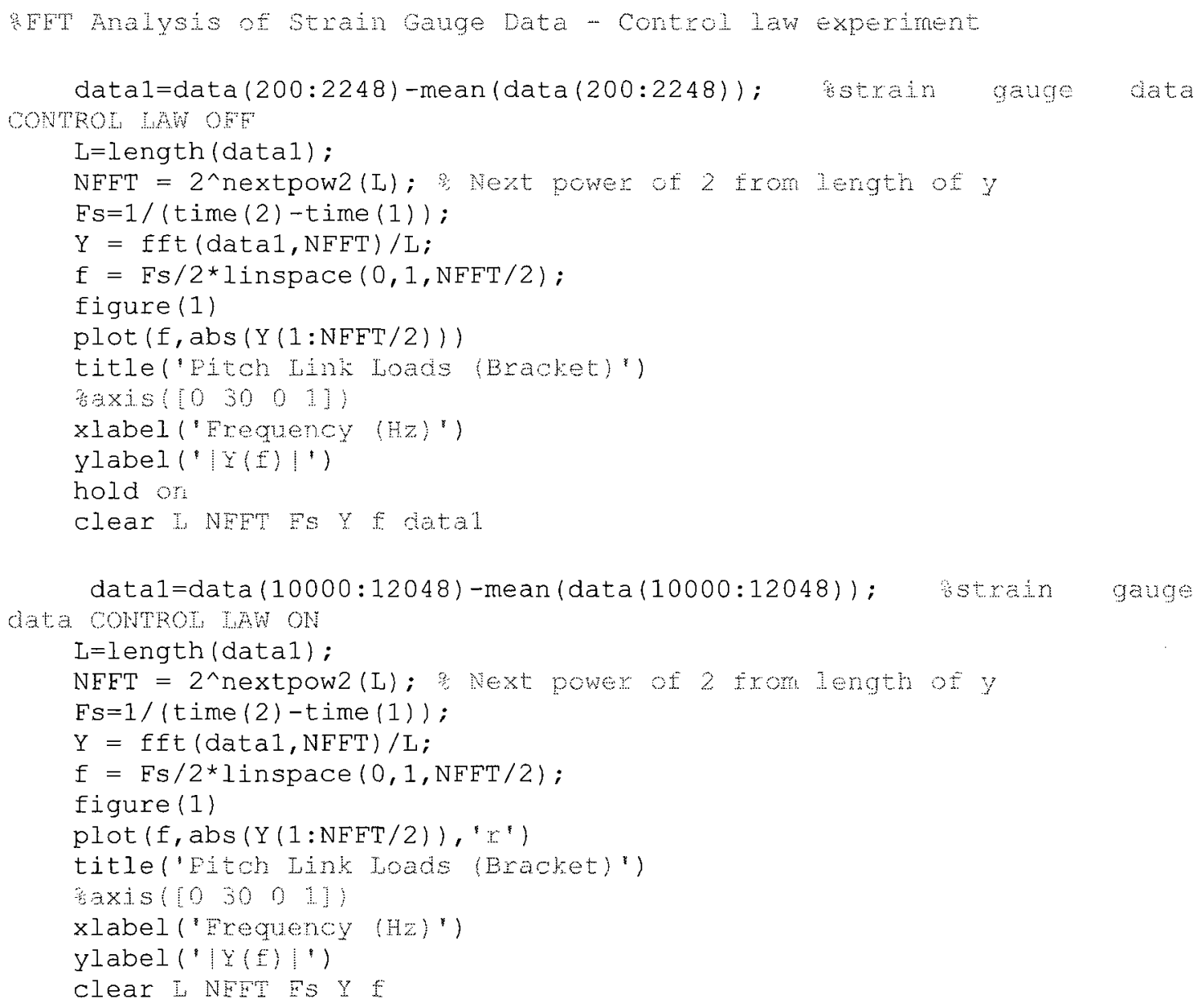




\section{Appendix E: Numerical extrapolation - fan plot (FanPlot.m).}

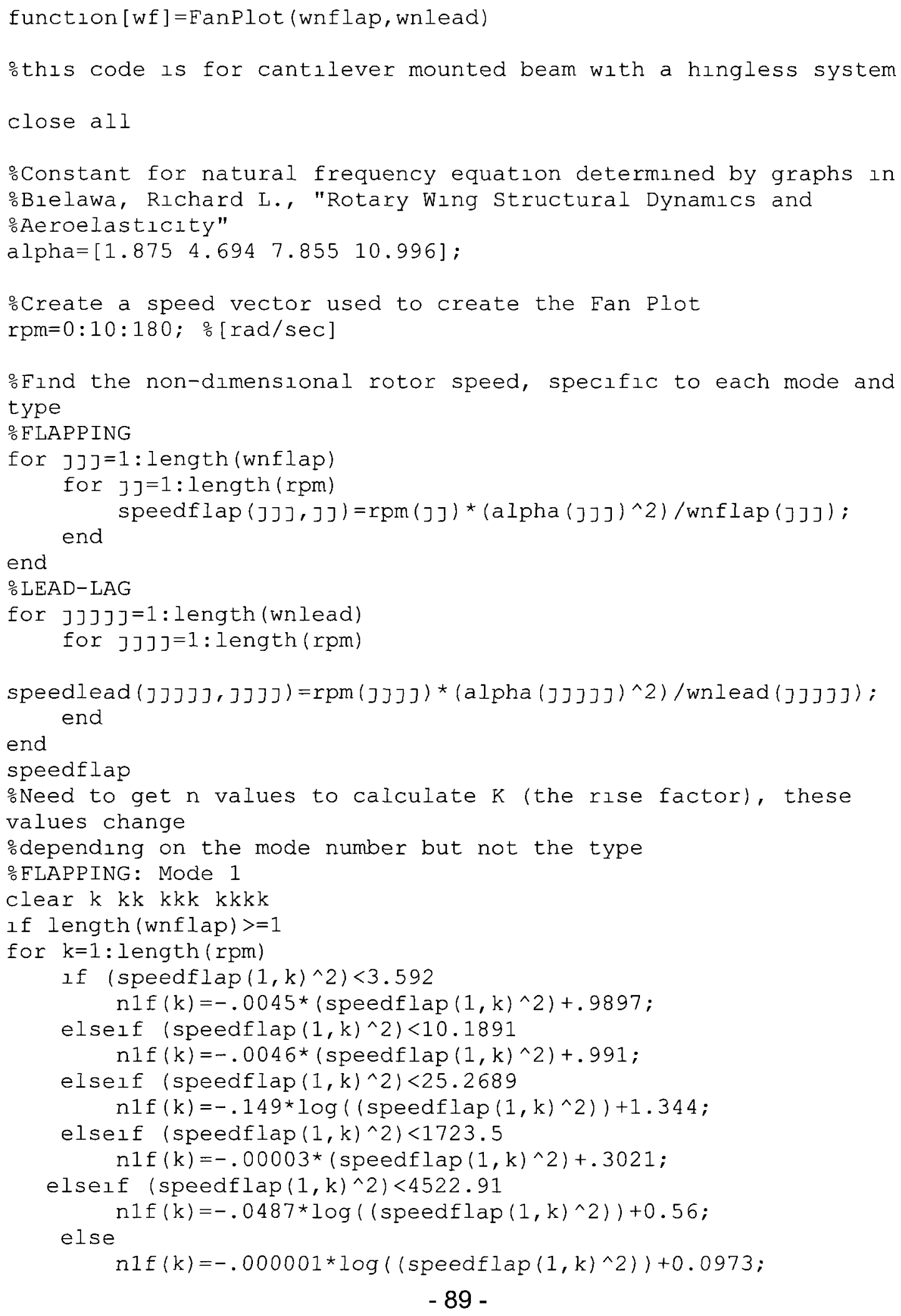


end

end

$\mathrm{nf}=[\mathrm{n} 1 \mathrm{f}]$;

end

$\mathrm{nlf}$

$\because$ FLAPPING: Mode 2

if length (wnflap) $>=2$

for $k \mathrm{k}=1$ : length ( $\mathrm{rpm}$ )

if ( $\left.\operatorname{speedflap}(2, \mathrm{kk})^{\wedge} 2\right)<46.822$

$\mathrm{n} 2 \mathrm{f}(\mathrm{kk})=-.00007 *(\operatorname{speedflap}(2, \mathrm{kk}) \wedge 2)+.9912$;

elseif (speedflap $\left.(2, k \mathrm{k})^{\wedge} 2\right)<95.6406$

$\mathrm{n} 2 \mathrm{f}(\mathrm{kk})=-.0006^{*}(\operatorname{speedflap}(2, \mathrm{kk}) \wedge 2)+1.0224$;

elseif ( $\left.\operatorname{speedflap}(2, k k)^{\wedge} 2\right)<244$

$\mathrm{n} 2 \mathrm{f}(\mathrm{kk})=-.0006^{\star}(\operatorname{speedflap}(2, \mathrm{kk}) \wedge 2)+1.0257$;

elseif (speedflap $(2, \mathrm{kk}) \wedge 2)<5648.38$

$\mathrm{n} 2 \mathrm{f}(\mathrm{kk})=-.18356^{*} \log \left(\left(\operatorname{speedflap}(2, \mathrm{kk})^{\wedge} 2\right)\right)+1.8801$;

elseif ( $\operatorname{speedflap}(2, k \mathrm{k}) \wedge 2)<10763.5$

$\mathrm{n} 2 \mathrm{f}(\mathrm{kk})=-.12021 * \log ((\operatorname{speedf} \operatorname{lap}(2, \mathrm{kk}) \wedge 2))+1.3326 ;$

else

$\mathrm{n} 2 \mathrm{f}(\mathrm{kk})=-.0807 * \log ((\operatorname{speedflap}(2, \mathrm{kk}) \wedge 2))+0.9662 ;$

end

end

$\mathrm{nf}=[\mathrm{n} 1 \mathrm{f} ; \mathrm{n} 2 \mathrm{f}]$;

end

FLAPPING: Mode 3

if length (wnflap) $>=3$

for $\mathrm{kkk}=1$ : length ( $\mathrm{rpm})$

if (speedflap $\left.(3, k k k)^{\wedge} 2\right)<22.1003$

$\mathrm{n} 3 \mathrm{f}(\mathrm{kkk})=-.0005 *(\operatorname{speedflap}(3, \mathrm{kkk}) \wedge 2)+.9912$;

elseif ( $\operatorname{speedflap}(3, k \mathrm{kk}) \wedge 2)<165.222$

$n 3 f(k k k)=-.0007 *(\operatorname{speedflap}(3, k k k) \wedge 2)+0.9941$;

elseif ( $\left.\operatorname{speedflap}(3, \mathrm{kkk})^{\wedge} 2\right)<394.645$

n3f $(\mathrm{kkk})=-.0004^{*}\left(\left(\operatorname{speedflap}(3, \mathrm{kkk})^{\wedge} 2\right)\right)+0.9572$;

elseif ( $\operatorname{speedflap}(3, \mathrm{kkk}) \wedge 2)<4963.57$

$\mathrm{n} 3 \mathrm{f}(\mathrm{kkk})=-.1877^{*} \log ((\operatorname{speedflap}(3, \mathrm{kkk}) \wedge 2))+1.9035$

elseif ( $\operatorname{speedflap}(3, \mathrm{kkk}) \wedge 2)<9441.58$

$\mathrm{n} 3 \mathrm{f}(\mathrm{kkk})=-.1519 * \log ((\operatorname{speedflap}(3, \mathrm{kkk}) \wedge 2))+1.5988 ;$

elseif (speedflap $(3, k k k) \wedge 2)<22584.2$

$\mathrm{n} 3 \mathrm{f}(\mathrm{kkk})=-.0985^{\star} \log ((\operatorname{speedflap}(3, \mathrm{kkk}) \wedge 2))+1.1103$;

else

$n 3 f(k k k)=-.0726 * \log ((\operatorname{speedflap}(3, k k k) \wedge 2))+.8506 ;$

end

end

$\mathrm{nf}=[\mathrm{n} 1 \mathrm{f} ; \mathrm{n} 2 \mathrm{f} ; \mathrm{n} 3 \mathrm{f}]$;

end

oFLAPPING: Mode 4

if length (wnflap) $>=4$

for $\mathrm{kkkk}=1$ : length ( $\mathrm{rpm}$ )

if (speedflap $\left(4, \mathrm{kkkk}^{\wedge} \wedge 2\right)<48.3034$

$n 4 f(k k k k)=-.0002 *($ speedflap $(4, k k k k) \wedge 2)+.9872 ;$ 


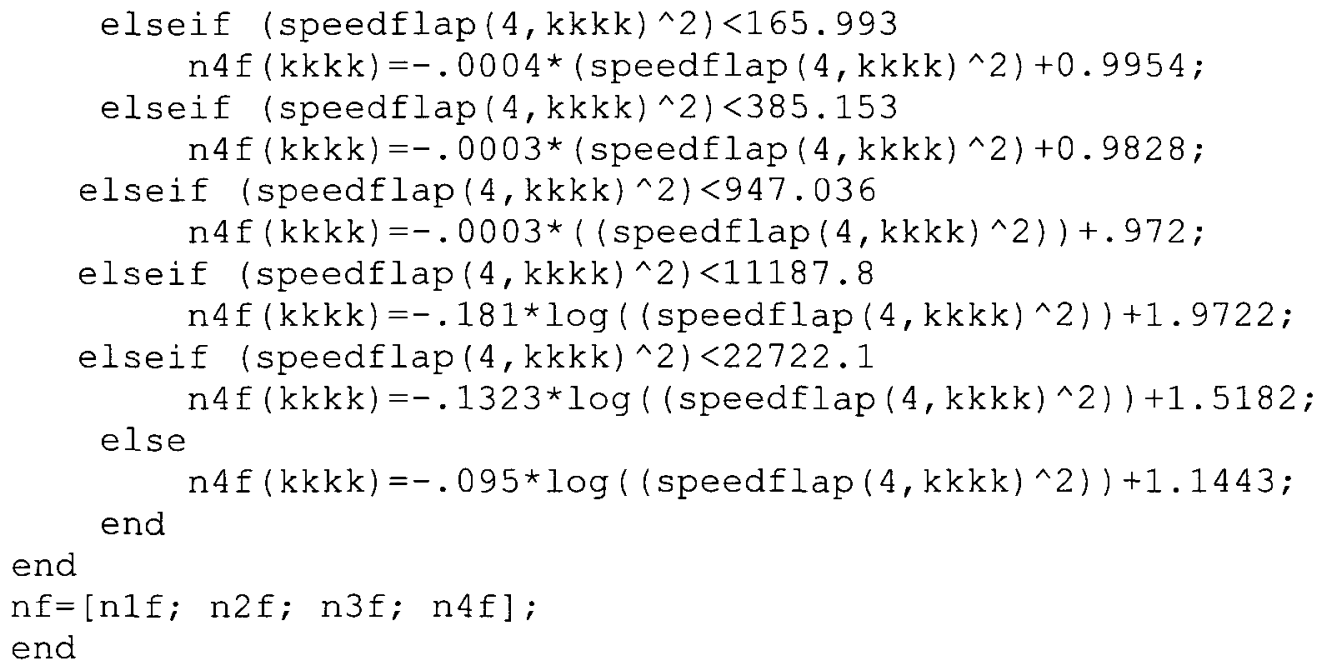




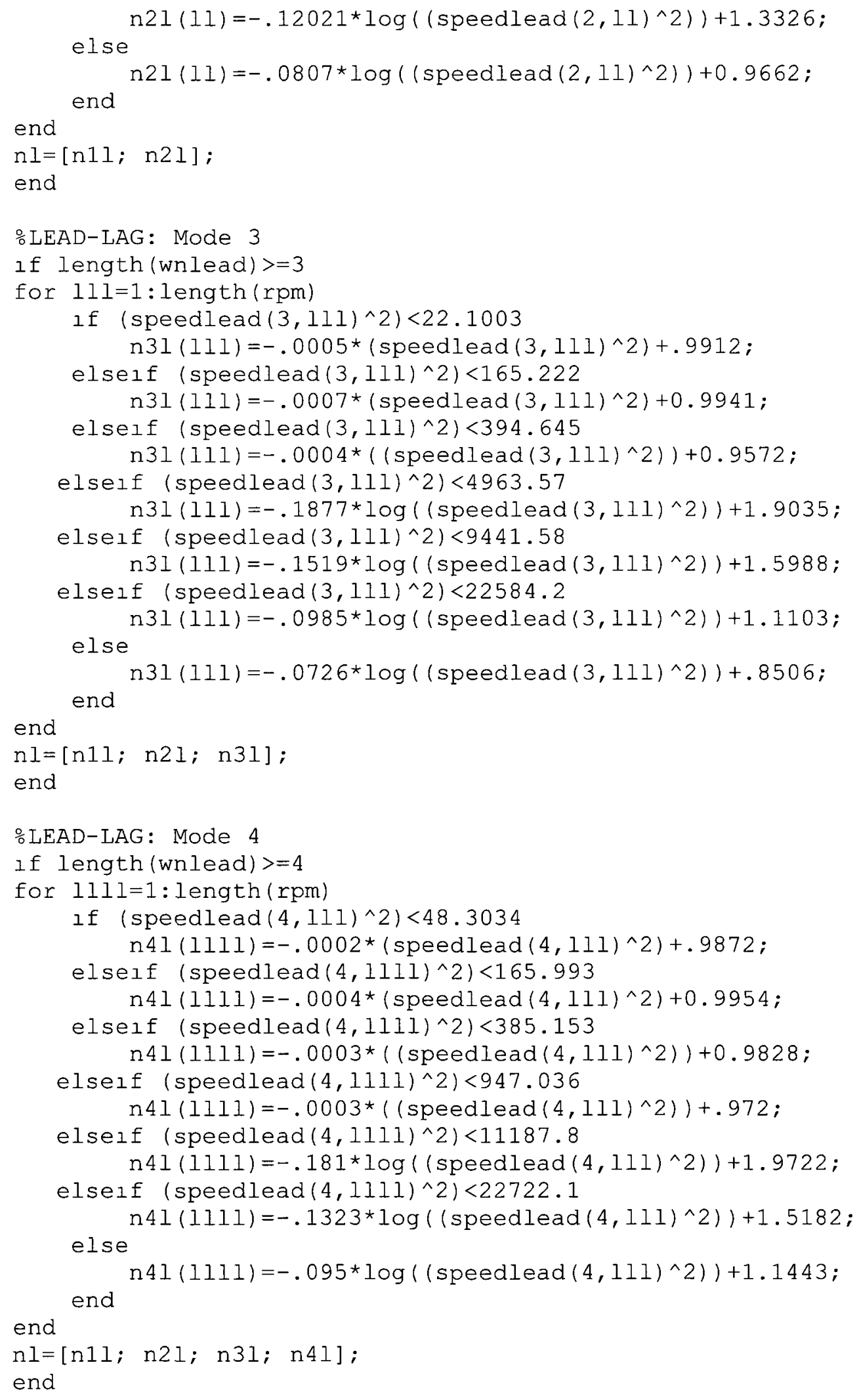




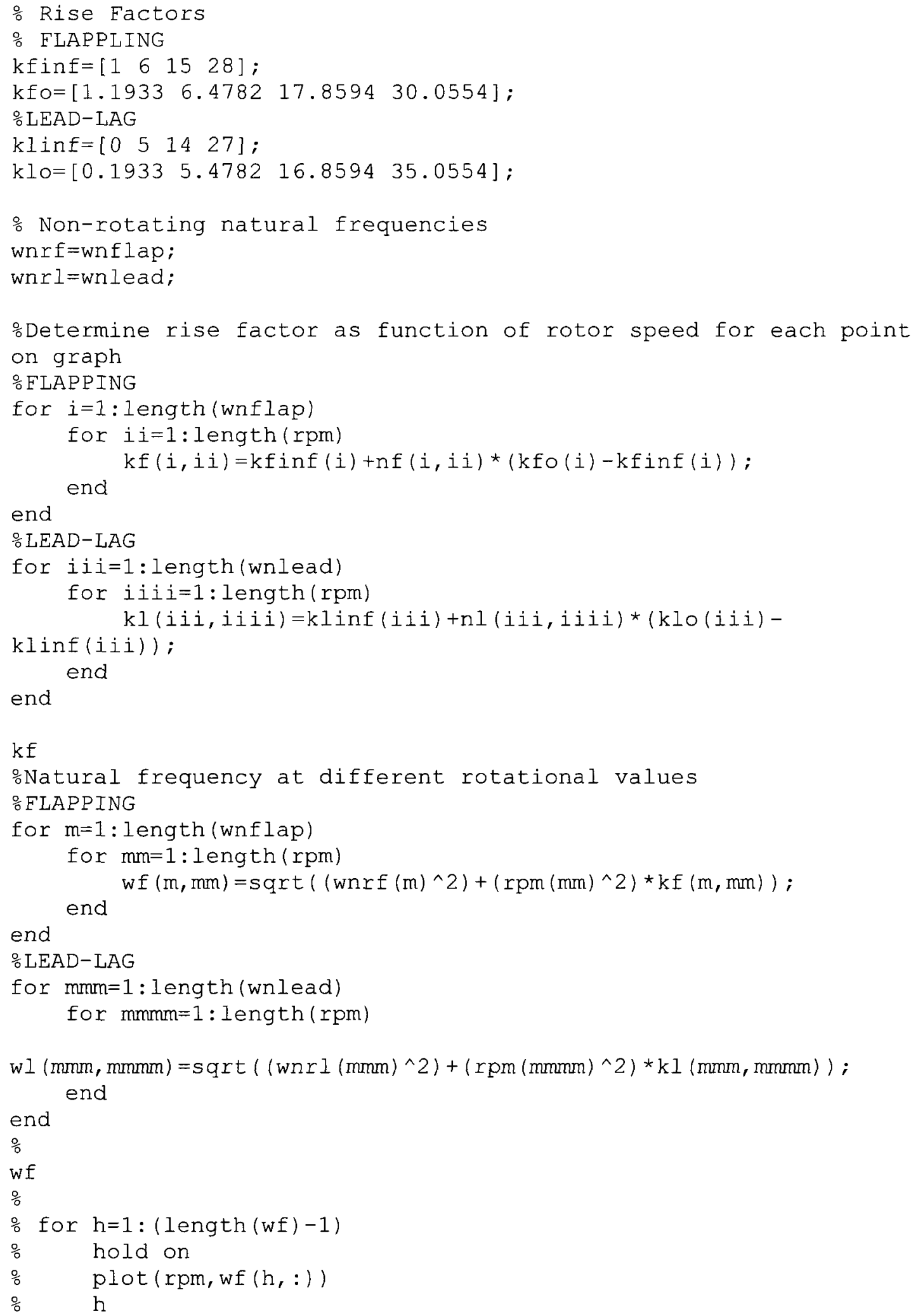




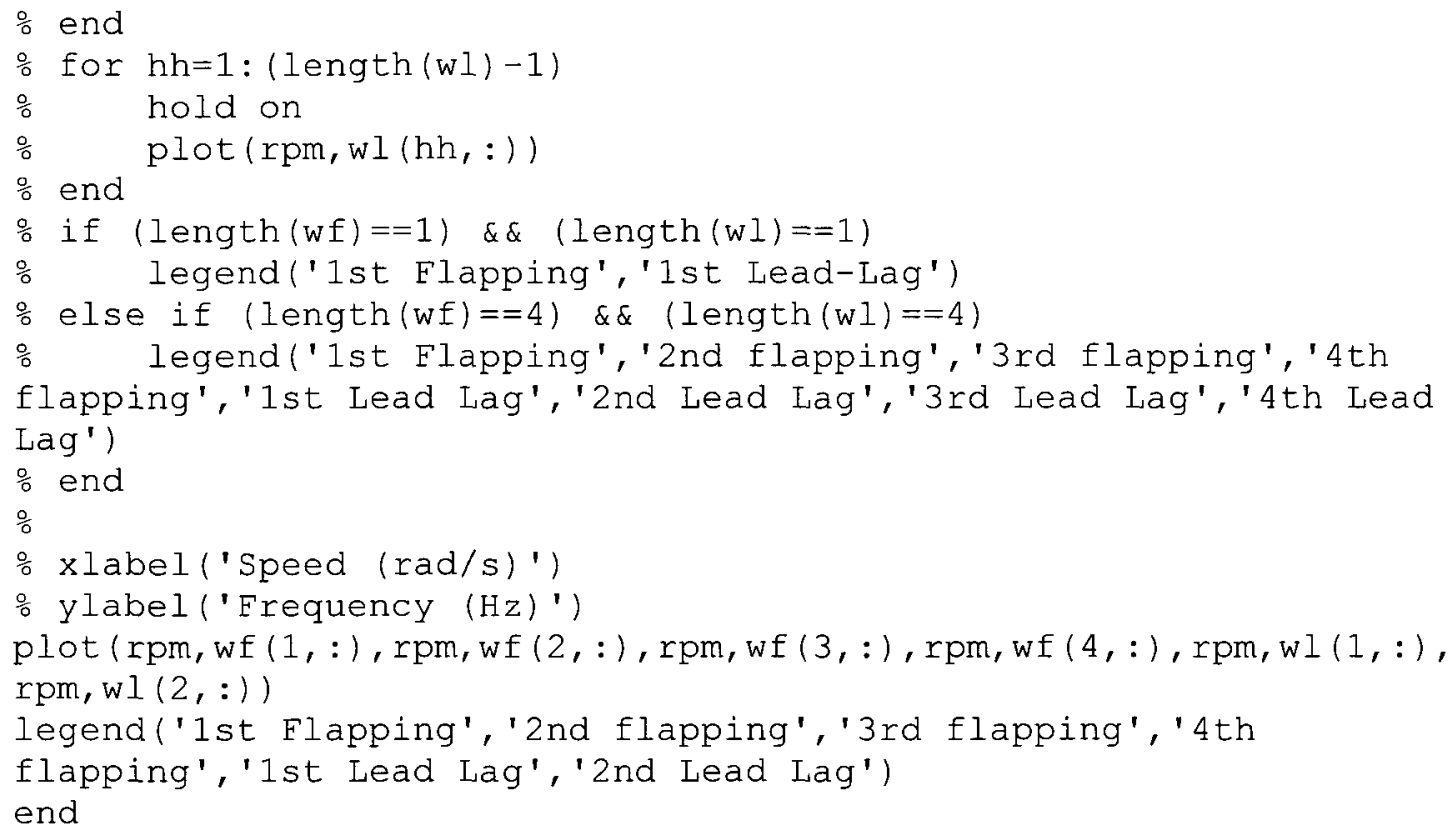


Appendix F: Files attached on CD.

A CD has been appended to this thesis and includes a copy of the following files:

\begin{tabular}{|c|c|}
\hline File & Description \\
\hline averagepeaks.m & $\begin{array}{l}\text { A Matlab script file used to determine the } \\
\text { average magnitude of a periodic signal } \\
\text { (Appendix A). }\end{array}$ \\
\hline StiffnessCurve.m & $\begin{array}{l}\text { A Matlab script file used to determine the } \\
\text { stiffness curve of the APL, based on } \\
\text { experimental data (Appendix B). }\end{array}$ \\
\hline DataProces.m & $\begin{array}{l}\text { A Matlab script file used to complete a FFT } \\
\text { analysis of strain gauge data/output loads } \\
\text { of the APL (Appendix D). }\end{array}$ \\
\hline FanPlot.m & $\begin{array}{l}\text { A Matlab script file used to create a } \\
\text { numerically extrapolated fan plot based on } \\
\text { experimental modal analysis data } \\
\text { (Appendix E). }\end{array}$ \\
\hline APLControlLaw2.pde & $\begin{array}{l}\text { A C++ based code used with the Arduino } \\
\text { microcontroller to implement the APL } \\
\text { closed-loop control algorithm (Appendix C). }\end{array}$ \\
\hline SetUpXpcTargetBox.doc & $\begin{array}{l}\text { A point form description for software and } \\
\text { hardware set-up of } \\
\text { TargetBox/Simulink, required for the } \\
\text { experiments presented in this thesis. }\end{array}$ \\
\hline $\begin{array}{l}\text { LM-SMPL-2010- } \\
\text { OXXX_Rotor_Blade_Strain_Gaugin } \\
\text { g.pdf }\end{array}$ & $\begin{array}{l}\text { A report provided by National Research } \\
\text { Council (IAR-NRC) explaining the strain } \\
\text { gauge instrumentation of the Bell } 412 \text { tail- } \\
\text { rotor blades. }\end{array}$ \\
\hline $\begin{array}{l}\text { Wind Tunnel Test Set-up and Data } \\
\text { Classification.doc }\end{array}$ & $\begin{array}{l}\text { Detailed description of NRC Bell } 412 \text { tail- } \\
\text { rotor experiments. Includes detailed } \\
\text { information about raw data files collected } \\
\text { during testing. }\end{array}$ \\
\hline Folder: "Wind Tunnel Test Data" & $\begin{array}{l}\text { This folder contains all the raw data } \\
\text { collected during the NRC Bell } 412 \text { tail-rotor } \\
\text { tests. A description of the files are outlined } \\
\text { in "Wind Tunnel Test Set-up and Data } \\
\text { Classification.doc". }\end{array}$ \\
\hline Folder: "NRC tail rotor-ProE" & $\begin{array}{l}\text { This folder contains Pro/E files that } \\
\text { represent the compoents included in the } \\
\text { NRC Bell } 412 \text { tail-rotor assembly (provided } \\
\text { by NRC). }\end{array}$ \\
\hline
\end{tabular}




\section{References}

[1] Domke, B., "Aviation Images", Internet: www.b-domke.de, [July 28, 2011].

[2] Konstanzer, P., Enenkl, B., Aubourg, P., Cranga, P., "Recent advances in Eurocopter's passive and active vibration control", paper no. 080170. 64th Annual Forum of the American Helicopter Society, Montreal, QC, Canada, 2008.

[3] Vallejo, P., Lopez, J., Rios-Tejada, F., Azofia, J., Del Valle, J., Velasco, C., Garcia-Mora, L." "Low Back Pain in Helicopter Pilots". RTO HFM Symposium on "Current Aeromedical Issues in Rotary Wing Operations", San Diego, CA, USA, 1998.

[4] Stepniewski, W.Z., Keys, C.N., "Rotary Wing Aerodynamics - Vol. II: Performance Prediction of Helicopters", p.103-104, Dover Publications Inc., New York, NY, USA, 1994.

[5] Viresh K. Wickramasinghe, David. G. Zimcik and Chen Yong, Fred Nitzsche, "Smart Spring - An Actively Tunable Vibration Absorber Designed to Control Aeroelastic Response", 44th AIAA/ASME/ASCE/AHS Structures, Structural Dynamics, and Materials Conference, Norfolk, Virginia, 7-10 April 2003.

[6] Nitzsche, F., Lammering, R. and Breitbach, E., "Can Smart Materials Modify Blade Root Boundary Conditions to Attenuate Helicopter Vibration?". 4th International Conference on Adaptive Structures, Cologne, Germany, E. Breitbach, B.K. Wada and M. Natori, Editors, Technomic, Lancaster, PA, p. 139-150, 1993.

[7] Nitzsche, F., Breitbach, E.J., "Vibration control of rotary wings using smart structures". Smart Materials and Structures, 3, 2, p. 181-189, 1994.

[8] Anusonti-Inthra, P., Gandhi, F., "Helicopter vibration reduction through cyclic variations in rotor blade root stiffness". Journal of Intelligent Material Systems and Structures, 11, 2, p. 153-166, 2000.

[9] Anusonti-Intra, P., and Ghandi, F. "Optimal control of helicopter vibration through cyclic variations in the blade root stiffness". Smart Materials and Structures, 10, p. 86-95, 2001. 
[10] Nitzsche, F. "Smart spring-type actuation for helicopter individual blade control", paper no. 230-40. Proceedings of the Sixth International Conference on Adaptive Structures, Key West, FL, USA, 1996.

[11] Brigley, M., Welsh, W., Altieri, R., Rich, A., "Design and Testing of a New Vibration Suppression System", paper no. 163. American Helicopter Society's 67th Forum, Virginia Beach, VA, USA, 2011.

[12] Feszty, D., Nitzsche, F., "Review of Active Control Research in Canada", Rotorcraft Research Group, Carleton University, Ottawa, ON, 2011.

[13] Schimke, D., Arnold, U., Kube, R., "Individual Blade Root Control Demonstration - Evaluation of Recent Flight Tests". Proceedings of the 54th Annual Forum of the American Helicopter Society, Washington, D.C., 1, 378-390, 1998.

[14] Roth, D., Enenkl, B., Dietrich, O., "Active rotor control by flaps for vibration reduction - full scale demonstrator and first flight test results". 32nd European Rotorcraft Forum, NLR, Maastricht, Netherlands, 1, p. 801-814, 2007.

[15] Straub, F.K., Kennedy, D.K., Stemple, A.D., Anand, V.R., Birchette, T., "Development and Whirl Tower Test of the SMART Active Flap Rotor". Proceedings of the SPIE - The International Society for Optical Engineering, 5388, 1, 202-12, 2004.

[16] Straub, F. K., Anand, V. R., Birchette, T. S., Lau, B. H., "Smart rotor development and wind tunnel test" 35th European Rotorcraft Forum 2009, 1, p. 413-430, 2009.

[17] Jacklin, S.A., Haber, A., de Simone, G., Norman, T.R., Kitaplioglu, C., Shinoda, P., "Full-scale Wind Tunnel Test of an Individual Blade Control System for a UH-60 Helicopter". American Helicopter Society 58th Annual Forum, Montreal, QC, Canada, 2002.

[18] Lorber, P., O'Neill, J., Hein, B., Isabella, B., Andrews, J., Brigley, M., Wong, J., LeMasurier, P., "Whirl and Wind Tunnel Testing of the Sikorsky Active Flap Demonstrator Rotor", paper no. 041. American Helicopter Society's 67th Forum, Virginia Beach, VA, USA, 2011.

[19] Riemenschneider, J., Keye, S., Wierach, P., Mercier Des Rochettes, H., "Review of the common DLR/ONERA project "Active Twist Blade" (ATB)". 30th European Rotorcraft Forum, Mareseilles, France, p. 273-281, 2005. 
[20] Wilbur, M.L., Mirick, P.H., Yeager, W. T., Langston, C.W., Cesnik, C. E. S., Shin, S., "Vibratory Loads Reduction Testing of the NASA/Army/MIT Active Twist Rotor". Journal of the American Helicopter Society, 47, 2, p. 123-133, 2002.

[21] Crozier, P., Leconte, P., Delrieux, Y., Gimonet, B., Le Pape, A., des Rochettes, H.M., "Wind-tunnel tests of a helicopter rotor with active flaps". 32nd European Rotorcraft Forum, Maastricht, Netherlands, 2006.

[22] Hasegawa, Y., Katayama, N., Kobiki, N., Nakasato, E., Yamakawa, E., and Okawa, H., "Experimental and Analytical Results of Whirl Tower Test of ATIC Full Scale Rotor System". American Helicopter Society 57th Annual Forum, Washington, DC, USA, 2001.

[23] Masaki, K., Hattori, K., Yoshimoto, M., Uchiyama, N., and Nakao, M., "Wind tunnel test for BVI noise and Vibration reduction using Blade Active Control". 31st European Rotorcraft Forum, Florence, Italy, 2005.

[24] Park, J.S., Kim, S.H., Jung, S.N., Lee, M.K., "Design and analysis of variable-twist tiltrotor blades using shape memory alloy hybrid composites". Smart Materials and Structures, 20, 1, 2011.

[25] Maughmer, M., Lesieutre, G., and Kinzel, M., "Miniature Trailing-Edge Effectors for Rotorcraft Performance Enhancement". American Helicopter Society's 61st Annual Forum, Grapevine, TX, USA, 2005.

[26] Thepvongs, S., Cook, J. R., Cesnik, C. E. S., and Smith, M. J., "Computational aeroelasticity of rotating wings with deformable airfoils". 65th Annual Forum Proceedings - AHS International, Grapevine, TX, USA, 2009.

[27] Muir, E. R., Liu, L., Friedmann, P. P., and Kumar, D., "Hysteresis Characterization in Piezoceramic Stack Actuators and Its Influence on Vibration and Noise Reduction in Helicopters Using Actively Controlled Flaps". AIAA 2010-2994, 51st AIAA/ASME/ASCE/AHS/ASC Structures, Structural Dynamics, and Materials Conference, Orlando, FL, USA, 2010.

[28] Koratkar, N. A. and Chopra, I., "Open-loop hover and wind tunnel testing of Mach-scaled rotor with trailing-edge flaps". 42nd AIAA/ASME/ASCE/AHS/ASC Structures, Structural Dynamics, and Materials Conference and Exhibit, Seattle, Washington, USA, 2001. 
[29] Chopra, I., Copp, P., "Continued Development of a Mach Scale Swashplateless Rotor with Integrated Trailing Edge Flap". American Helicopter Society's 64th Annual Forum, Montreal, QC, Canada, 2008.

[30] Bauchau, O. A., Agarwal, S., "The semi-active coulomb friction lead-lag damper concept". AHS International 62nd Annual Forum. III, p. 1945-1953, 2006 .

[31] Feszty, D., Nitzsche, F., Mander, A., Coppotelli, G., Vetrano, F., Riemenschneider, J, Wierach, P., "Whirl Tower Demonstrations of the SHARCS Hybrid Control Concept". 65th Annual Forum of the American Helicopter Society, Grapevine, TX, USA, 2009.

[32] Ulker, F. D., Mander, A., Feszty, D., Nitzsche, F., "SHARCS: Hybrid control concept for vibration reduction of helicopters". Proceedings of the 34th European Rotorcraft Forum 2008, 3, p. 2020-2052, Liverpool, U.K, 2008.

[33] Feszty, D., Nitzsche, F., Khomutov, K., Lynch, B., Mander, A., Ülker, F.D., "Design and instrumentation of the SHARCS scaled rotor with three independent control systems", paper no. 080166. 64th Annual Forum of the American Helicopter Society, Montreal, QC, Canada, 2008.

[34] Oxley, G., Nitzsche, F., Feszty, D., "Smart Spring Control of Vibration on Helicopter Rotor Blades", Journal of Aircraft, vol.46, no.2, p. 692-696, 2009.

[35] Opoku, D.G., Nitzsche, F., "Acoustic Validation of a New Code Using Particle Wake Aerodynamics and Geometrically-Exact Beam Structural Dynamics", Aeronautical Journal, Vol 109, p. 257-267, 2005.

[36] Feszty, D., Nitzsche, F., Mander, A., Coppotelli, G., Vetrano, F., Riemenschneider, J, Wierach, P., "Whirl Tower Demonstrations of the SHARCS Hybrid Control Concept", paper presented at the 65th Annual Forum of the American Helicopter Society, Grapevine, TX, 27-29 May 2009.

[37] Mander, A., Feszty, D., Nitzsche, F., "Active Pitch Link Actuator for Impedance Control of Helicopter Vibration", Paper no. 080170, 64th Annual Forum of the American Helicopter Society 29 April -1 May 2008, Montreal, QC, Canada, 2008.

[38] Nitzsche, F., Oxley, G., "Smart Spring Control of Vibration and Noise in Helicopter Blades", AIAA paper 2005-2270, 64th 
AIAA/ASME/ASCE/AHS/ASC Structures, Structural Dynamics and Materials Conference, Austin, Texas, Apr. 18-21, 2005.

[39] Nitzsche, F., Harold, T., "Experimental System Identification of the Smart Spring Device for Semi-Active Vibration Control," Proceedings: 15th International Conference on Adaptive Structures and Technology, Bar Harbor, ME, Oct. 24-27, 2004.

[40] Harold, T., "Performance Characterization and Control of a Smart Spring Device for Indirect-Active Vibration Suppression", M. App. Sc. Thesis, Carleton University, 2004.

[41] Feszty, D., Nitzsche, F., Khomutov, K., Lynch, B., Mander, A., Ülker, F.D., "Design and instrumentation of the SHARCS scaled rotor with three independent control systems", Paper no. 080166, 64th Annual Forum of the American Helicopter Society, 29 April -1 May 2008, Montreal, QC, Canada, 2008.

[42] Bielawa, Richard L., "Rotary Wing Structural Dynamics and Aeroelasticity", American Institute of Aeronautics and Astronautics, 2nd ed, 2006. 